SERGIO MARTINS FERNANDES

CATÁLOGO DE MODELOS DE COMPUTAÇÃO PARA O DESENVOLVIMENTO DE LINGUAGENS ESPECÍFICAS DE MODELAGEM DE DOMÍNIO

SÃO PAULO

2013 
SERGIO MARTINS FERNANDES

\section{CATÁLOGO DE MODELOS DE COMPUTAÇÃO PARA O DESENVOLVIMENTO DE LINGUAGENS DE MODELAGEM ESPECÍFICAS DE DOMÍNIO}

Tese apresentada à Escola

Politécnica da Universidade de São Paulo para a obtenção do título de Doutor em Engenharia

Área de Concentração: Sistemas Digitais

Orientador: Profa. Dra. Selma Shin Shimizu Melnikoff

SÃO PAULO

2013 
Este exemplar foi revisado e corrigido em relação à versão original, sob responsabilidade única do autor e com a anuência de seu orientador.

São Paulo, de novembro de 2013.

Assinatura do autor

Assinatura do orientador

FICHA CATALOGRÁFICA

Fernandes, Sergio Martins

Catálogo de modelos de computação para desenvolvimento de linguagens específicas de modelagem de domínio / S.M. Fernandes. -- versão corr. -- São Paulo, 2013.

$145 \mathrm{p}$.

Tese (Doutorado) - Escola Politécnica da Universidade de São Paulo. Departamento de Engenharia de Computação e Sistemas Digitais.

1.Engenharia de software 2.Desenvovlimento de software I.Universidade de São Paulo. Escola Politécnica. Departamento de Engenharia de Computação e Sistemas Digitais II.t. 


\section{DEDICATÓRIA}

Dedico este trabalho a minha mãe, Formosina 


\section{AGRADECIMENTO}

À professora Selma Melnikoff, pela orientação, amizade e paciência. 


\section{RESUMO}

Esta tese apresenta um processo para a criação de um catálogo de modelos de computação para apoiar o design de DSMLs, e a primeira versão do catálogo, com atributos que ajudam a selecionar os modelos de computação mais adequados para cada desenvolvimento de DSML, e as características dos sistemas de software para os quais esses modelos de computação são mais adequados. O contexto de aplicação desse catálogo é o Model-Driven Development (MDD - desenvolvimento dirigido por modelos) - a abordagem em que o desenvolvimento de software é baseado em modelos gráficos que são posteriormente traduzidos (transformados) em modelos de nível mais baixo e, no final, em código de linguagens de programação, tais como Java ou C\#. A aplicação do processo gerou uma versão inicial do catálogo com os seguintes modelos de computação: diagramas BPMN, diagramas de classe da UML e regras de negócio. Visa-se contribuir para popularizar a abordagem de MDD com base em DSMLs e, em particular, a elaboração do design das DSMLs a partir de modelos de domínio, para o que o uso do catálogo efetivamente contribui.

Palavras-chave: Desenvolvimento de Software, Desenvolvimento Dirigido por Modelos (MDD), Linguagem de Modelagem Específica de Domínio (DSML), modelo de Computação, Design Pattern,. 


\begin{abstract}
This thesis presents a process for the creation of a catalog of models of computation to support the design of Domain-Specific Modeling Languages (DSMLs), and the first version of the catalog, which comprises attributes that aim to help the selection of the most suitable models of computation for each DSML development, and characteristics of software systems for which these models of computation are more appropriate. The context for the use of the catalog is the Model-Driven Development (MDD) - the approach where software development is based on graphical models that are subsequently translated (transformed) into lower-level models and, in the end, in source code in programming languages, such as Java or C \#. The process was applied to generate an initial version of the catalog with the following models of computation: BPMN diagrams, UML class diagrams and business rules. It aims to contribute to popularize the MDD approach - based in DSMLs -, and in particular, the development of the DSMLs design from domain models, for which the use of the catalog effectively contributes.
\end{abstract}

Keywords: Software Development, Model-Driven Development (MDD), DomainSpecific Modeling Language (DSML), Model of Computation, Design Pattern, Modeling Formalism. 


\section{LISTA DE ABREVIATURAS E SIGLAS}

AVOPT

$B N F$

$B P M N$

CAMPaM

$C R M$

$D S L$

$D S M$

$D S M L$

ERP

GME

GPL

IDEFO

$M B D$

$M D A$

Domain-Specific Analysis, Verification, Optimization, Parallelization, and Transformation (análise, verificação, otimização, paralelização e transformação específicas de domíno)

Backus-Naur Form

Business Process Modeling Notation (notação de modelagem de processos de negócio)

Computer Automated Multi-Paradigm Modeling (modelagem com múltiplos paradigmas para automação por computador)

Customer Relationship Management (gerência de relacionamento com clientes)

Domain-Specific Language (linguagem específica de domínio) Domain-Specific Modeling (modelagem específica de domínio)

Domain-Specific Modeling Language (linguage de modelagem específica de domínio)

Enterprise Resource Planning (planejamento corporativo de recursos)

Generic Modeling Environment - ambiente generic de modelagem

General Purpose Language (linguagem de propósitos gerais)

Icam DEFinition for Function Modeling (definição ICAM para modelagem de funções)

Model Based Design (design baseado em modelos)

Model-Driven Architecture (Arquitetura dirigida a modelos) 
Model-Driven Development (desenvolvimento dirigido por modelos)

$M D E$

Model-Driven Engineering (engenharia dirigida a modelos)

$M D S D$

Model-Driven Software Development (desenvolvimento de software dirigido a modelos)

MDSE

Model-Driven Software Engineering (engenharia de software dirigida a modelos)

$O C L$

Object Constraint Language (Linguagem de Restrições de Objetos)

$O M G$

Object Management Group (Grupo de Gerenciamento de Objetos)

$S A P$

Systemanalyse und Programmentwicklung, ou System Analysis and Program Development (desenvolvimento de análise e programação de sistemas) 


\section{LISTA DE FIGURAS}

FIGURA 1 - ANATOMIA DE UMA LINGUAGEM .33

FIGURA 2 - ESTRUTURA DE CONSTRUÇÃO E UTILIZAÇÃO DE UMA DSML .....37 FIGURA 3 - ESTRUTURA INFORMAL DOS ELEMENTOS DO RATIONAL FOCAL POINT 90

FIGURA 4 - PROCESSO EXEMPLO DE SELEÇÃO DE PROJETOS .92

FIGURA 5 - MODELO DE DOMÍNIO, PARTE 1 100

FIGURA 6 - MODELO DE DOMÍNIO, PARTE 2. 101 


\section{LISTA DE TABELAS}

TABELA 1 - SUMÁRIO HISTÓRICO DE TAXONOMIAS QUALITATIVAS DE SISTEMAS .22

TABELA 2 - ATRIBUTOS QUE DESCREVEM PADRÕES DE DESIGN E DE ARQUITETURA DE SOFTWARE 52

TABELA 3 - IDENTIFICAÇÃO DOS ATRIBUTOS DO CATÁLOGO A PARTIR DAS REFERÊNCIAS. .54

TABELA 4 - CONTAS A SEREM CREDITADAS E DEBITADAS NUMA TRANSAÇÃO FINANCEIRA - 


\section{SUMÁRIO}

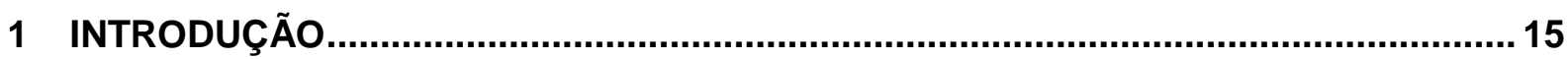

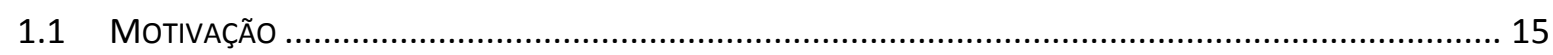

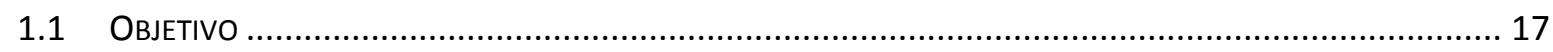

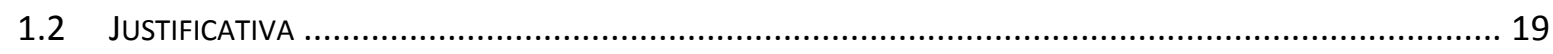

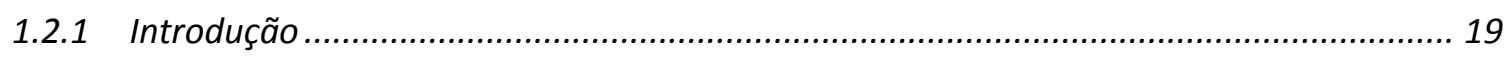

1.2.2 Pesquisas para viabilizar a adoção de MDD baseado em DSMLs .................................. 19

1.2.3 Melhoria do desenvolvimento de DSML através do catálogo de modelos de computação 20

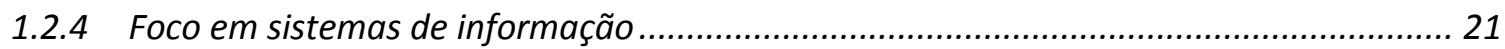

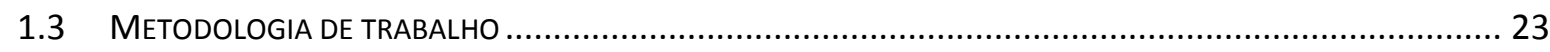

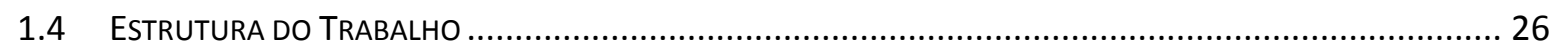

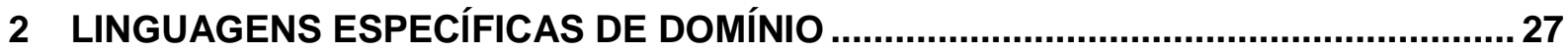

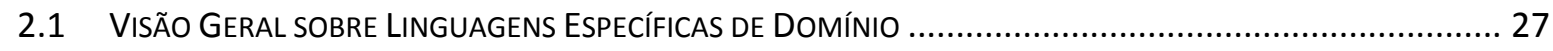

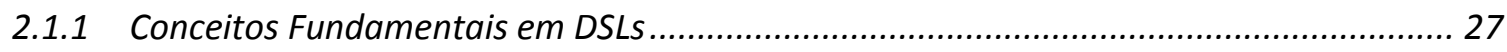

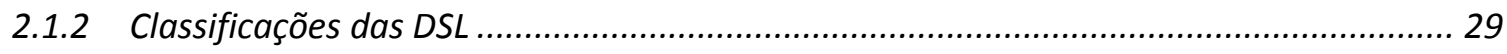

2.1.3 DSLs no contexto do Desenvolvimento Dirigido por Modelos........................................ 31

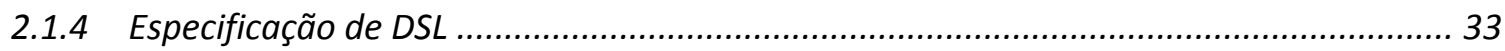

2.2 VISÃo GeRAL SOBRE LINGUAGENS DE ModeLAGEM ESPECífICAS DE DomínIO (DSML) .......................... 36

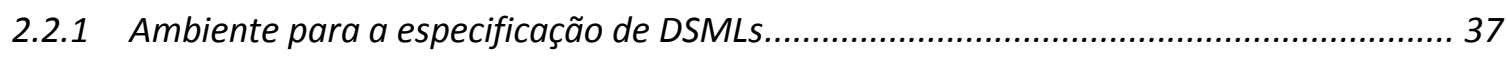

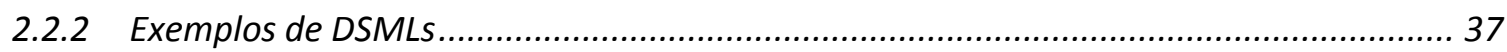

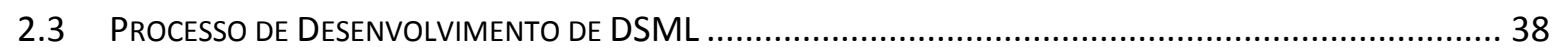

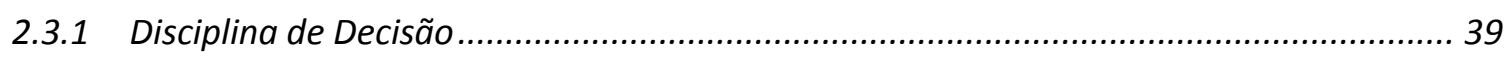

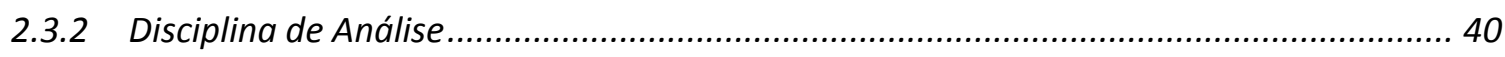

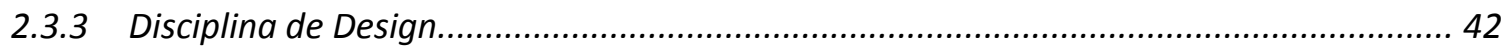

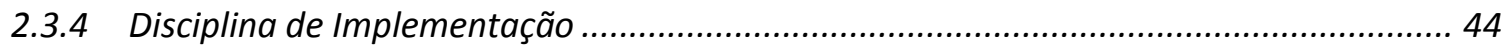

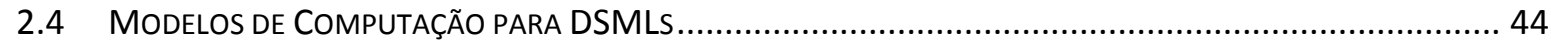

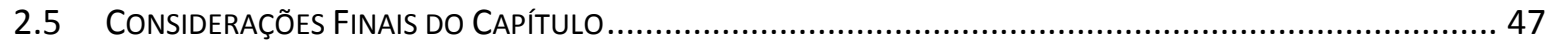

\section{CATÁLOGO DE MODELOS DE COMPUTAÇÃO PARA CONSTRUÇÃO DE DSMLS. 49}

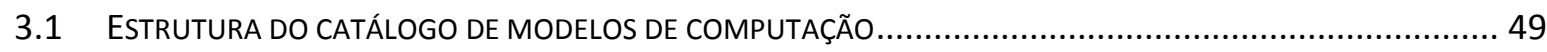

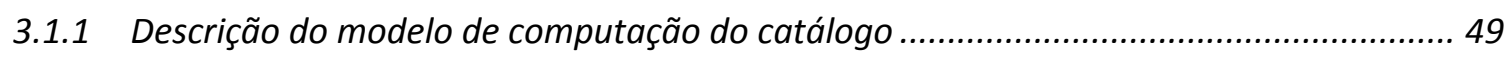

3.1.2 Utilização do catálogo de modelos de computação ....................................................... 56

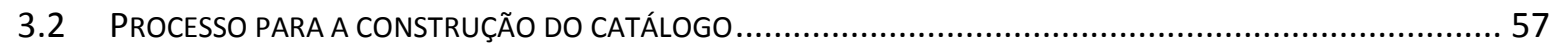


3.2.1 Amadurecimento do processo ao longo do tempo ….................................................. 57

3.2.2 Descrição do processo para construção do catálogo ..................................................... 58

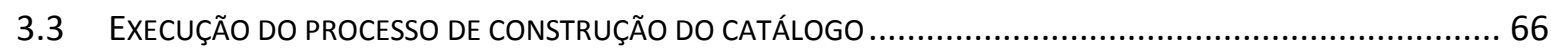

3.3.1 A-Identificar modelos de computação potencialmente relevantes para o contexto do

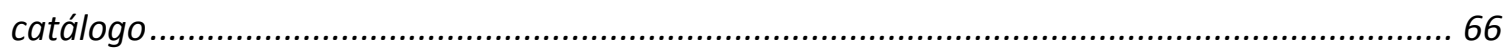

3.3.2 B-Selecionar um conjunto relevante de sistemas do domínio para análise .................. 69

3.3.3 C-Analisar a descrição do sistema selecionado ............................................................ 71

3.3.4 D-Identificar um conjunto de modelos de computação candidatos nos sistemas analisados

3.3.5 E-Caso haja candidatos alternativos a modelo de computação, selecionar um deles de

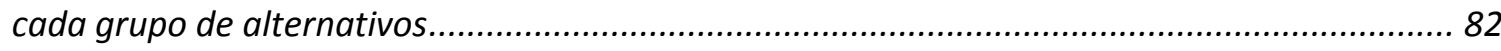

3.3.6 Etapa F-Descrever cada modelo de computação do catálogo ....................................... 83

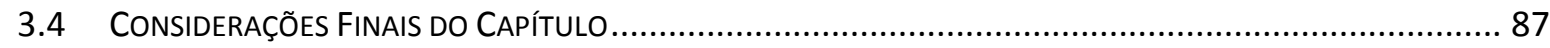

\section{USO DO CATÁLOGO DE MODELOS DE COMPUTAÇÃO PARA}

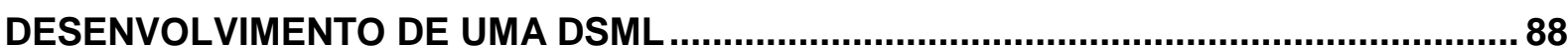

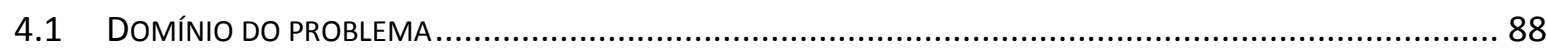

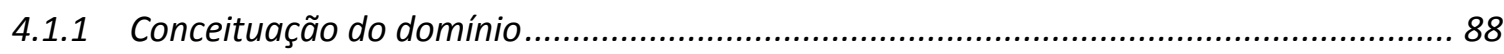

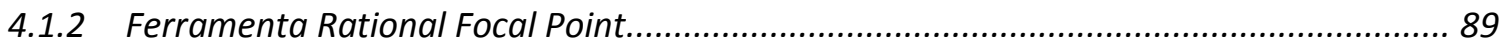

4.1.3 Um exemplo de processo do domínio ............................................................................... 91

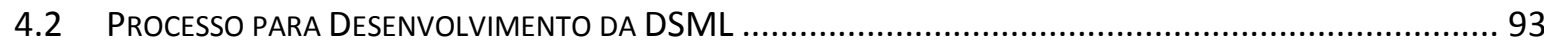

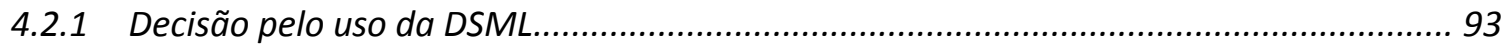

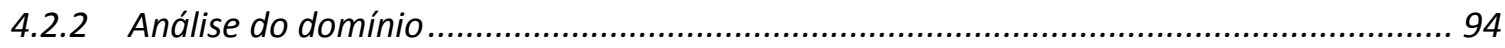

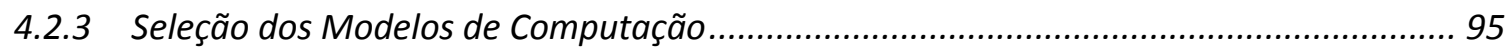

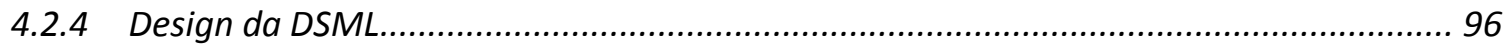

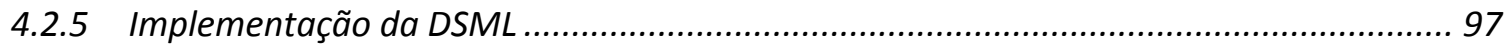

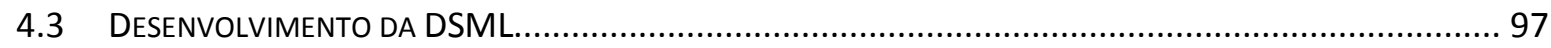

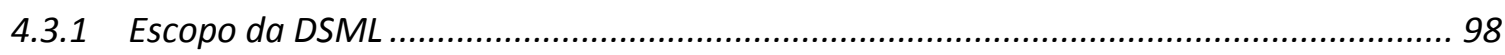

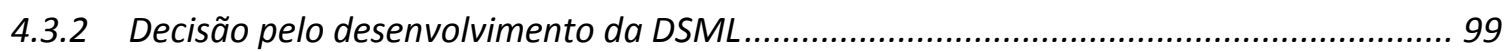

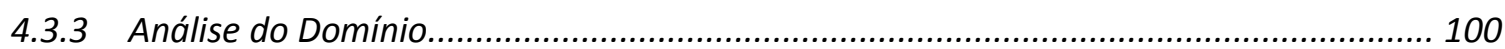

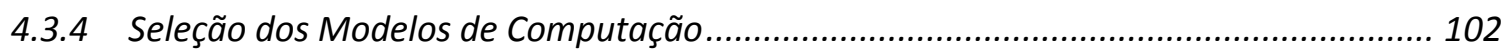

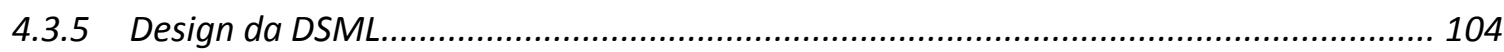

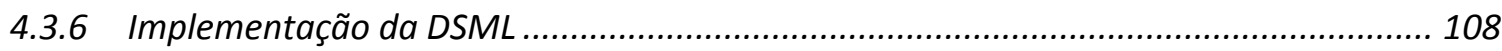

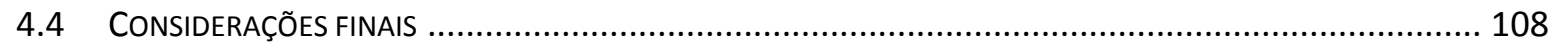

5 CONSIDERAÇÕES FINAIS ........................................................................... 110 


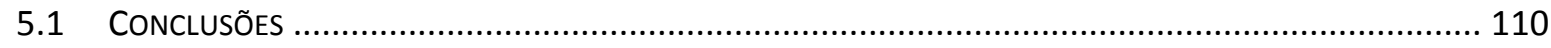

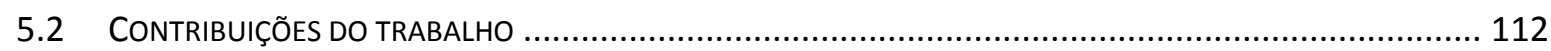

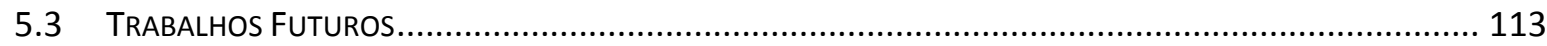

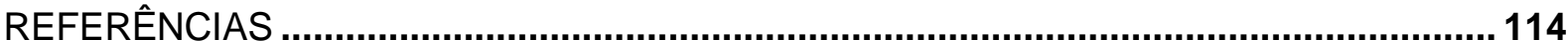

A APÊNDICE A

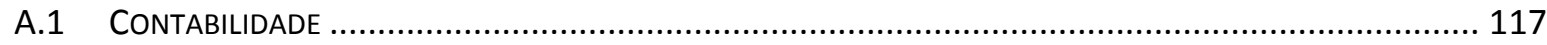

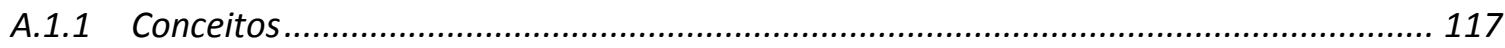

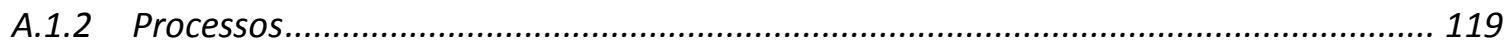

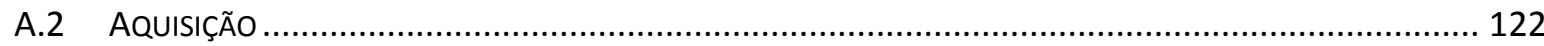

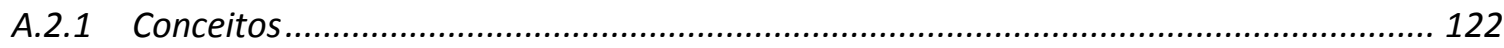

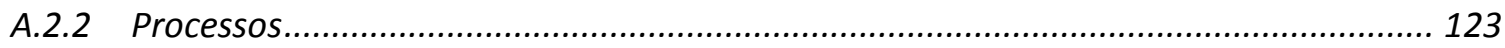

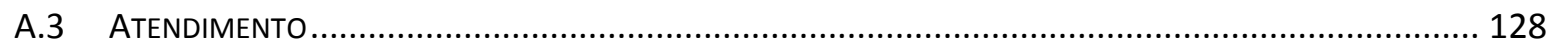

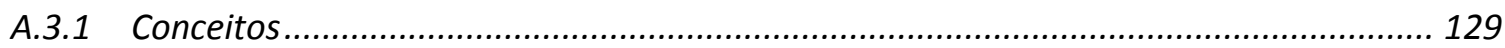

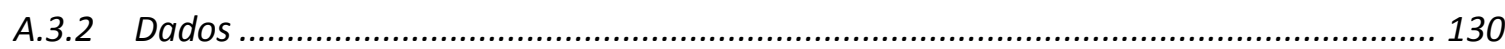

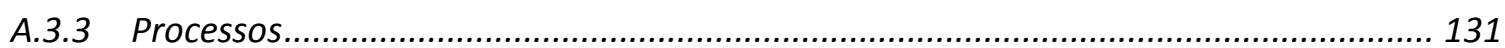

B APÊNDICE B - FERRAMENTAS GERADORAS DE DSML ATUALMENTE

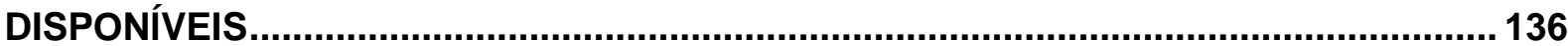

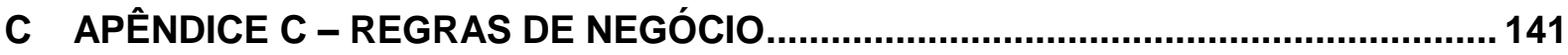

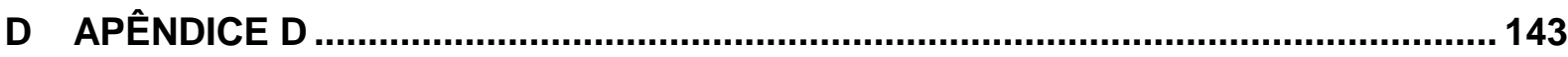

D.1 DIRETRIZES PARA DEFINIÇÃO DOS CONCEITOS DE MODELAGEM ..................................................... 143

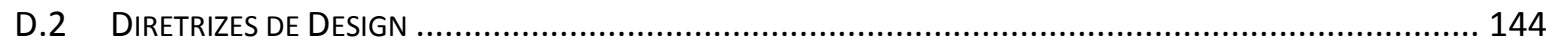




\section{Introdução}

Este capítulo tem, como objetivo, contextualizar o cenário no qual a proposta desta tese se situa, apresentar e justificar o objetivo desta tese, e apresentar sucintamente a metodologia de trabalho e a estrutura da tese.

\subsection{Motivação}

Buscando aprimorar o processo de desenvolvimento de software, no início dos anos 2000, foi proposta a abordagem denominada Desenvolvimento Dirigido por Modelos (MDD - model-driven development) (KLEPPE, WARMER; BAST, 2003). Essa abordagem visa elevar o nível de abstração em que se desenvolve software: em vez de utilizar as plataformas de desenvolvimento baseadas em linguagens de programação, os modelos do software, que representam, em mais alto nível, o domínio e a lógica de negócio é convertido automaticamente em códigos. Essa conversão é realizada através. de transformadores que traduzem esses modelos em código de linguagem de programação de uma determinada plataforma de desenvolvimento (KLEPPE, WARMER; BAST, 2003).

Desde então, a abordagem MDD se desdobrou em diversas variantes. Uma dessas variantes, denominada Arquitetura Dirigida a Modelos (MDA - model-driven architecture) propõe o uso da Linguagem de Modelagem Unificada (UML - Unified Modeling Language) para representar os modelos gráficos que expressam o software (MELLOR; CLARK; FUTAGAMI, 2003).

Outras variantes do MDD propõem que o software seja representado através de linguagens de modelagem específicas de domínio (DSMLs - domain-specific modeling languages), que são linguagens gráficas voltadas especificamente para um determinado domínio do problema (por exemplo medicina diagnóstica, sistema embarcado ou indústria financeira) ((GREENFIELD, 2004),(KARZAI, 2003)).

Essas variantes do MDD baseadas em DSMLs argumentam que as representações do software através de DSMLs são mais expressivas e simples que linguagens de modelagem de propósitos gerais, como a UML, e poderiam ser utilizadas por um universo mais amplo de profissionais, particularmente especialistas no domínio em questão, e não apenas especialistas em modelagem UML. 
No entanto, a abordagem MDD não obteve o sucesso esperado até o momento, porque provavelmente o mercado de desenvolvimento de software está menos preparada para se expressar através de modelos gráficos e conduzir o desenvolvimento sistemático até código. Muitas vezes, são elaborados os modelos iniciais e, após o entendimento inicial, são gerados códigos. Além disso, as diversas variantes do MDD ainda não evoluíram o suficiente para serem absorvidas pelo mercado.

De fato, Schmidt (2006) afirma que é difícil encontrar material técnico sólido referente à tecnologias de MDD, aplicação dessas tecnologias à produção de sistemas complexos em escala de produção e avaliações efetivas dos benefícios do MDD e áreas que ainda precisam de atenção.

Quanto ao desenvolvimento de DSMLs, Mernik, Heering, e Sloane (2005) afirmam que o assunto é difícil, requerendo tanto conhecimento do domínio quanto especialização em desenvolvimento de linguagens. Afirmam também que, embora haja muitos artigos escritos sobre o desenvolvimento de DSMLs específicas, a literatura sobre metodologias de desenvolvimento de DSMLs é muito limitada e que existem muitas questões sobre quando e como desenvolver uma DSML.

A lacuna mais importante identificada por estes autores é a ausência de diretrizes claras para desenvolver a DSML a partir da informação obtida na disciplina de Análise, embora haja algumas apresentadas no texto referenciado de (THIBAULT; MARLET; CONSEL, 1999).

Desde então, pesquisas tem sido efetuadas, abordando diversos aspectos do desenvolvimento baseado em MDD, com o intuito de ampliar o nível de adoção de MDD.

Uma das linhas de pesquisa propõe simplificar e aumentar a qualidade do design das DSMLs através da utilização de fragmentos pré-definidos na sua construção. Essa linha evoluiu, ao longo dos últimos anos, para considerar não apenas pequenos fragmentos que resolvem questões específicas, mas modelos de computação que norteiam a estrutura e funcionamento das DSMLs (EMERSON; SZTIPANOVITS, 2006), (MANNADIAR; VANGHELUWE, 2010), (KELLY; TOLVANEN, 2008), entre outros. 
Um modelo de computação, conforme definido por (MOSTERMAN; VANGHELUWE, 2002), é um conjunto de requisitos que guiam a modelagem de um sistema, em um domínio específico. Esses requisitos fornecem base para o design de DSMLs e especificam:

- os tipos de entidades e os relacionamentos que podem ser modelados;

- a melhor forma de modelá-los;

- os atributos das entidades e dos relacionamentos;

- número e tipo de vistas necessários para particionar o espaço de design logicamente e eficientemente.

Exemplos de modelos de computação são máquinas de estado, redes de Petri e diagramas de classes da UML.

Kelly e Tolvanen (2008), entre outros, propõem que o design de uma DSML seja baseado em um ou mais modelos de computação, e a escolha dos modelos e a sua combinação dependem do alvo da modelagem. Esta escolha é geralmente feita implicitamente, em função da experiência dos projetistas, mas se explicitadas podem definir procedimentos para auxiliar na utilização de DSMLs.

Em essência, a pesquisa para o design de DSMLs, com base em fragmentos, considerava inicialmente fragmentos de design muito específicos, que resolvem questões pontuais de design; evoluiu gradativamente para a proposta de construir DSMLs a partir de modelos de computação, levando-se em consideração as características da DSML a ser projetada. Dentro deste contexto, a pesquisa no sentido de explorar a proposta de (MANNADIAR; VANGHELUWE, 2010) que busca os modelos de computação para o design de DSMLs foi considerado como um assunto relevante para a condução deste trabalho.

\subsection{Objetivo}

Uma DSML deve ter a capacidade de representar bem o tipo do domínio a ser modelado. Desta forma, quando os seus modelos são mais voltados para estruturas estáticas, é denominada de DSML estática e os modelos de computação mais adequados são os diagramas de classes ou de entidades e relacionamentos. Por outro lado, quando a representação do comportamento é mais relevante, é 
denominada de DSML dinâmica e os modelos de computação mais adequados são diagramas de transição de estados ou diagramas de atividades.

Observa-se, ainda, que os modelos de computação, para serem utilizados em uma DSML, devem ser especializados para o contexto específico de um determinado modelo. Uma forma de sistematizar o uso de modelos de computação para esta finalidade é descrevê-los de forma padronizada e disponibilizá-los para os projetistas de DSMLs.

O objetivo do trabalho é, portanto, especificar um catálogo de modelos de computação que podem ser utilizados no design de DSMLs, no contexto de MDD.

O termo catálogo foi selecionado para que o conjunto de modelos de computação fossem apresentados como uma relação sistemática dos itens, geralmente em alguma ordem pré-definida (por exemplo, alfabética) de seu nome, com uma descrição resumida para facilitar a sua localização (WEISZFLOG, 2004).

No desenvolvimento da DSML, os modelos de computação são geralmente utilizados após a elaboração dos modelos do domínio em questão, que fornecem as características do sistema a ser desenvolvido, e antes do design detalhado da DSML. Como os elementos do catálogo apresentam uma descrição padronizada dos atributos dos modelos de computação, espera-se que possam simplificar a construção de uma DSML.

A especificação do catálogo consiste da definição do conteúdo e da estrutura para descrever os modelos de computação. É também contemplado neste trabalho, a definição de um processo empírico para geração do catálogo. A avaliação do catálogo é feita através da aplicação dos modelos de computação definidos no catálogo em um domínio selecionado.

O conteúdo do catálogo de modelos de computação é dinâmico, ou seja, deve ser atualizado cada vez que for detectada necessidade de novos modelos de computação durante o desenvolvimento de DSMLs e, portanto, não tem a pretensão de ser completo. 


\subsection{Justificativa}

\subsubsection{Introdução}

Esta seção busca responder às seguintes questões:

- Como viabilizar a adoção da abordagem MDD baseada em DSMLs?

- Por que um catálogo de modelos de computação melhora o desenvolvimento de DSMLs?

- Por que focar na construção de sistemas de informação?

As seções a seguir buscam discutir essas questões.

\subsubsection{Pesquisas para viabilizar a adoção de MDD baseado em DSMLs}

Schmidt (2006) afirma que é necessário que haja mais pesquisa e desenvolvimento em diversas áreas pertinentes à abordagem MDD, por exemplo, para suportar engenharia direta e reversa entre modelos e código fonte ou entre modelos e outros modelos de representação; melhorar a depuração no nível de modelagem; garantir compatibilidade das ferramentas MDD com o legado; padronizar ambientes de metamodelagem e formatos de intercâmbio de modelos; capturar a intenção do design para domínios de aplicação arbitrários; automatizar a especificação e síntese de transformação de modelos e requisitos de qualidade para simplificar a evolução de modelos e metamodelos, entre outras questões.

Em suma, o MDD é uma área de conhecimento muito ampla e complexa, que envolve um conjunto grande de abordagens conceituais e tecnologias de implementação, ainda em evolução, e com amplas áreas de estudo em aberto.

Agrawalkarzai e Ledcz (2003) afirmam que, para que as DSMLs sejam mais utilizadas (...) o custo de desenvolvimento (em termos de tempo e esforço) precisa ser reduzido pela criação de um framework para desenvolver DSMLs. O texto se refere explicitamente a ferramentas gerados de DSMLs, como o GME, mas consideramos que a afirmativa é perfeitamente válida para a definição do processo de desenvolvimento de uma DSML.

Mais recentemente, o processo de desenvolvimento de DSMLs no contexto do MDD tem evoluído, inclusive no que diz respeito à lacuna identificada de tradução do modelo de domínio no design da DSML. Kelly e Tolvanen (2008), por exemplo, 
definiram um processo detalhado de desenvolvimento de DSMLs, que contempla diretrizes empíricas para a geração do design da DSML.

\subsubsection{Melhoria do desenvolvimento de DSML através do catálogo de modelos de computação}

Dentre as propostas de geração de DSML, existem aquelas que defendem o uso de blocos básicos de construção, que podem ser considerados como fragmentos padrões no design de uma DSML (EMERSON; SZTIPANOVITS; 2006).

Essa área de pesquisa tem evoluído, ao longo dos últimos anos, e deixou-se de considerar apenas pequenos fragmentos de modelos de design, que resolvem problemas muito específicos. Ao invés disso, buscou-se utilizar blocos básicos correspondentes aos modelos de computação, no design da DSML, conforme discutido na seção 1.1 .

Como uma das referências iniciais a essa abordagem, Mosterman e Vangheluwe (2002) propõem que o design de DSMLs seja baseado em linguagens de modelagem específica (como Rede de Petri ou diagramas de classes da UML), as quais foram denominadas de modelos de computação neste trabalho.

Na mesma linha, Emerson e Sztipanovits (2006) propõem que haja bibliotecas de fragmentos ou padrões (patterns) reutilizáveis que sirvam como blocos de construção de DSMLs.

Kelly e Tolvanen (2008), ao apresentar um processo de desenvolvimento de DSML, afirmam que a existência de Bibliotecas de Modelos de Computação pode auxiliar na seleção dos modelos de computação que norteiem o design da DSML. Nesta linha de raciocínio, Levendovsky, Lengyel e Mészáros (2009) sugerem ambientes de metamodelagem para fornecer suporte teórico na incorporação de padrões reutilizáveis para a construção de DSMLs.

Kelly e Tolvanen (2008) distinguem DSMLs estáticas, que proveem apenas visão estrutural do domínio que representam, e DSMLs dinâmicas, que representam alguma forma de comportamento (possivelmente além de representarem estrutura do domínio). O(s) modelo(s) de computação no(s) qual(is) uma DSML se baseia definem em que tipo de linguagem a DSML se encaixa. 
Assim, uma DSML estática, cujos modelos produzidos não especificam comportamento dinâmico e apenas estruturas estáticas, pode ter, como modelo de computação, modelos de computação como diagramas de classes ou de entidaderelacionamento. Por outro lado, uma DSML dinâmica pode ter, como modelo de computação, um diagrama de transição de estados ou diagrama de atividades, dependendo do domínio e do intuito da DSML.

Um modelo de computação deve ser especializado para o contexto específico de uma DSML, ou seja, a sintaxe abstrata da DSML é composta por especializações dos modelos de computação para um determinado domínio.

Como evolução de ideias, Mannadiar e Vangheluwe (2010) apresentam uma questão fundamental em relação à identificação de modelos de computação que formem a base para o design de DSMLs. Não fornecem uma resposta completa a essa questão, mas relaciona os modelos de computação que consideram imprescindíveis para o design de DSMLs

Ao analisar estes trabalhos, detectou-se uma oportunidade de pesquisa em relação à definição de modelos de computação para DSMLs, relativa à construção de um catálogo de modelos de computação através de um estudo mais sistemático sobre a seleção de modelos de computação para DSMLs.

\subsubsection{Foco em sistemas de informação}

A primeira abordagem que foi tentada para criar o catálogo de modelos de computação envolveu encontrar uma classificação abrangente de sistemas de engenharia, e associar (quando apropriado) algum modelo de computação a cada variável relevante na qual a classificação seria composta.

A pesquisa efetuada não encontrou essa classificação abrangente de sistemas de engenharia

Há muitas classificações. Por exemplo, Mosterman e Pieter (2007) definem uma classificação na qual a variável base é o fato de o sistema ser de tempo contínuo, de tempo discreto ou de evento discreto.

Cada classificação é normalmente focada uma critério base específico, ou eixo, para algum propósito também específico e, como consequência, não é possível agregar numa classificação mais ampla os critérios base das classificações existentes. 
Ford et al (2009) pesquisaram taxonomias relevantes de sistemas, e identificou diversas taxonomias e os critérios base referentes a cada uma delas. A tabela 1 , originalmente de (FORD et al; 2008), apresenta essas classificações.

\begin{tabular}{|c|c|c|c|}
\hline Ano & Originador & Base & $\begin{array}{l}\text { Propósito da } \\
\text { Taxonomia }\end{array}$ \\
\hline 1955 & Von Bertanlanffy & Aberto / fechado & GST \\
\hline 1956 & Boulding & Complexidade & GST \\
\hline 1957 & Goode \& Machol & Entrada do sistema & $\begin{array}{l}\text { Encontrar soluções } \\
\text { para problemas }\end{array}$ \\
\hline 1962 & Hall & Nenhuma provida & $\begin{array}{l}\text { Particionar } \\
\text { subsistemas / definir } \\
\text { sistema }\end{array}$ \\
\hline 1968 & Jordan & Princípios organizacionais & $\begin{array}{l}\text { Apoio à concepção de } \\
\text { sistemas }\end{array}$ \\
\hline 1971 & Ackoff & Conceitos de sistemas & $\begin{array}{l}\text { Criar um framework de } \\
\text { conceitos de sistemas }\end{array}$ \\
\hline 1981 & Checkland & Origem do sistema & Agrupar por origem \\
\hline 1990 & Wilson & Nenhuma provida & $\begin{array}{l}\text { Refinar a definição de } \\
\text { sistema }\end{array}$ \\
\hline 1997 & Shenar \& Boner & Incerteza técnica e escopo & $\begin{array}{l}\text { Alocar de forma } \\
\text { apropriada engenharia } \\
\text { de sistemas e métodos } \\
\text { gerenciais }\end{array}$ \\
\hline 1999 & Maier & $\begin{array}{l}\text { Independência de componentes gerenciais } \\
\text { e operacionais }\end{array}$ & $\begin{array}{l}\text { Arquitetura de sistemas } \\
\text { de sistemas }\end{array}$ \\
\hline 2005 & Gideon et al & Aquisição, operação, tipo de domínio & $\begin{array}{l}\text { Auxiliar a compreensão } \\
\text { de sistemas de } \\
\text { sistemas }\end{array}$ \\
\hline 2006 & $\begin{array}{l}\text { Blanchard \& } \\
\text { Fabrycky }\end{array}$ & Similaridades e diferenças & $\begin{array}{l}\text { Prover insight para } \\
\text { ampla gama de } \\
\text { sistemas }\end{array}$ \\
\hline 2007 & Valdma & Classes de informação & $\begin{array}{l}\text { Estudo de fenômenos } \\
\text { não determinísticos. }\end{array}$ \\
\hline
\end{tabular}

Tabela 1 - Sumário histórico de taxonomias qualitativas de sistemas

Ao se identificar ser excessivamente complexo, mesmo inviável, definir uma classificação ampla de sistemas de engenharia, escolheu-se nesta tese focar numa categoria específica de sistema - sistemas de informação - por dois motivos:

- Os sistemas de informação constituem-se no tipo de sistema mais comumente desenvolvido pelo mercado de desenvolvimento de software, o que os torna 
particularmente relevantes para contribuir para viabilizar o sucesso da abordagem de MDD;

- Ao se focar em uma classe (ou contexto) de sistemas, fica mais fácil identificar um conjunto de sistemas (por exemplo, sistemas corporativos, também denominados ERPs, enterprise resource planning) para nortear a identificação dos modelos de computação mais relevantes para dar suporte ao design de DSMLs nesse contexto.

\subsection{Metodologia de trabalho}

O trabalho foi realizado através das seguintes atividades:

- Estudo de temas relacionados com MDD, DSL e DSML;

- Especificação do catálogo de modelos de computação;

- Seleção de uma classe de sistemas;

- Análise de entidades e lógica de execução dos sistemas selecionados;

- Identificação de um conjunto de candidatos a modelos de computação;

- Seleção dos modelos de computação para o catálogo;

- Descrição dos modelos de computação conforme especificação do catálogo;

- Aplicação dos modelos de computação na definição de uma DSML.

As atividades e os respectivos produtos gerados estão descritos a seguir.

\section{Estudo de temas relacionadas com MDD, DSL e DSML}

Foi realizada uma pesquisa bibliográfica sobre MDD, linguagens específicas de domínio (DSL e DSML) e modelos de computação. Esta atividade teve continuidade ao longo do desenvolvimento do trabalho para acompanhar a evolução da área.

Desta atividade resultou o conhecimento que permitiu elaborar o texto sobre motivação, objetivo, e justificativa da tese e o tutorial sobre Linguagens Específicas de Domínio.

\section{Especificação do catálogo de modelos de computação}

Uma vez identificada a validade e a finalidade do catálogo de modelos de computação, foi feita a definição da sua estrutura e do seu conteúdo, através dos tipos de atributos para especificar os modelos de computação do catálogo. Essa 
definição foi feita com base e nos objetivos definidos para o catálogo e nas referências.

O produto desta etapa foi a definição dos atributos e sua descrição e a elaboração de um exemplo para os modelos de computação.

\section{Seleção de uma classe de sistemas}

Como as DSMLs são construídas para um domínio específico, foi selecionado a classe de sistemas de informação, por constituírem um tipo de sistemas mais comumente desenvolvido pelo mercado de desenvolvimento de software.

Para a identificação dos modelos de computação, era necessário conhecer as características de sistemas para os quais seriam construídas as DSMLs, em nível macroscópico, com descrição com certo detalhamento das funções principais.

Os sistemas foram considerados relevantes para a análise, quando suas entidades e sua lógica de execução foram consideradas representativas dentro do domínio de sistemas de informação. Com isso, os modelos de computação identificados teriam alta probabilidade de serem usados em outros sistemas desse domínio.

O produto desta atividade foi a identificação de uma classe de sistemas de informação para análise mais detalhada.

\section{Análise das entidades principais e lógica de execução dos sistemas selecionados}

Esta análise foi feita sobre descrições textuais com nível adequado de detalhamento; não se parte, portanto, da premissa de se ter acesso ao código fonte dos sistemas a serem analisados.

A descrição desses sistemas deve ter detalhes suficientes para que seja possível identificar os modelos de computação que eventualmente implementam as suas características. Para isso, não é suficiente apenas uma descrição dos objetivos de cada função. É necessário poder deduzir a lógica de execução de cada função e entidades mais relevantes manipuladas pelas funções.

O produto desta atividade foi uma descrição sucinta dos dados de entrada, lógica de cada função, e entidades geradas, para cada passo de cada função de um sistema 
em análise. A descrição deve ser suficientemente detalhada para permitir inferir qual o algoritmo ou a lógica de execução utilizada.

\section{Identificação de um conjunto de modelos de computação candidatos}

A identificação dos modelos de computação úteis para as funções dos sistemas em análise foi realizada analisando a descrição detalhada das entidades e das funções desses sistemas, geradas na atividade 4 .

O produto desta atividade foi, portanto, um conjunto de modelos de computação candidatos para a classe de sistemas em análise.

\section{Seleção dos modelos de computação para o catálogo}

Quando houve alternativas de candidatos de modelos de computação para uma característica (por exemplo, diagrama de atividade versus diagrama business process modeling notation - BPMN), foi necessário identificar, caso a caso, critérios de comparação e selecionar um deles como sendo o modelo de computação a ser incluído no catálogo.

O produto desta etapa foi um subconjunto dos candidatos a modelos de computação obtido na etapa anterior, selecionado para constar no catálogo.

\section{Descrição dos modelos de computação conforme especificação do catálogo}

Cada modelo de computação selecionado para o catálogo foi descrito, conforme definido na etapa 2.

O produto desta etapa foi o catálogo de modelos de computação descrito em detalhes.

\section{Aplicação dos modelos de computação na definição de uma DSML}

Nesta atividade, foi elaborado o design de uma DSML de Definição de um Processo de Seleção de Projetos de um Portfólio de projetos, utilizando um processo de desenvolvimento de DSMLs definido dentre os apresentados nas referências. Uma etapa desse processo selecionou o(s) modelo(s) de computação que vão nortear a definição do design da DSML, usando o catálogo de modelos de computação do catálogo como fonte de informação. 
O produto desta atividade foi a DSML definida, usando no seu design, os modelos de computação existentes no catálogo.

\subsection{Estrutura do Trabalho}

O capítulo 1 da tese apresenta motivação, objetivo, justificativa, metodologia e estrutura da tese.

O capítulo 2 apresenta o estado da arte dos temas abordados pela tese: MDD, DSMLs, processo de definição de DSMLs, modelos de computação.

O capítulo 3 define e exemplifica o processo de geração do catálogo de modelos de computação e, a seguir, apresenta a execução desse processo para a classe de sistemas selecionada como fonte de informação.

O capítulo 4 apresenta a criação de uma DSML exemplo, para ilustrar o processo de criação de uma DSML e exemplificar o uso do catálogo de modelos de computação.

O capítulo 5 apresenta considerações finais, contribuições da tese, e trabalhos futuros. 


\section{Linguagens Específicas de Domínio}

Este capítulo tem o objetivo de apresentar uma visão geral sobre Linguagens Específicas de Domínio (DSL - Domain Specific Language) e Linguagens de Modelagem Específicas de Domínio (DSML - Domain Specific Modeling Language), e um processo de desenvolvimento de DSMLs com base no processo de (MERNIK; HEERING; SLOANE, 2005).

\subsection{Visão Geral sobre Linguagens Específicas de Domínio}

Esta seção apresenta os pontos relevantes sobre as Linguagens Específicas de Domínio (DSL - Domain Specific Language).

Uma DSL é uma linguagem de programação ou linguagem de especificação executável que oferece, através de notações e abstrações apropriadas, poder de expressão normalmente restrito a, um particular domínio de interesse (DEURSEN; KLINT; VISSER, 2000).

\subsubsection{Conceitos Fundamentais em DSLs}

Os conceitos fundamentais em DSLs compreendem o domínio e o modelo de domínio.

O termo domínio recebe significados diferentes dependendo das disciplinas tais como linguística, pesquisa cultural, inteligência artificial, tecnologias orientadas a objetos e reuso de software.

No contexto deste trabalho, pode-se considerar, como discussão inicial, a abordagem de (SIMONS et al, 1996) que distingue duas categorias para o uso desse termo:

- Domínio como o mundo real

- Domínio como um conjunto de sistemas

O domínio como o mundo real consiste do conhecimento sobre uma área específica, através de terminologia, definições e regras que regem os conceitos e atividades envolvidas. Por exemplo, o domínio das contas bancárias envolve conceitos como contas, clientes, depósitos, saques, e assim por diante. 
$\mathrm{Na}$ área de desenvolvimento de software, mais especificamente na orientação a objetos, o domínio é considerado como uma área de conhecimento ou atividade, caracterizada por um conjunto de conceitos e terminologia compreendidos pelos praticantes da área (BOOCH; RUMBAUGH; JACOBSON, 2005).

O domínio como um conjunto de sistemas abrange o conhecimento sobre a construção de software, do ponto de vista de componentes reutilizáveis, além do conhecimento do mundo real em uma determinada área específica. Esse ponto de vista sobre domínio é utilizado na área de reuso de software.

Para este trabalho, foi adotada a abordagem de (CZARNECKI; EISENECKER, 2000) que define domínio como uma área de conhecimento que:

- É delimitada para maximizar a satisfação dos requisitos dos stakeholders (partes interessadas);

- Inclui um conjunto de conceitos e terminologia compreendidos pelos praticantes da área;

- Inclui conhecimento sobre como construir sistemas de software (ou partes dos sistemas de software) naquela área.

Estes autores destacam que um domínio é definido por consenso entre os stakeholders e que a delimitação de um domínio é externa e arbitrária, sendo definida para atender aos interesses dos stakeholders.

Da mesma forma, a definição de modelo de domínio também varia, dependendo da área que a utiliza.

Como exemplo, Fowler (1996) e Larman (2002), atuantes na área de engenharia de software, definem o modelo de domínio como um conjunto de diagramas de classes nos quais não se definem operações. Esses diagramas podem exibir:

- Objetos do domínio, ou classes conceituais;

- Associações entre as classes conceituais;

- Atributos das classes conceituais.

Por outro lado, Czarnecki e Eisenecker (2000), da área de reuso de software, definem o modelo de domínio como uma representação explícita das propriedades 
comuns e variáveis dos sistemas em um domínio, da semântica e das propriedades dos conceitos do domínio, e das dependências entre as propriedades variáveis.

As definições desses autores não são contraditórias, mas a definição de Czarnecki e Eisenecker (2000) identifica os elementos que constituem um modelo de domínio, enquanto Fowler (1996) e Larman (2002) focam em descrever a representação gráfica. Este texto considera mais esclarecedora sobre o que constitui um modelo de domínio e a definição de Czarnecki e Eisenecker (2000), que será adotada como referência, ao longo do texto.

\subsubsection{Classificações das DSL}

As DSLs podem ser classificadas através de diversos critérios. No entanto, para este trabalho foram considerados dois tipos de classificações por serem mais significativos para o seu contexto:

- DSLs textuais e gráficas;

- DSLs executáveis e não executáveis.

\subsubsection{DSLs textuais e gráficas}

As representações textuais ou gráficas geralmente podem ser mais adequadas dependendo do domínio em que são utilizadas.

Segundo Agrawal, Karsai e Ledczi (2003) as linguagens gráficas são geralmente pouco práticas para programação de propósitos gerais, mas podem ser úteis em contextos limitados, em domínios específicos. O pacote Matlab/Simulink para simulação e projeto de engenharia de controle é citado como exemplo bem sucedidos de DSL gráfica.

Uma solução mais flexível para certos casos, segundo esses autores é o uso de uma notação mista, envolvendo representação gráfica e textual. Citam a UML, que expressa modelos em forma de gráficos e as restrições textualmente, através de OCL (Object Constraint Language). Como outro exemplo, apresentam as ferramentas para projeto de hardware que utilizam a notação gráfica para a descrição estrutural do hardware e texto para a descrição comportamental. 


\subsubsection{DSLs executáveis e não executáveis}

As DSLs podem ser concebidas para serem executáveis ou não, dependendo da sua finalidade. Em certos casos, a denominação mais adequada de um programa expresso através de uma DSL é especificação, definição ou descrição (MERNIK; HEERING; SLOANE, 2005).

Esses autores, apresentam uma escala informal para o nível de execução das DSLs, através dos seguintes exemplos:

- DSL executável, com semântica de execução bem definida como, por exemplo, a linguagem de macros do Excel ou HTML;

- Linguagem de entrada para geradores de aplicações, que é uma linguagem executável, mas geralmente com caráter mais declarativo, porém com uma semântica de execução menos bem definida no que diz respeito aos detalhes da aplicação gerada. Neste caso, o gerador de aplicações é um compilador para a DSL em questão;

- DSL útil para a geração de aplicações, ainda que não tenham como objetivo principal serem executáveis. Um exemplo é o BNF (Backus-Naur Form), que tem um caráter declarativo, mas pode ser utilizada como linguagem de entrada para um analisador de um compilador;

- DSL concebida para não ser executável. Como exemplo citam-se representações de estruturas de dados específicas de determinado domínio.

Deursen, Klint e Visser (2000) apresentam uma visão semelhante, afirmando que as DSLs podem ser linguagens de especificação ou linguagens de programação e enumera algumas situações típicas:

- DSL como linguagem de geração de aplicações e, nessas situações, um compilador transforma os programas DSL em aplicações. Nesse caso, a DSL é denominada linguagem de aplicações específicas;

- DSL para geração de bibliotecas ou componentes e não de aplicações completas;

- DSLs para geração de documentos, como a linguagem para processamento de texto $T_{E} X$. 
Cabe observar que uma DSL, para ser executável, deve ser formalmente especificada, para viabilizar a tradução automática.

\subsubsection{DSLs no contexto do Desenvolvimento Dirigido por Modelos}

A abordagem MDD (model driven development - desenvolvimento dirigido por modelos) consiste do desenvolvimento de software com base em modelos gráficos, e tradução automática destes modelos para código, e ganhou destaque nesta década (KLEPPE; WARMER; BAST, 2003). Esses modelos gráficos podem ser expressos em UML ou em modelos construídos usando DSLs que, neste contexto, são denominadas de Linguagens de Modelagem Específicas de Domínio (DSML domain specific modeling languages) por diversos autores (CHEN; SZTIPANOVITS; NEEMA, 2005), (SCHMIDT, 2006), (BALASUBRAMANIAN et al, 2006).

As DSMLs, usadas para os propósitos de MDD, devem permitir a tradução automática de modelos para código e, portanto, devem ser manipuláveis computacionalmente.

Uma variante do MDD que utiliza a UML para geração dos modelos gráficos é denominada MDA (Model Driven Architecture - Arquitetura Dirigida por Modelos), criada pela OMG (Object Management Group).

$\mathrm{Na}$ abordagem MDA, pressupõe-se a construção de modelos gráficos do software que são sucessivamente traduzidos automaticamente, em parte ou totalmente, em modelos de níveis mais baixos de abstração e, por fim, em código em alguma linguagem de programação (MELLOR; CLARK; FUTAGAMI, 2003).

Por outro lado, diversos autores consideram que o uso da UML como linguagem para a especificação de modelos gráficos, no contexto do MDD, não é muito adequado, devido aos seguintes argumentos (FRANCE et al, 2006), (ENGELS et al, 2001):

- A UML não possui especificação formal, causando dificuldades para a tradução automática de seus modelos em outros modelos ou código;

- As abstrações fornecidas pela UML nem sempre são adequadas para representar modelos concisos e claros, para domínios complexos, por serem genéricas; 
- A verificação da consistência entre os diversos tipos de modelos em UML de sistemas complexos é trabalhosa e não trivial, devido ao volume de informação neles contidos. Se os modelos do mesmo nível de abstração não forem consistentes, a implementação do sistema pode se tornar inexequível (BELIX, 2006);

- A verificação da consistência entre o detalhamento dos modelos em UML de sistemas complexos também é trabalhosa e não trivial, pelos mesmos motivos do item anterior. (BELIX, 2006);

- Os recursos da definição da semântica e do mecanismo de extensão não são formais. Também não possui mecanismos para definição de pontos de vista. (FRANCE et al, 2006).

Devido aos argumentos apresentados, outras variantes do MDD propõem o uso de DSMLs, concebidas formalmente, para representar os modelos gráficos. Nessas propostas, é usualmente utilizado um núcleo essencial, bem delimitado, da UML, com semântica claramente definida, como metalinguagem para a definição das DSMLs (NORDSTROM et al; 2003), (GREENFIELD, 2004).

Como exemplo de DSMLs, pode-se citar o trabalho de (CHEN; SZTIPANOVITS; NEEMA, 2005), no contexto de sistemas embarcados. As DSMLs representam os aspectos estruturais e comportamentais de sistemas e software e a sua semântica inclui concorrência, abstrações de comunicação, temporais e outras propriedades físicas.

Ainda, pode-se citar (BALASUBRAMANIAN et al., 2006) que amplia o contexto da utilização de DSMLs para representar elementos de sistema e os relacionamentos entre eles, bem como as transformações desses elementos para artefatos específicos de determinada plataforma de desenvolvimento. Para os autores, as DSMLs podem representar desde uma entidade muito específica, como os componentes de um sistema de radar, até entidade tão abrangente quanto middleware baseado em componentes construído utilizando plataformas como EJBs ou CCM. 


\subsubsection{Especificação de DSL}

Esta seção apresenta os conceitos de uma linguagem no contexto de MDD, com base principalmente em (GREENFIELD, 2004) e (KARZAI, 2003);. outras fontes de referências, quando utilizadas, estão explicitadas no texto.

Dessa forma, uma linguagem possui sintaxe abstrata, sintaxe concreta e semântica e a sua estrutura está apresentada na figura 1 (GREENFIELD, 2004).

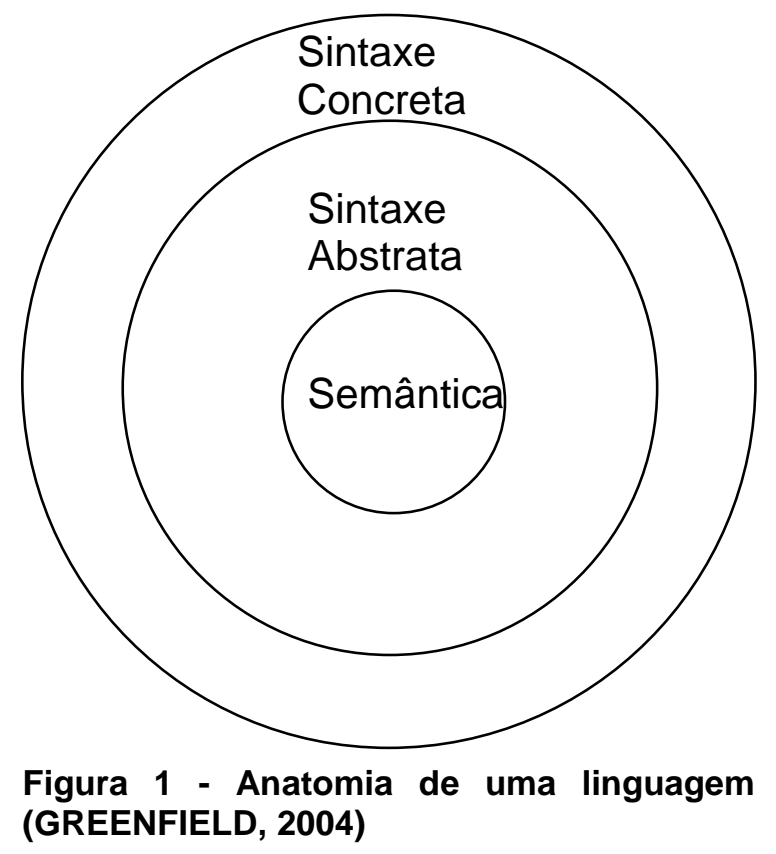

A sintaxe abstrata define os conceitos essenciais e a estrutura das expressões de uma linguagem.

A sintaxe concreta define como os conceitos abstratos, expressos pela sintaxe abstrata, são realizados por uma notação concreta, seja ela textual, gráfica, ou alguma outra forma.

A semântica define o significado dos conceitos da sintaxe abstrata. Em linguagens naturais, a definição semântica de uma linguagem é complexa e feita de maneira informal. Já em linguagens formais, há abordagens específicas para definição da 
semântica. Pode-se ainda citar as linguagens semi-formais, cujas representações não podem ser definidas de forma precisa e que são processadas com apoio da interpretação humana, como na geração de diagramas UML.

\subsubsection{Sintaxe abstrata}

A sintaxe abstrata define os tipos de elementos que formam uma linguagem e as regras para que esses elementos possam ser combinados. Estes elementos podem ser atômicos ou compostos e as regras indicam como os elementos compostos são formados pela combinação de outros elementos, atômicos ou compostos.

Há diversas formas de definir elementos e regras. Entre elas podem-se citar linguagens livres de contexto e meta-modelos, como formas mais utilizadas para se definir, respectivamente, linguagens textuais e gráficas.

As linguagens livres de contexto são tradicionalmente utilizadas para definir a sintaxe abstrata e concreta de linguagens de programação. Nada impede, entretanto, que sejam utilizadas para definir linguagens gráficas.

Uma linguagem livre de contexto consiste em um conjunto de produções, em que o lado esquerdo é chamado não-terminal (símbolo) e o lado direito detalha a sua estrutura interna em função de outros não terminais e terminais. Um terminal é um elemento atômico da linguagem; um não terminal é um elemento composto.. Um único terminal é selecionado para representar o símbolo inicial, que representa o elemento de mais alto nível da linguagem.

A notação mais comum para expressar linguagens livres de contexto é a BackusNaur Form (BNF).

A abordagem de meta-modelos foi utilizada para expressar a sintaxe abstrata da UML e foi intensamente adotada como recurso de modelagem de sistemas de software (OBJECT MANAGEMENT GROUP, 2005). No caso, o meta-modelo caracteriza os elementos das linguagens tais como classes e relacionamentos, utilizando atributos e associações. Além disso, possui recursos para definir restrições dos seus elementos, através da linguagem OCL (Object Constraint Language - Linguagens de Restrições sobre Objetos) (OBJECT MANAGEMENT GROUP, 2006). 
Greenfield (2004) identifica um conjunto de vantagens no uso de meta-modelos sobre as linguagens livres de contexto, para o contexto do MDD, sumarizadas a seguir:

- Em um meta-modelo, a habilidade de dar nomes a atributos torna mais fácil armazenar as intenções do projetista da linguagem.

- Em uma linguagem livre de contexto, existe a tendência de introduzir níveis adicionais de indireção para aumentar a legibilidade.

- Um meta-modelo expressa uma estrutura em grafo, enquanto uma linguagem livre de contexto expressa uma estrutura em árvore. Portanto, em um metamodelo, a referência direta a objetos por objetos que não são o proprietário do referenciado pode ser facilmente obtida utilizando atributos.

- O meta-modelo possui uma representação gráfica, que torna a compreensão da definição mais fácil.

- A definição de regras de boa formação da linguagem no meta-modelo é mais completa que a definição em uma linguagem livre de contexto, em que regras implícitas são construídas no código que efetua a análise contextual, como no caso de identificação de checagem de tipos.

\subsubsection{Sintaxe Concreta}

O objetivo de uma sintaxe concreta é definir os elementos (gráficos ou textuais) da linguagem e as combinações possíveis entre eles, para serem utilizados pelos usuários da linguagem para produzir os programas na linguagem considerada.

Greenfield (2004) definiu uma técnica para mapear uma sintaxe concreta em uma sintaxe abstrata, utilizando como referência a UML.

A técnica, resumidamente, consiste em associar notas (da representação UML) com expressões $\mathrm{OCL}$ aos elementos da sintaxe abstrata da linguagem. Essas notas definem os elementos correspondentes da sintaxe concreta $e$ as regras de representação e de relacionamento entre esses elementos. As notas devem definir os elementos gráficos que representam a sintaxe concreta da linguagem.

A premissa é que essas notas com as expressões OCL possam ser transformadas automaticamente em código executável através do editor gráfico da linguagem. 
Desta forma, tanto a sintaxe concreta quanto o mapeamento sintático entre a sintaxe concreta e a abstrata podem ser definidas formalmente.

\subsubsection{Semântica}

A semântica define o significado dos elementos da linguagem. Podem-se considerar dois estilos para expressar a semântica de uma linguagem: semântica translacional e semântica baseada em traços (trace-based).

A semântica translacional consiste em traduzir expressões da linguagem considerada em outra linguagem que já possui uma semântica bem definida. Por exemplo, a linguagem de programação C\# pode ter as regras de tradução definidas para a linguagem intermediária IL, cuja semântica já está previamente definida para conjunto de instruções de uma particular plataforma.

Quanto a semântica baseada em traços, a seguir é apresentada uma definição informal baseada em (GREENFIELD, 2004). Uma definição com rigor matemático foge aos objetivos deste texto.

Uma semântica baseada em traços define o significado de uma linguagem observando traços da execução dessa linguagem. As observações podem ser efetuadas a partir das saídas geradas pelo programa - caso haja informação suficiente nessas saídas; ou utilizando uma ferramenta de depuração que exponha suficientes traços de execução dessa linguagem para que seja possível entender seu significado.

\subsection{Visão geral sobre Linguagens de Modelagem Específicas de Domínio (DSML)}

As DSML constituem um subconjunto das DSLs; são tipicamente gráficas e são voltadas para modelagem. Conforme comentado na seção 2.1.3, as DSMLs devem, no contexto do MDD, possuir recursos para permitir a tradução automática dos modelos gráficos para código.

Além disso, para que o desenvolvimento de sistemas com abordagem MDD possa ser realizada, é importante um ambiente e um processo de desenvolvimento apropriados. 


\subsubsection{Ambiente para a especificação de DSMLs}

Um ambiente para uso de DSMLs deve possuir recursos para a especificação de DSMLs e as ferramentas geralmente trabalham em dois níveis de abstração. Inicialmente, a DSML é gerada através de um editor de DSMLs, que utiliza um metamodelo (gráfico ou textual); em seguida, a DSML gerada é tratada por um editor de modelos de domínio, gerando os modelos de domínio do sistema a ser desenvolvido. $\mathrm{O}$ ambiente pode ainda integrar os geradores de transformações, que traduzem os modelos de domínio gerados em modelos de nível de abstração mais baixo ou código em linguagens como Java ou linguagens do ambiente .Net, fornecendo, desta forma, soluções mais completas de MDD (SCHMIDT, 2006).

A figura 2 apresenta a estrutura típica da construção e utilização de DSMLs nessas ferramentas (KELLY; TOLVANEN, 2008).

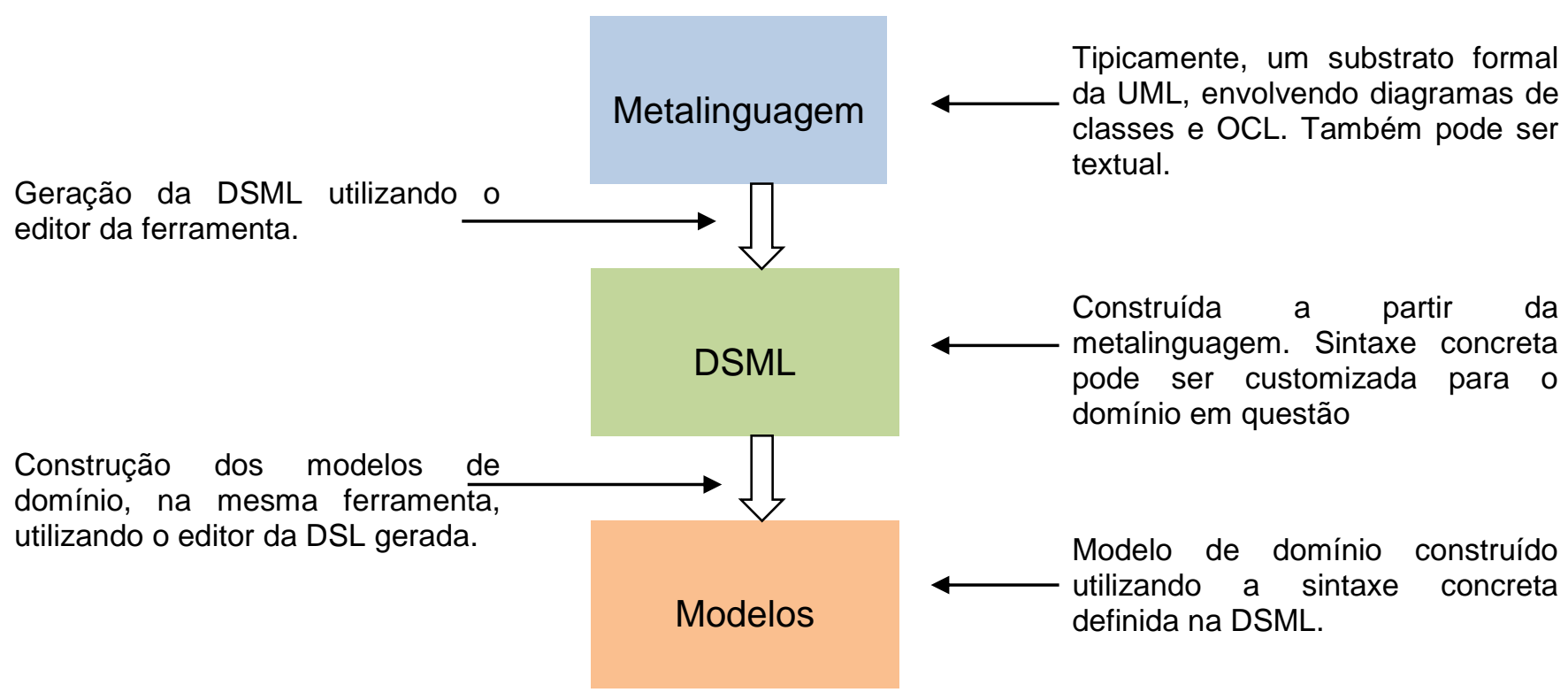

Figura 2 - estrutura de construção e utilização de uma DSML (KELLY; TOLVANEN, 2008)

Um conjunto de características desejáveis para ferramentas para geração de DSML, proposto por KELLY e TOLVANEN (2008), pode ser encontrado na Apêndice B.

\subsubsection{Exemplos de DSMLs}

É apresentada, a seguir, exemplos de DSMLs mais representativos, para ilustrar os ambientes que utilizam DSMLs. 
Balasubramanian et al (2006) citam duas DSMLs geradas utilizando o GME (Generic Modeling Environment), que é uma ferramenta faz parte de um framework para MDD (veja apêndice B para maiores detalhes sobre o GME):

- PICML (Platform Independent Component Modeling Language - Linguagem de Modelagem de Componentes Independente de Plataforma), que auxilia o desenvolvimento, a configuração e a implantação de sistemas que usam tecnologias de middleware de componentes;

- ECSL (Embedded Control Systems Language - Linguagem de Controle de Sistemas Embarcados), que fornece suporte ao desenvolvimento de aplicações embarcadas distribuídas na área automotiva.

Além disso, Balasubramanian et al (2006) apresentam a CALM (Cadena Architecture Language and Metamodeling - Arquitetura de Linguages e Metamodelos Cadena), uma linguagem de descrição de arquiteturas, que propicia a modelagem de plataformas fortemente tipadas, componentes nessas plataformas, e montagem de componentes em cenários concretos.

Agrawal, Karsai e Ledczi (2003) apresentam a linguagem MOLES (Modeling Language for Embedded Systems - Linguagem de Modelagem para Sistemas Embarcados), que propicia o projeto das interfaces e dos comportamento de componentes, a criação de fluxos de dados envolvendo os componentes e os recursos para implementar interrupções de tempo, filas e elementos de atraso.

\subsection{Processo de Desenvolvimento de DSML}

Para analisar os processos de desenvolvimento de DSLs, foi adotada a nomenclatura disciplina para os diversos tipos de atividades. Analisando os processos propostos por diversos autores, adotou-se as fases apresentadas por (MERNIK; HEERING; SLOANE, 2005) pois essa estruturação é referenciada por diversos textos que abordam o tema processo de desenvolvimento de DSLs.

Um outro trabalho relevante é (KELLY; TOLVANEN, 2008), o qual define um processo de desenvolvimento de DSMLs, denominado Domain-Specific Modeling (DSM - modelagem específica de domínio) com diretrizes detalhadas para cada etapa do processo. 
Para cada disciplina considerada, são apresentadas referências relevantes para a sua definição e uma breve análise da contribuição fundamental dos textos de referência.

\subsubsection{Disciplina de Decisão}

Esta disciplina aborda uma questão que antecede o desenvolvimento propriamente dito da DSL, relativa à decisão ou não do seu desenvolvimento.

As referências que deram base para a sua definição são apresentadas a seguir:

(Mernik, Heering e Sloane (2005) afirmam que o investimento em uma DSL deve se pagar em termos de economia no desenvolvimento ou posterior manutenção do software desenvolvido com base na DSL. Definem um conjunto de patterns que abordam situações típicas em que uma DSL deve ser desenvolvida. Essa é uma referência fundamental, porque contempla um conjunto de situações amplo, que vai além de expressar variabilidade, nas quais se justifica o desenvolvimento de DSLs. O foco não é especificamente o desenvolvimento de DSMLs.

Consel e Marlet (1998) propõem o uso de DSLs para configurar instâncias de famílias de produtos. Identificam um conjunto de domínios para os quais é comum se desenvolver DSLs: gráfico, financeiro, telefonia, protocolos, sistemas operacionais, drivers de dispositivos, roteadores de redes, linguagens de robôs. A contribuição maior é o fato de contemplarem explicitamente uma fase de decisão. $O$ conteúdo em si não enriquece tanto a discussão.

Greenfield et al (2004) afirmam que construir uma linguagem e um framework para um domínio estreito faz mais sentido, do ponto de vista econômico, no contexto de uma família de produtos de software. Múltiplas DSLs são necessárias para descrever uma aplicação de negócios. O ponto forte é a idéia de múltiplas DSLS para descrever aspectos distintos de uma única solução.

Cook et al (2007) apresentam motivações para desenvolver uma DSL. Identificam variabilidade que pode ser mais bem abordada por uma DSL: maner uma linha de produtos de múltiplos produtos similares, com features diferentes; facilitar variação ao longo do tempo para cada produto. Contribuem ao distinguir variabililidade de uma família de produtos ou de um único produto ao longo do tempo. 
Czarnecki e Eisenecker (2000) afirmam que DSLs são importantes por que são utilizadas para definir a configuração especifica de um membro concreto de uma família de sistemas. Consideram que, em geral, é necessário definir várias DSLs diferentes para uma aplicação completa. Distinguem DSLs de configuração de DSLs de expressão. A contribuição principal é a distinção entre DSLs de configuração e DSLs de extensão.

Visser (2008) argumenta informalmente que bibliotecas ou frameworks são alternativas à construção de uma DSL. Consideram que não se deve tentar construir uma DSL para domínios sobre os quais ainda se tem pouco conhecimento. Nesses casos, desenvolver sistemas usando abordagens convencionais, gerando código básico com uso de bibliotecas. Afirmam que, quando houver suficiente conhecimento sobre o domínio e as técnicas convencionais de programação falharem em fornecerem os mecanismos de abstração adequados, pode ser o caso de desenvolver uma DSL. A contribuição é a recomendação para que sejam desenvolvidas DSLs apenas quando o conhecimento sobre o domínio for adequadamente maduro.

\subsubsection{Disciplina de Análise}

Esta disciplina é relativa à análise do domínio em questão, como base para o posterior design da DSML. Essa análise pode ser realizada informalmente, ou utilizando técnicas como a construção de ontologias ou diagramas de features que são utilizados para representar o domínio.

As referências que deram base para a sua definição são apresentadas a seguir:

(Mernik, Heering w Sloane (2005) definem a análise de domínio como sendo uma fase essencial para o desenvolvimento de DSLs. Citam três abordagens possíveis para efetuar a análise de domínio.

- Uma abordagem informal

- Uma abordagem top-down: usar técnicas como modelagem de features ou ontologias

- Uma abordagem bottom-up: análise de código. 
Este é um texto muito genérico, não focado em linguagens específicas de domínio voltadas para expressar variabilidade do domínio, no contexto do MDD. O texto abre o leque de alternativas de técnicas para análise de domínio.

O ponto forte do texto é a definição de que o produto da análise de domínio, independentemente do padrão utilizado para produzi-lo, é fonte de informação fundamental para produzir uma DSL pertinente àquele domínio e enfatiza o papel da análise como base para a elaboração do design da DSML.

Czarnecki e Eisenecker (2000) propõem que se use a modelagem de features para expressar conhecimento sobre o domínio e compilam uma técnica própria, a partir da análise de diversos métodos pré-existentes. A técnica proposta para modelagem de features é clara, simples e muito bem documentada. É elaborada tendo como referências as técnicas de mesmo objetivo que possuem maior relevância na literatura de referência.

Consel e Marlet (1998) identificam fontes de informação para a análise de domínio. Propõem que técnicas de modelagem de features sejam utilizadas para expressar o domínio. Definem, como produto da análise, uma abordagem que integra, ou mistura, análise propriamente dita do domínio com elementos do design da linguagem.

Essa referência traz duas contribuições para a elaboração da disciplina de Análise: a definição de fontes de informação para análise do domínio; a proposta de utilização de modelagem de features para expressar o modelo de domínio. O produto da análise não é tão útil, já que não apresenta conceitos muito claros, e por conta da mistura entre análise e design.

Cook et al (2007) propõem a definição de modelo de domínio que, na estrutura de disciplinas de (MERNIK; HEERING; SLOANE, 2005) é design da DSL (o metamodelo). Identificam uma técnica muito peculiar para identificar esse meta-modelo, que é a abstração a partir de snapshots dos objetos do domínio. Por conta de pouca clareza conceitual, a abordagem proposta não é muito útil para a construção da disciplina de análise. Os pontos chaves são a definição dos conceitos de domínio vertical e domínio horizontal, que podem nortear a construção de aspectos da disciplina; e a proposta que a modelagem se dê de forma híbrida: top-down e bottom-up. 
(Kelly e Tolvanen (2008) discutem a abordagem mais apropriada para identificar os conceitos do domínio (top-down ou bottom-up), e apresentam uma série de argumentos para justificar que uma abordagem top-down é mais apropriada, podendo ser complementada por uma abordagem bottom-up. Identificam fontes e categorias de fontes a partir das quais se pode extrair conhecimento sobre 0 domínio.

Não contemplam a definição explícita de um modelo de domínio. Os conceitos de domínio são identificados a partir das fontes de conhecimento disponíveis e servem como base para a definição dos conceitos de modelagem (design da linguagem). A discussão sobre abordagem top-down versus bottom-up é muito bem embasada, e a proposta elaborada é consistente. A definição de fontes e categorias de informação é abrangente e clara, e deve ser incorporada ao processo de desenvolvimento de DSMLs. Ponto fraco é a falta de clareza para distinguir análise de design.

Visser (2008) discutem as abordagens indutiva versus dedutiva para a análise de domínio. Pode-se entender que se trata de uma discussão sobre desenvolvimento top-down versus bottom up. Após essa discussão, o artigo passa a contemplar a construção do design da DSL. A etapa de análise não parece bem resolvida, e parece haver certa mistura sobre o que é análise e o que é design da DSL, que o texto não procura esclarecer. Disciplinas de análise e design são citadas de forma distinta, mas não apropriadamente descritas. O ponto forte é a definição de uma abordagem bottom-up detalhada para definir uma DSL para especificar aplicações web (domínio vertical).

\subsubsection{Disciplina de Design}

Essa disciplina tem a finalidade de gerar o design da DSML - mais especificamente, o metamodelo - com base no conhecimento adquirido sobre o domínio, na disciplina de Análise.

As referências que deram base para a sua definição são apresentadas a seguir:

Mernik, Heering e Sloane (2005) consideram que a linguagem pode ou não ser definida formalmente, e que pode ser definida a partir do zero ou com base em outra linguagem. 
Quanto à dimensão de formalidade da linguagem, o padrão que interessa aos objetivos deste texto é o padrão formal, pois é especificamente projetado para processamento por máquinas, conforme (Greenfield et al, 2004), (Agrawal, A.; Karsai, G.; Ledczi, A., 2003) e (Karzai et al, 2003).

Quanto à dimensão de relacionamento com linguagens existentes, os textos focados especificamente no desenvolvimento de DSMLs, tipicamente abordam a criação de linguagens, sem ter como base linguagens pré-existentes.

Cook et al (2007) focam na definição de variabilidade. Propõem que se use diagramas de features para expressar variabilidade. Não distinguem modelo de domínio e meta-modelo da linguagem. Não trazem uma contribuição expressiva para nortear a elaboração do design da DSML. Ponto forte: definição do conceito de variabilidade em uma família de sistemas ou variabilidade ao longo do tempo; ponto fraco: não haver distinção entre modelo de domínio e meta-modelo da linguagem, ao contrário de todas as demais referências.

Kelly e Tolvanen (2008) explicitam a necessidade de definição de um modelo de computação para a linguagem. Definem um conjunto de diretrizes para a elaboração do meta-modelo da linguagem, abrangendo o meta-modelo propriamente dito e restrições que se aplicam. Definem também um conjunto detalhado de diretrizes para a elaboração da sintaxe concreta da linguagem. É a referência principal para a elaboração do design de uma DSML e, de certa forma, uma solução para o problema apontado por (MERNIK; HEERING; SLOANE, 2005) de não haver diretrizes claras para elaborar o design da DSML.

Visser (2008) contempla um processo relativamente detalhado para construção de uma DSML, em uma abordagem bottom-up, centrada em análise de código e estruturas de implementação em linguagens de programação, no caso, em ambiente web. O processo só pode ser utilizado para domínios horizontais, como o apresentado pelo texto (desenvolvimento de aplicações web). Diretrizes são um tanto complexas, e fortemente baseadas no estudo de caso progressivamente desenvolvido ao longo do texto. Ainda assim, as diretrizes são úteis para domínios como o proposto pelo texto. 


\subsubsection{Disciplina de Implementação}

Esta disciplina tem a finalidade de definir a implementação da DSL, tendo como fonte de informação principal o design gerado anteriormente. Alternativas para efetuar essa implementação são discutidas a seguir.

Mernik; Heering e Sloane (2005) restringem esta disciplina apenas a DSLs computacionalmente executáveis. Afirmam que a implementação da uma DSL pode se valer de técnicas substancialmente distintas da implementação de linguagens de propósitos gerais (GPL - general purpose language, como a UML ou Java).

Spinellis (2001) argumenta que o desenvolvimento de GPLs é radicalmente distinto do de DSLs, já que o desenvolvimento de DSLs constituiria, normalmente, apenas uma parte de um projeto mais amplo e, portanto, os custos de desenvolvimento devem se moderados. Por isso, o uso de técnicas mais complexas de implementação DSLs, como a criação de compiladores, seria limitado.

Mernik; Heering e Sloane (2005), por outro lado, consideram que a interpretação e compilação são tão relevantes para DSLs quanto e GPLs, e que a premissa citada por (SPINELLIS; 2001) nem sempre seria verdadeira.

Em relação ao desenvolvimento de DSMLs, a disciplina de implementação tem aqui menor ênfase que as demais, pois o uso de ferramentas de meta-modelagem para a construção de DSMLs provê essa implementação de forma automatizada, ou seja, essas ferramentas geram automaticamente a implementação da DSML, de modo que não cabe ao processo de desenvolvimento de DSMLs considerar atividades referentes a isso.

\subsection{Modelos de Computação para DSMLs}

Conforme definido na seção 1.1, utiliza-se, neste trabalho, a definição de (MOSTERMAN; VANGHELUWE, 2002) para definição de modelo de computação. Segundo estes autores, modelo de computação é um conjunto de requisitos que guiam a modelagem de um sistema, em um domínio específico. Esses requisitos especificam os tipos de entidades e os relacionamentos que podem ser modelados, a melhor forma de modelá-los, os atributos das entidades e dos relacionamentos e número e tipo de vistas necessários para particionar o espaço de design logica e eficientemente. 
Existem abordagem de desenvolvimento de DSMLs que consideram estruturas previamente definidas como seus elementos. Inicialmente, o desenvolvimento era baseado em fragmentos de design muito específicos (EMERSON; SZTIPANOVITS; 2006) e, nos últimos anos, na ideia de elaboração do design de DSMLs baseada em modelos de computação (KELLY; TOLVENEN, 2008), (MANNADIAR; VANGHELUWE, 2010).

Da mesma forma que a modelagem de um sistema necessita de pontos de vista inter-relacionados para modelar um sistema, principalmente se este for complexo, as DSMLs devem ser concebidos para representar as diversas visões. Mannadiar e Vangheluwe (2010) identificam dois pontos de vista que devem ser considerados para definição de DSMLs. Por um lado, isso pode significar fundir ou interrelacionar vistas distintas de uma único sistema: por exemplo, diagramas de classes para estruturas estáticas e diagramas de sequência para comportamento dinâmico de um sistema. Neste contexto, Vallecillo (2010) argumenta que não é possível modelar um sistema complexo usando uma única DSML, e propõe que diferentes facetas de um sistema complexo seja modelado usando DSMLs ou sub-DSMLs interrelacionadas.

Por outro lado, a combinação de DSMLs pode ser compreendida sob a perspectiva de engenharia, estudando como estruturas recorrentes em diversas situações podem ser transformadas em blocos de construção genéricos (MANNADIAR, VANGHELUWE; 2010). As referências bibliográficas citadas a seguir apresentam abordagens referentes a esse ponto de vista.

A proposta de Mosterman e Vangheluwe (2002) apresenta uma abordagem para desenvolvimento de sistemas complexos denominada Computer Automated MultiParadigm Modeling (CAMPaM - modelagem com múltiplos paradigmas para automação por computador) que contempla a definição de DSMLs e que permite a combinação de DSMLs para permitir o uso de pontos de vista. Um conceito fundamental do CAMPaM é o de formalismo de modelagem. Neste contexto, é uma linguagem de modelagem específica usada para descrever parcialmente um sistema e serve de base para a DSML a ser criada para modelar o sistema.

Emerson e Sztipanovits (2006) consideram fragmentos reutilizáveis de sintaxe abstrata como fragmentos ou padrões (patterns) a serem utilizadas na construção de DSMLs sem, no entanto, considerar sua semântica. Afirmam a necessidade de 
bibliotecas de fragmentos ou padrões (patterns) reutilizáveis que sirvam como blocos de construção de DSMLs.

Pedro, Buchs e Amaral (2008) desenvolveram uma abordagem mais abrangente que a anterior e, em vez de utilizar fragmentos de sintaxe abstrata, propõem a inclusão da semântica no fragmento ou pattern usado para construir a DSML. Para isso, definiu-se o que se denomina conceito do domínio, um fragmento de meta-modelo que é associado a uma transformação para uma linguagem alvo, tal que seja precisa e contemple uma semântica bem definida. Esses conceitos do domínio são identificados em um domínio específico, mas são suficientemente genéricos para que possam ser usados em domínios diferentes. os autores propõem uma estratégia para projetar DSMLs com base nesses conceitos de domínio e afirmam que existe uma lista de conceitos de domínio pré-definidos, composta dos seguintes conceitos,: patterns de dados estruturais (tipo de dado, estrutura de dados); patterns de estruturas de controle (atribuição, declaração condicional, iteração); patterns comportamentais (máquinas de estados finitos).

Kelly e Tolvanen (2008) também apresentam a ideia de design de DSMLs com base em modelos de computação. Distingue as DSMLs, que fornecem a visão estrutural do domínio que representam e as dinâmicas, que representam alguma forma de comportamento (possivelmente além de representarem estrutura do domínio).

Dentro da mesma linha, Levendovsky, Lengyel e Mészáros (2009) propõem suporte teórico e prático para ambientes de meta-modelagem que forneçam suporte para a incorporação de design patterns à construção de DSMLs.

Mannadiar e Vangheluwe (2010) argumentam que o design de uma DSML pode ser definida pela integração de modelos de computação de mais baixo nível, tais como máquinas de estado para comportamento. Considerando a possibilidade da integração, os autores apresentam uma questão fundamental, correspondente à identificação de modelos de computação que formem a base para design de DSMLs Não chegam a apresentar uma resposta, mas são apresentados alguns modelos de computação que consideram ser imprescindíveis para formar a base de design de DSMLs: máquinas de estado, para modelar comportamento reativo; redes de Petri, para modelar processos distribuídos e a sincronização deles; diagramas de bloco causais, para modelar sistemas físicos, layout (um design pattern introduzido pelos 
autores) para modelar interfaces visuais; código de ação (outro design pattern introduzido pelos autores), para modelar chamadas de APIs.

Analisando as referências citadas anteriormente, verifica-se que, em essência, a pesquisa para desenvolver DSMLs com base em fragmentos ou padrões evoluiu de algo muito similar aos design patterns de software para uma ideia mais abrangente: o uso de blocos de construção maiores, como modelos de computação da DSML sendo gerada.

Diversas das referências citadas acima consideram a necessidade de definição de um conjunto de modelos de computação que seria, de alguma forma, necessário e suficiente para embasar o desenvolvimento de DSMLs. Nenhuma delas responde a esta questão.

\subsection{Considerações Finais do Capítulo}

As DSLs, existentes desde final dos anos 50 e utilizadas em um amplo espectro de aplicações, ganharam maior destaque nos últimos anos, com a emergência de novos paradigmas de desenvolvimento de sistemas, como o MDD ou linhas de produto de software. No contexto desse trabalho, consideram-se as DSMLs, que é uma abordagem específica das DSLs, destinada à modelagem gráfica de domínios de sistemas complexos.

Ha diversos ramos de pesquisa quanto ao desenvolvimento de DSMLs. Este capítulo destacou dois deles, que se considerou particularmente relevantes para a disseminação do uso da abordagem de MDD baseada em DSMLs, e para os quais pesquisas adicionais e novas soluções são necessárias: processos de desenvolvimento de DSMLs; e construção de DSMLs com base em patterns ou, em maior escala, em modelos de computação.

A seção 2.4 procurou traçar uma evolução dessa linha de pesquisa que propõe incorporar patterns ou modelos de computação ao design de uma DSML. Identificouse que há uma lacuna nessas pesquisas: a definição de um conjunto de modelos de computação de referência para o design de uma DSML. Esse é um desafio proposto por diversos autores, como (PEDRO; BUCHS; AMARAL, 2008), (KELLY; TOLVANEN, 2008), (MANNADIAR; VANGHELUWE, 2010), mas para o qual não se identificou uma solução. 
Esta tese foca na abordagem baseia-se na abordagem de (MANNADIAR; VANGHELUWE, 2010) de tentar obter uma resposta mais ambiciosa para a questão referente a quais modelos de computação são fundamentais para o design de uma DSML. É esse desafio que será abordado nos próximos capítulos desta tese. 


\section{Catálogo de modelos de computação para construção de DSMLs}

Este capítulo tem o objetivo de apresentar a definição do catálogo de modelos de computação para ser utilizado no desenvolvimento de DSMLs, no contexto de MDD. Para isso, foi definida, inicialmente, a estrutura do catálogo, através de como os modelos de computação devem ser especificados, como seus elementos. Em seguida, foi definido um processo para a construção do catálogo, ou seja, como os modelos de computação devem ser selecionados para compor o catálogo. 0 processo de construção de catálogo foi, então, executado, resultando em modelos de computação do catálogo proposto.

\subsection{Estrutura do catálogo de modelos de computação}

Conforme comentado na seção 1.1, entende-se como catálogo um conjunto de elementos descritos de forma sistemática e relacionados em alguma ordem prédefinida (por exemplo, alfabética) de seu nome, para facilitar a sua localização (WEISZFLOG, 2004). Nesta tese, os elementos citados na definição são modelos de computação.

A estrutura do catálogo foi especificada, através da definição dos tipos de atributos necessários para descrever um modelo de computação pertinente ao catálogo.

\subsubsection{Descrição do modelo de computação do catálogo}

Um modelo de computação do catálogo é descrito através de um conjunto de atributos. Entende-se, neste contexto, como atributo cada propriedade ou tipo de informação, que descreve um aspecto relevante de um modelo de computação pertinente ao catálogo.

A definição dos atributos de um modelo de computação do catálogo foi inspirada em em catálogos de padrões para design de uma solução de software (GAMMA et al, 1994), (BUSCHMANN et al, 1996). Embora os tipos de catálogos tenham objetivos distintos, a descrição de um padrão de design apresentou muitos conceitos similares para descrever um modelo de computação: 
A tabela 2, apresenta os atributos utilizados pelos trabalhos citados anteriormente para descrever, respectivamente, padrões de arquitetura de software e padrões de design. Quando um mesmo atributo (ainda que utilizando um nome distinto) é comum a ambas as referências, ele aparece na mesma linha da tabela.

\begin{tabular}{|c|c|c|c|}
\hline \multicolumn{2}{|c|}{ (BUSCHMANN et al, 1996) } & \multicolumn{2}{|c|}{ (GAMMA et al, 1994) } \\
\hline $\begin{array}{l}\text { Nome do } \\
\text { atributo }\end{array}$ & Descrição do atributo & $\begin{array}{l}\text { Nome do } \\
\text { atributo }\end{array}$ & $\begin{array}{c}\text { 1.4.1.1.1 Descrição do } \\
\text { atributo }\end{array}$ \\
\hline Nome & $\begin{array}{l}\text { Nome e descrição } \\
\text { sucinta do padrão }\end{array}$ & $\begin{array}{l}\text { Nome e } \\
\text { classificação }\end{array}$ & $\begin{array}{l}\text { Além do nome, uma } \\
\text { classificação proposta }\end{array}$ \\
\hline $\begin{array}{l}\text { Também } \\
\text { conhecido } \\
\text { como }\end{array}$ & $\begin{array}{l}\text { Outros nomes para o } \\
\text { padrão, quando } \\
\text { pertinente }\end{array}$ & $\begin{array}{l}\text { Também } \\
\text { conhecido } \\
\text { como }\end{array}$ & $\begin{array}{l}\text { Outros nomes para o } \\
\text { padrão, quando houver }\end{array}$ \\
\hline Exemplo & $\begin{array}{l}\text { Um exemplo do mundo } \\
\text { real que mostra a } \\
\text { existência do problema } \\
\text { e a necessidade do } \\
\text { padrão }\end{array}$ & $\begin{array}{l}\text { Usos } \\
\text { conhecidos }\end{array}$ & $\begin{array}{l}\text { Exemplos do padrão } \\
\text { encontrados em sistemas } \\
\text { reais. }\end{array}$ \\
\hline Contexto & $\begin{array}{l}\text { Situações em que o } \\
\text { padrão pode ser } \\
\text { aplicável }\end{array}$ & Intenção & $\begin{array}{l}\text { Uma descrição sucinta } \\
\text { sobre o que o padrão faz, } \\
\text { qual sua intenção, em que } \\
\text { problemas podem ser } \\
\text { usados }\end{array}$ \\
\hline Problema & $\begin{array}{l}\text { O problema em que o } \\
\text { padrão pode ser usado, } \\
\text { incluindo a discussão } \\
\text { das forças associadas }\end{array}$ & Motivação & $\begin{array}{l}\text { Um cenário que ilustra um } \\
\text { problema de design e } \\
\text { como o padrão pode } \\
\text { resolver o problema }\end{array}$ \\
\hline Solução & $\begin{array}{l}\text { O princípio de solução } \\
\text { fundamental } \\
\text { relacionado ao padrão }\end{array}$ & $\begin{array}{l}\text { Motivação } \\
\text { (repetido) }\end{array}$ & $\begin{array}{l}\text { Um cenário que ilustra um } \\
\text { problema de design e } \\
\text { como o padrão resolve o }\end{array}$ \\
\hline
\end{tabular}




\begin{tabular}{|c|c|c|c|}
\hline & & & problema \\
\hline & & Participantes & $\begin{array}{l}\text { As classes e objetos que } \\
\text { participam do padrão, e } \\
\text { suas responsabilidades }\end{array}$ \\
\hline Estrutura & $\begin{array}{l}\text { Uma especificação } \\
\text { detalhada dos aspectos } \\
\text { estruturais do padrão }\end{array}$ & Estrutura & $\begin{array}{l}\text { Representação gráfica das } \\
\text { classes no padrão }\end{array}$ \\
\hline Dinâmica & $\begin{array}{l}\text { Cenários típicos } \\
\text { descrevendo o } \\
\text { comportamento do } \\
\text { padrão em tempo de } \\
\text { execução }\end{array}$ & $\begin{array}{l}\text { Colabora- } \\
\text { ções }\end{array}$ & $\begin{array}{l}\text { Colaboração dos } \\
\text { participantes para cumprir } \\
\text { suas responsabilidades }\end{array}$ \\
\hline \multirow[t]{2}{*}{$\begin{array}{l}\text { Implemen- } \\
\text { tação }\end{array}$} & $\begin{array}{l}\text { Diretrizes para } \\
\text { implementar o padrão. } \\
\text { Consistem em } \\
\text { sugestões, não em } \\
\text { regras imutáveis }\end{array}$ & $\begin{array}{l}\text { Implemen- } \\
\text { tação }\end{array}$ & $\begin{array}{l}\text { Relação de problemas } \\
\text { potenciais, } \\
\text { recomendações ou } \\
\text { técnicas sobre o padrão }\end{array}$ \\
\hline & & $\begin{array}{l}\text { Código } \\
\text { exemplo }\end{array}$ & $\begin{array}{l}\text { Fragmentos de código que } \\
\text { ilustram a implementação } \\
\text { do padrão }\end{array}$ \\
\hline Variantes & $\begin{array}{l}\text { Uma descrição sucinta } \\
\text { de variantes ou } \\
\text { especializações do } \\
\text { padrão }\end{array}$ & & \\
\hline $\begin{array}{l}\text { Usos } \\
\text { conheci- } \\
\text { dos }\end{array}$ & $\begin{array}{l}\text { Exemplos de uso do } \\
\text { padrão, com base em } \\
\text { sistemas conhecidos }\end{array}$ & Aplicabilidade & $\begin{array}{l}\text { Relação das situações em } \\
\text { que o padrão pode ser } \\
\text { aplicado }\end{array}$ \\
\hline $\begin{array}{l}\text { Conse- } \\
\text { quências }\end{array}$ & $\begin{array}{l}\text { Os benefícios do padrão } \\
\text { e potenciais } \\
\text { desvantagens }\end{array}$ & $\begin{array}{l}\text { Consequên- } \\
\text { cias }\end{array}$ & $\begin{array}{l}\text { Atendimento dos objetivos } \\
\text { padrão. Custo-benefício e } \\
\text { resultados do uso do }\end{array}$ \\
\hline
\end{tabular}




\begin{tabular}{|l|l|l|l|}
\hline & & & padrão. \\
\hline $\begin{array}{l}\text { Veja } \\
\text { também }\end{array}$ & $\begin{array}{l}\text { Referências a outros } \\
\text { padrões que resolvem } \\
\text { problemas semelhantes }\end{array}$ & $\begin{array}{l}\text { Padrões } \\
\text { relacionados }\end{array}$ & $\begin{array}{l}\text { Padrões de design } \\
\text { relacionados a este }\end{array}$ \\
\hline
\end{tabular}

Tabela 2 - atributos que descrevem padrões de design e de arquitetura de software

Os atributos citados na tabela 5 foram analisados e adaptados para os modelos de computação do catálogo. São também apresentadas as justificativas da seleção ou não de cada um dos atributos.

\begin{tabular}{|c|c|c|}
\hline $\begin{array}{l}\text { Nome do } \\
\text { atributo das } \\
\text { referências } \\
\text { bibliográficas }\end{array}$ & $\begin{array}{l}\text { Nome do } \\
\text { atributo do } \\
\text { catálogo } \\
\text { (caso } \\
\text { selecionado) }\end{array}$ & $\begin{array}{l}\text { Justificativa da seleção ou não seleção do } \\
\text { atributo }\end{array}$ \\
\hline $\begin{array}{l}\text { Nome / Nome } \\
\text { e classificação }\end{array}$ & $\begin{array}{l}\text { Nome do } \\
\text { modelo de } \\
\text { computação }\end{array}$ & $\begin{array}{l}\text { Selecionado. Cada elemento do catálogo é um tipo } \\
\text { de diagrama previamente conhecido na área de } \\
\text { software. A referência pelo nome conhecido propicia } \\
\text { rápido reconhecimento pelo usuário do catálogo }\end{array}$ \\
\hline $\begin{array}{l}\text { Também } \\
\text { conhecido } \\
\text { como }\end{array}$ & & $\begin{array}{l}\text { Não selecionado. Não é relevante para o contexto } \\
\text { dos modelos de computação do catálogo, já que } \\
\text { cada modelo de computação tem um nome bem } \\
\text { conhecido na área de software. }\end{array}$ \\
\hline $\begin{array}{l}\text { Exemplo / } \\
\text { Usos } \\
\text { conhecidos }\end{array}$ & $\begin{array}{l}\text { Utilização do } \\
\text { modelo de } \\
\text { computação } \\
\text { no contexto } \\
\text { do MDD }\end{array}$ & $\begin{array}{l}\text { Selecionado e adaptado para os objetivos do } \\
\text { catálogo, de forma a abordar exemplos no contexto } \\
\text { do MDD }\end{array}$ \\
\hline $\begin{array}{l}\text { Contexto / } \\
\text { Intenção }\end{array}$ & $\begin{array}{l}\text { Contexto do } \\
\text { modelo de } \\
\text { computação }\end{array}$ & $\begin{array}{l}\text { Selecionado. O atributo contexto é utilizado para } \\
\text { categorizar os modelos de computação em relação } \\
\text { ao domínio de um agrupamento de sistemas }\end{array}$ \\
\hline
\end{tabular}




\begin{tabular}{|c|c|c|}
\hline & & utilizado para a seleção do modelo de computação \\
\hline $\begin{array}{l}\text { Problema / } \\
\text { Motivação / } \\
\text { Solução }\end{array}$ & $\begin{array}{l}\text { Conceituação } \\
\text { básica do } \\
\text { modelo de } \\
\text { computação }\end{array}$ & $\begin{array}{l}\text { Selecionado e adaptado. } \\
\text { Não foi selecionado conforme proposto pelas } \\
\text { referências bibliográficas, porque os modelos de } \\
\text { computação são conhecidos e estão } \\
\text { documentados. Não foi o caso de padrões de } \\
\text { design e de arquitetura, que são disciplinas mais } \\
\text { recentes. } \\
\text { Este atributo tem, então, objetivos semelhantes aos } \\
\text { das referências, mas adaptado ao contexto do } \\
\text { catálogo de modelos de computação. No catálogo } \\
\text { de modelos de computação, este atributo fornece } \\
\text { uma descrição básica do tipo de diagrama } \\
\text { selecionado como modelo de computação. }\end{array}$ \\
\hline Participantes & $\begin{array}{l}\text { Elementos } \\
\text { constituintes } \\
\text { do modelo de } \\
\text { computação }\end{array}$ & $\begin{array}{l}\text { Selecionado, para fornecer uma visão sucinta dos } \\
\text { componentes do padrão e o relacionamento entre } \\
\text { eles. }\end{array}$ \\
\hline Estrutura & & $\begin{array}{l}\text { Não selecionado, porque está abrangido pelo } \\
\text { atributo anterior. }\end{array}$ \\
\hline $\begin{array}{l}\text { Dinâmica / } \\
\text { Colaborações }\end{array}$ & & $\begin{array}{l}\text { Não selecionado, porque os modelos de } \\
\text { computação são conhecidos e estão } \\
\text { documentados. Não foi o caso, de padrões de } \\
\text { design e de arquitetura que são disciplinas mais } \\
\text { recentes. }\end{array}$ \\
\hline $\begin{array}{l}\text { Implementa- } \\
\text { ção }\end{array}$ & & $\begin{array}{l}\text { Não selecionado para esta versão do catálogo. Mas } \\
\text { versões posteriores podem contemplar, com base } \\
\text { em alguma meta linguagem para design de DSMLs }\end{array}$ \\
\hline $\begin{array}{l}\text { Código } \\
\text { exemplo }\end{array}$ & & $\begin{array}{l}\text { Não se aplica, porque o atributo citado } \\
\text { anteriormente atende a essa necessidade de } \\
\text { informação, no nível de design. }\end{array}$ \\
\hline
\end{tabular}




\begin{tabular}{|l|l|l|}
\hline Variantes & $\begin{array}{l}\text { Não selecionado, porque o processo de construção } \\
\text { do catálogo já aborda variantes e seleciona uma } \\
\text { delas, quando isso é pertinente }\end{array}$ \\
\hline $\begin{array}{l}\text { Usos } \\
\text { conhecidos / } \\
\text { Aplicabilidade } \\
\text { práticos do } \\
\text { uso de } \\
\text { modelo de } \\
\text { computação }\end{array}$ & $\begin{array}{l}\text { Selecionado, porque apresentar exemplos práticos } \\
\text { de uso contribui para esclarecer o objetivo e } \\
\text { funcionamento de cada modelo de computação. } \\
\text { Dessa forma, facilita a seleção do modelo de } \\
\text { computação mais adequado pelo usuário do } \\
\text { catálogo. }\end{array}$ \\
\hline $\begin{array}{l}\text { Consequên- } \\
\text { cias }\end{array}$ & $\begin{array}{l}\text { Não selecionado para esta versão do catálogo. } \\
\text { Esse atributo é útil, mas será necessário acumular } \\
\text { experiência prática de utilização do catálogo em } \\
\text { projetos de construção de DSMLs para que haja } \\
\text { massa crítica definir quais benefícios e } \\
\text { consequências cada modelo de computação } \\
\text { implica. }\end{array}$ \\
\hline $\begin{array}{l}\text { Veja também / } \\
\text { Padrões } \\
\text { relacionados }\end{array}$ & $\begin{array}{l}\text { Não selecionado, porque o processo de construção } \\
\text { do catálogo já aborda variantes e seleciona uma } \\
\text { delas, quando isso é pertinente }\end{array}$ \\
\hline
\end{tabular}

Tabela 3 - identificação dos atributos do catálogo a partir das referências

Os atributos selecionados, de acordo com as justificativas da Tabela 6, permitem que os desenvolvedores da DSMLpossam ter informação suficiente para avaliar se o modelo de computação é adequado para o seu projeto.

Dessa forma, os atributos definidos para o catálogo de modelos de computação são os seguintes:

1. Contexto do modelo de computação;

2. Nome do modelo de computação;

3. Conceituação básica do modelo de computação;

4. Elementos constituintes do modelo de computação;

5. Exemplos práticos do uso de modelo de computação; 
6. Utilização do modelo de computação no contexto do MDD.

O atributo contexto do modelo de computação classifica um modelo de computação do catálogo em relação a um agrupamento de sistemas com características semelhantes. Isso faz com que se justifique o compartilhamento deste modelos de computação do catálogo entre esses sistemas. Pode-se, ainda, entender que o atributo contexto de modelo de computação propicia uma subdivisão do catálogo de modelos de computação por categoria, em que cada categoria de sistemas de computação compartilhem um conjunto de modelos de computação. Um exemplo de categorização de sistemas corporativos é a fornecida por (LAUDON; LAUDON, 2011): sistemas empresariais, sistemas de gestão de cadeia de suprimento, sistemas de gestão de relacionamento com clientes, entre outros.

A premissa deste atributo é que sistemas pertencentes a uma mesma categoria utilizam um mesmo conjunto de modelos de computação e, por consequência, categorias distintas de sistemas podem utilizar modelos de computação potencialmente distintos. Essa premissa parte de uma avaliação empírica. Por exemplo, sistemas do tipo ERP possuem em geral diversos módulos, cada módulo automatizando processos de negócio distintos, mas tipicamente utilizando os mesmos modelos de computação (nesta tese, identificou-se que os modelos de computação que embasam sistemas de ERP são diagramas BPMN, diagramas de classes, e regras de negócio). Por outro lado, sistemas de análise preditiva baseiamse em modelos de computação muito distintos em relação a sistemas ERP. Por exemplo, a descrição de processos de negócio, que se constitui num modelo de computação de ERPS, não o é no caso de sistemas de análise preditiva, pois o foco destes são algoritmos de mineração de dados e modelos matemáticos preditivos, para os quais seria necessário generalizar modelos de computação específicos não abordados nesta tese.

O atributo nome do modelo de computação identifica um modelo de computação de forma única, de forma semelhante à denominação que se utiliza para design patterns. A diferença é que os modelos de computação são elementos previamente conhecidos e com nomes definidos, tais como redes de Petri e diagramas de atividade. 
O atributo conceituação básica do modelo de computação tem a finalidade de fornecer informação adicional ao nome do modelo de computação. Por exemplo, para um diagrama de transição de estados, esse atributo pode ser um texto do tipo: um diagrama de transição de estados especifica a sequência de estados pelos quais um objeto passa, ao longo do seu ciclo de vida, em resposta a eventos, juntamente com as respostas a esses eventos (BOOCH; RUMBAUGH; JACOBSON, 2005).

O atributo elementos constituintes do modelo de computação tem a finalidade de identificar os elementos principais do modelo de computação e a relação entre eles. Por exemplo, para diagrama de transição de estados, este atributo é um texto do tipo: estados simples e compostos, transições, elementos e ações.

O atributo exemplos práticos do uso de modelo de computação apresenta as aplicações do modelo de computação em situações práticas. Por exemplo, os diagramas de transição de estados podem ser usados para representar sistemas reativos, nos quais uma entidade externa executa ações que alteram o estado do sistema.

O atributo utilização do modelo de computação no contexto do MDD tem a finalidade de descrever a forma e as condições em que o modelo de computação pode ser usado para a de construção de DSMLs no contexto do MDD. Um exemplo para este atributo é o texto seguinte: diagramas de transição de estados podem ser utilizados como modelo de computação em domínios em que há um conceito ou entidade, que possui um ciclo de vida complexo. Domínios como o de vendas de serviços (como pacotes de viagem) ou ciclos de vendas complexas (nos quais oportunidades de venda têm também um ciclo de vida complexo) apresentam situações em que $\mathrm{s}$ diagramas de transição de estados são candidatos a modelos de computação.. No caso de venda de pacotes de viagem, u pacote de viagem pode assumir, pelo menos, o estado de definido, vendido e em utilização.

\subsubsection{Utilização do catálogo de modelos de computação}

Uma vez que o catálogo contém os modelos de computação que direcionam o desenvolvimento de DSML, os usuários podem se valer desses elementos para nortear o projeto de uma DSML específica. 
Para fazer um uso eficiente do catálogo, o usuário deve ter conhecimento prévio do domínio no qual se quer desenvolver a DSML e, também, sobre modelagem. Deve, então, buscar os modelos de computação mais de adequados ao contexto específico da DSML, com base nos seus atributos. Se necessário, deve recorrer à literatura específica sobre modelos de computação, para aprofundar o conhecimento sobre os modelos de computação.

Para exemplificar, seja o processo de desenvolvimento de DSML definido em (KELLY; TOLVANEN, 2008), que é composto das etapas de introdução e objetivos da linguagem; identificação e definição dos conceitos de modelagem (análise); formalização das linguagens usando um metamodelo (projeto); definição das regras da linguagem (projeto); integração de múltiplas linguagens (projeto); notação para a linguagem (projeto). Neste caso, o catálogo de modelos de computação seria consultado durante a sub-etapa de definição do modelo de computação, após a análise do domínio e antes de efetuar o projeto da DSML. Os modelos de computação que mais se adequem ao projeto da DSML em desenvolvimento seriam selecionados do catálogo, através da análise dos seus atributos. Modelos de computação necessários, não encontrados no catálogo, podem ser especificados e incluídos para uso futuro.

\subsection{Processo para a construção do catálogo}

Uma vez definidos os atributos que descrevem os modelos de computação do catálogo, foi definido o processo para a sua construção.

\subsubsection{Amadurecimento do processo ao longo do tempo}

Foi constatado ao longo da pesquisa que os modelos de computação apropriados para uma DSLM depende do domínio em que se insere o sistema a ser desenvolvido.

Inicialmente buscou-se identificar e analisar classificações existentes de sistemas de computação e associar, quando pertinente, modelos de computação a cada classe de sistemas. Dessa forma, o catálogo seria construído definindo-se um conjunto de modelos de computação apropriado para as classes de sistemas identificadas. Entre os trabalhos consultados, podem-se citar (MOSTERMAN, 2007) e (FORD et al 
2008), mas as classificações de sistemas por eles apresentados, apesar de relevantes, são muito direcionados para propósitos específicos.

Tendo em vista que os modelos de computação a ser utilizados em DSMls dependem do domínio em que o sistema vai ser desenvolvido, a abordagem alternativa consistiu em identificar, empiricamente, os modelos de computação a partir de um conjunto de características básicas de sistemas de um determinado domínio, com base em descrições existentes em artigos publicados Este processo foi descrito em (FERNANDES; MELNIKOFF, 2012) mas, posteriormente, foi evoluído para dar um embasamento mais sistemático para essa abordagem.

A evolução da abordagem consistiu em relalizar uma análise das funcionalidades de sistemas selecionados deum domínio e deduzir, a partir dos resultados, os modelos de computação que representassem as características desses sistemas. A análise é realizada sobre as informações manipuladas pelos sistemas e a descrição de cada função dos sistemas que manipulam essas informações.

A abordagem resultante parte da premissa de que os modelos de computação dos sistemas selecionados apresentam uma probabilidade significativa de serem também utilizados em outros sistemas do mesmo domínio e, consequentemente, em DSMLs que tenham como objetivo gerar outros sistemas semelhantes.

\subsubsection{Descrição do processo para construção do catálogo}

Com base na abordagem descrita na seção 3.2.1, foi definido o processo para construção do catálogo de modelos de computação, o qual contempla as seguintes etapas:

A. Identificar modelos de computação potencialmente relevantes para o contexto do catálogo

B. Selecionar um conjunto relevante de sistemas do domínio para análise;

C. Analisar entidades representativas e a lógica de execução dos sistemas selecionados;

D. Identificar um conjunto de modelos de computação candidatos nos sistemas analisados;

E. Caso haja candidatos alternativos a modelo de computação, selecionar um deles de cada grupo de alternativos; 
F. Descrever cada modelo de computação do catálogo.

Descrevem-se, a seguir as etapas listadas anteriormente.

Para cada etapa, é apresentada sua descrição, justificativa da sua existência e um exemplo sucinto do resultado da aplicação da etapa.

\section{A. Identificar modelos de computação potencialmente relevantes para o contexto do catálogo}

\section{Descrição}

Esta etapa consiste em identificar um conjunto de modelos de computação usados na literatura de desenvolvimento de DSMLs, para que as experiências de diversos especialistas possam servir de referência inicial para a construção do catálogo, principalmente se o responsável pelo catálogo não tiver ainda conhecimento sólido sobre o assunto. Os elementos resultantes são denominados de modelos de computação de referência nesse processo.

As fontes de informação a serem pesquisadas, a priori, são:

- Descrições de DSMLs;

- Textos sobre modelos de computação;

- Referências mais genéricas sobre MDD.

\section{Justificativa}

A premissa é que um conjunto inicial de referências de modelos de computação usados previamente no desenvolvimento de DSMLs seja útil ao responsável pela construção do catálogo, para aproveitar o conhecimento de especialistas. Isso porque, no processo de construção do catálogo proposto, sistemas relevantes do domínio são analisados para se inferir os modelos de computação que podem servir de base para sua estrutura e sua lógica de execução. Dessa forma, supõe-se que a identificação inicial de modelos de computação potencialmente relevantes fornece dados que podem ser consideradas como referências para a construção do catálogo.

Observa-se que não há garantia de que os modelos de computação identificados dessa maneira constituam um conjunto completo para o propósito da construção do 
catálogo dos modelos de computação. Entretanto, é uma forma de auxiliar a identificação e este conjunto não deve ser limitante para a identificação de novos modelos de computação.

\section{Exemplo}

Os diagramas da UML e a rede de Petri constituem exemplos típicos de modelos de computação, candidatos a compor o catálogo de modelos de computação.

\section{B. Selecionar um conjunto relevante de sistemas do domínio para análise}

\section{Descrição}

O objetivo desta etapa é selecionar os sistemas do domínio, cujos elementos manipulados e o comportamento sejam representativos para sugerir os modelos de computação para o catálogo. A etapa abrange duas tarefas: a primeira é a definição de um agrupamento de sistemas de interesse e a segunda é a seleção de sistemas específicos nesse agrupamento, para a análise a ser efetuada na etapa C. Esse agrupamento corresponde ao atributo contexto do elemento do catálogo, conforme definido na seção 3.1.1.

Para d definição do agrupamento de sistemas, seleciona-se um contexto significativo para os objetivos da construção do catálogo de modelos de computação Um contexto significativo é aquele para o qual se supõe ou se sabe que serão desenvolvidas diversas DSMLs. Como exemplo, pode-se citar o ERP (enterprise resource planning) como contexto de sistemas corporativos.

Identificado o agrupamento, a seleção de sistemas representativos desse contexto consiste em identificar um ou mais sistemas, para posterior análise, com base nos seguintes critérios:

- Relevância: selecionar sistemas que automatizem processos de negócio fundamentais para as Organizações em que são utilizados.

- Disseminação do uso: selecionar sistemas que sejam utilizados em muitas Organizações, para aumentar a probabilidade de que os modelos de computação selecionados sejam efetivamente relevantes;

- Selação de sistemas para os quais haja documentação detalhada de cada funcionalidade, incluindo a manipulação das entidades relevantes. Justificativa 
Ao selecionar sistemas mais representativos do domínio, a serem analisados influencia o grau de abrangência e, consequentemente, a utilidade do catálogo produzido.

Dessa forma, se os sistemas automatizam processos de negócio relevantes das Organizações, sua estrutura e sua arquitetura tendem a influenciar a construção de outros sistemas que se integrarão com esses. Como consequência, os modelos de computação dos sistemas que automatizam processos de negócio fundamentais podem tender a ser utilizados em outros sistemas e, consequentemente, relevantes como elementos de um catálogo.

\section{Exemplo}

Os Sistemas de Gestão de Relacionamento com Clientes (CRM - Customer Relationship Management), fornecem suporte aos processos de negócio relevantes para quaisquer empresas que têm necessidade de relacionamento mais sofisticado com seus clientes. Dessa forma, constituem uma categoria que atendem aos requisitos definidos nesta etapa.

\section{Identificar as entidades representativas e a lógica de execução dos sistemas selecionados}

\section{Descrição}

A análise a ser realizada nesta etapa é baseada em descrições textuais que permitam identificar a lógica das funções dos sistemas e as entidades (organização de dados) manipuladas por elas.

A descrição dos sistemas não exige a existência de modelos gráficos do tipo UML, referentes a cada funcionalidade dos sistemas em análise. Bastaria que relacione as funções com descrição da manipulação de entidades relevantes. Não se espera também acesso aos códigos fonte dos sistemas, pois geraria uma análise de um material por demais detalhado e complexo.

O produto desta etapa é uma descrição das entidades de entrada, da lógica da função e das entidades geradas, para cada função dos sistemas analisados. A descrição da função deve ser suficientemente detalhada para permitir inferir o 
algoritmo ou a lógica de execução utilizada, para poder identificar os modelos de computação.

\section{Justificativa}

O conhecimento das entidades e da descrição relativamente detalhada das funções dos sistemas permite, conforme verificado nos experimentos feitos para a definição deste processo, identificar a lógica de execução das funções e das entidades manipuladas.

\section{Exemplo}

No caso de sistemas de CRM, uma entidade fundamental é a Oportunidade em um ciclo de vendas complexas e a sequência de estados pelas quais passa uma Oportunidade é um aspecto fundamental a ser gerenciado. Portanto, é necessário conhecer os atributos da Oportunidade e as descrições das funções do sistema que a manipulam.

\section{Identificar um conjunto de modelos de computação dos sistemas analisados}

\section{Descrição}

A identificação dos modelos de computação para o catálogo é feita a partir da descrição das entidades e das funções dos sistemas realizada na etapa C.

Para essa identificação, parte-se do conjunto de modelos de computação de referência, identificados na etapa A. Caso nenhum deles seja adequado, outros candidatos ao modelo de computação podem ser identificados, devem-se .buscar outros que atendam às características do sistema analisado.

Para facilitar a identificação dos modelos de computação da funcionalidade do sistema sob análise pode ser útil gerar diagramas UML de nível mais abstrato que descrevam, em linhas gerais, a sua funcionalidade. No entanto, nos experimentos realizados durante o projeto do processo de construção de catálogo, foi possível deduzir os modelos de computação da funcionalidade do sistema sob análise apenas a partir das suas descrições textuais. 
Para cada função ou conjunto de funções de semelhantes, podem existir modelos de computação alternativos como candidatos. Por exemplo, redes de Petri e diagramas de transição de estados são modelos de computação que expressam transições de estados de uma entidade, em detalhes diferentes. Todas as opções devem ser consideradas como resultados dessa etapa.

\section{Justificativa}

Esta etapa é fundamental porque é nela que são identificados os modelos de computação dos sistemas sendo analisados.

Ainda é necessário detalhar as diretrizes detalhadas para nortear a dedução dos modelos de computação a partir da funcionalidade do sistema em análise. Para isso, é necessário analisar mais tipos de sistema e formalizar o passos seguidos. Por enquanto, a diretriz geral é entender o funcionamento de determinada funcionalidade e pesquisar, no conjunto de modelos de computação de referência definido etapa $A$ do processo, os modelos de computação que forneçam base para essa funcionalidade. Caso não encontre, deve-se repetir o passo $A$ para complementar o conjunto de referência.

\section{Exemplo}

Para o caso do sistema de CRM, um modelo de computação identificado é o diagrama de transição de estados, identificado a partir da análise da entidade Oportunidade (conforme descrito na etapa $\mathrm{C}$ ). Esta entidade possui um ciclo de vida complexo, descrito a partir das funções do CRM que a manipulam, e evolui de um estado para outro, até ser derivada em uma venda.

\section{E. Caso haja modelos de computação alternativos, selecionar um deles de cada grupo de alternativos}

\section{Descrição}

A execução desta etapa é condicional e é realizada caso haja mais de um candidato para representar um determinado modelo de computação.

A entrada para essa etapa é o conjunto de modelos de computação alternativos para representar um modelo de computação, identificado na etapa $D$. 
Os modelos de computação alternativos são analisados para que seja selecionado apenas um deles para compor o catálogo.

Os critérios para seleção de um modelo de computação entre os alternativos devem ser definidos caso a caso. Recomenda-se que a seleção seja efetuada com base em análise de bibliografia que compara explicitamente os modelos de computação candidatos, caso seja encontrada, ou que se defina critérios de seleção entre as alternativas e se efetue a seleção com base nesses critérios.

O objetivo é ter um catálogo que contemple um conjunto mínimo de modelos de computação, o que pode facilitar a compreensão e a utilização do catálogo. O catálogo dispor de modelos de computação muito semelhantes - por exemplo, diagramas BPMN e diagramas de atividade da UML para modelagem de processos de negócio - dificultaria seu uso por profissionais de desenvolvimento de software que não sejam especialistas em modelagem.

\section{Justificativa}

Durante a definição do processo, considerou-se a possibilidade de incluir, no catálogo de modelos de computação, todos os modelos de computação candidatos, em vez de selecionar apenas um quando houvesse mais de uma alternativa. Considerou-se, porém, que essa alternativa tornaria o uso do catálogo mais complexo, pela dificuldade de seleção de um determinado modelo de computação quando mais de um fosse, a priori, adequado para determinada situação. Esse raciocínio foi baseado na premissa de que o uso do catálogo fosse feito por um um público alvo amplo, e não apenas especialistas em modelagem. Isso porque um objetivo do catálogo de modelos de computação é justamente propiciar a disseminação do desenvolvimento de DSMLs no mercado de desenvovimento de software, ampliando o uso do MDD. Por conta disso, incluiu-se no processo essa etapa de seleção de modelos de computação alternativos.

Buscou-se inicialmente definir critérios de seleção genéricos para comparação entre modelos de computação alternativos, analisando referências bibliográficas que comparam modelos de computação distintos. Esses critérios constariam nesta etapa. Por exemplo, Birkmeier, Klöckner e Overhage (2012) comparam empiricamente diagramas de atividades com a diagramas BPMN; ou Eshuis e 
Wieringa (2002), comparam redes de Petri com diagramas de atividades para a modelagem de fluxos de trabalho, entre outras.

Verificou-se, porém, que os critérios de comparação são muito específicos para cada situação, não sendo viável obter uma diretriz genérica para este processo.

\section{Exemplo}

Em um sistema em que a modelagem do fluxo de processos de negócio é um aspecto fundamental, podem ser utilizados diagramas BPMN (business process modeling notation) ou diagramas de atividade da UML. Há diversas fontes bibliográficas que comparam especificamente esses dois tipos de diagramas, como (BIRKMEIER; KLÖCKNER; OVERHAGE, 2010) e (ELORANTA; KALLIO; TERHO, 2006). Considerando a análise dessas fontes, pode-se selecionar o diagrama BPMN para constar no catálogo, por conta do seu maior poder de representação. No entanto, se o processo a ser modelado não for complexo, pode-se selecionar o diagrama de atividade por ser mais simples.

\section{F. Descrever cada modelo de computação do catálogo}

\section{Descrição}

A entrada para esta etapa é o conjunto de modelos de computação selecionados para inclusão no catálogo.

Nesta etapa, os modelos de computação selecionados na etapa E para inclusão no catálogo são descritos, definindo-se os atributos definidos na seção 3.1 .

Para isso, recomenda-se buscar referências bibliográficas sobre os modelos de computação selecionados, e efetuar descrições sucintas e registrar as referências no catálogo.

\section{Justificativa}

Esta etapa efetivamente cria (ou expande, se já houver uma versão anterior) o catálogo de modelos de computação.

\section{Exemplo}

A seção 3.1.1 já apresenta uma descrição dos atributos do modelo de computação diagrama de transição de estados. 


\subsection{Execução do processo de construção do catálogo}

Esta seção apresenta o detalhamento do processo de construção de catálogo de modelos de computação, através da execução desse processo em um domínio esprcífico, seguindo as etapas descritas na seção 3.2.

\subsubsection{A - Identificar modelos de computação potencialmente relevantes para o contexto do catálogo}

As fontes de referência na literatura consultadas são aquelas que identificam modelos de computação no contexto de MDD, considerando-se aquelas que apresentam diretamente os modelos de computação e as que citam outras referências de interesse.

O trabalho de Kelly e Tolvanen (2008) foi considerado como um dos relevantes, pois foca a DSML no contexto MDD. Nele, os autores classificam as DSMLs em aquelas que modelam estruturas estáticas e as que especificam comportamento dinâmico. Para DSMLs que especificam comportamento dinâmico, classificam ainda em concorrentes ou não, distribuídas ou centralizadas, comunicação síncrona ou assíncrona, processamento paralelo ou não, conexões unidirecionais ou bidirecionais, determinísticas ou não determinísticas.

Com base nas características mencionadas, Kelly e Tolvanen (2008) identificam os seguintes modelos de computação relevantes para DSMLs:

1. Para linguagens estáticas: diagrama de classe, diagrama de grupos (cluster), diagrama de features, diagrama de sistemas, diagrama de componentes, diagramas de Venn, modelo de herança e diagrama de entidade-relacionamento;

2. Para linguagens dinâmicas: máquina de estado, diagrama de interação, rede de Petri, diagrama de processo e de fluxo para modelagem de processos, modelagem de fluxo de trabalho (workflow), fluxo de dados e processamento de sinais. 
Outros autores, apesar de não focarem seus trabalhos em DSMLs, apresentam modelos de computação alternativos, seguindo uma classificação correspondente à visão estática e visão dinâmica.

Buede (1999) é referenciado por (KELLY; TOLVANEN, 2008) como uma pesquisa mais abrangente sobre modelos de computação, úteis para geração de DSMLs. Nele são identificados os seguintes modelos de computação:

1. Para modelagem de dados: diagrama de entidade e relacionamento, higraph;

2. Para modelagem de processos: diagrama de fluxo de dados, IDEF0, gráfico N2;

3. Para modelagem comportamental: diagrama de transição de estados, diagrama de fluxo e de controle, rede de Petri.

A UML (Unified Modeling Language) define os seguintes tipos de diagramas para modelagem de software (BOOCH; JACOBSON; RUMBAUGH, 2005):

1. Para modelagem estática (estrutural): diagrama de classes, diagrama de objetos, diagrama de componentes; diagrama de implantação;

2. Para modelagem dinâmica (comportamental): diagrama de interação, diagrama de casos de uso, diagrama de atividades, diagrama de estados.

Mosterman e Vangheluwe (2002) propõem uma abordagem para desenvolvimento de sistemas complexos denominada CAMPaM, citada na seção 2.3.3.1, que é uma das variações da abordagem de MDD. Citam como potencialmente úteis os seguintes modelos de computação: diagramas de fluxo de dados, diagramas de fluxo de controle, diagramas de transição de estados, Grafcet, redes de Petri, gráfico de ligações (bond graph), diagramas de objetos, diagramas de blocos e diagramas de processos.

Considerando-se a união dos modelos de computação propostos nestes trabalhos, resulta nos conjuntos apresentados a seguir.

Para modelagem estática: diagrama de classes, diagrama de grupos (cluster), diagrama de features, diagrama de sistemas, diagrama de componentes, diagramas de Venn, modelo de herança e diagrama de entidade-relacionamento, higraph, diagrama de objetos, diagrama de implantação (para modelagem de arquitetura). 
Para modelagem dinâmica: diagrama de interação, rede de Petri, diagrama de processos e de fluxo para modelagem de processos, modelagem de fluxo de trabalho (workflow), diagrama de fluxo de dados, IDEF0, gráfico N2, diagrama de processamento de sinais, diagrama de transição de estados, diagrama de fluxo e de controle, diagrama de interação, diagrama de casos de uso, diagrama de atividades, diagramas de fluxo de controle, Grafcet, gráfico de ligações (bond graph), diagramas de blocos.

Os modelos de computação citados pelos autores variam em função da sua área de atuação, da época em que os textos foram escritos e dos objetivos específicos de cada texto. Alguns desses modelos de computação caíram em desuso, ou são conhecidos e relevantes apenas em áreas mais específicas, não sendo possível, inclusive, localizar referências mais detalhadas.

Avaliou-se, então, que é conveniente considerar, a priori, um universo relativamente amplo de candidatos a modelos de computação, de modo a propiciar um conjunto adequado de modelos de computação de referência. Por outro lado, modelos de computação relevantes para compor o conjunto de referência são aqueles sobre os quais haja conhecimento e literatura relativamente amplos, como por exemplo, os que compõem a linguagem UML ou redes de Petri.

Considerou-se, ainda, que o contexto da execução do processo de construção do catálogo de modelos de computação é o de sistemas de informação (conforme seção 1.3.2), optou-se por priorizar os diagramas propostos pela UML em relação aos propostos por (BUEDE, 1999), cujo contexto é de sistemas de engenharia e em relação aos propostos por (MOSTERMAN; VANGHELUWE, 2002), cujo contexto é de sistemas de controle complexos que envolvem interação contínua e discreta.

.Ao conjunto de diagramas UML foram acrescentados outros três:

- Diagrama de entidade-relacionamento, pela ampla disseminação pela comunidade de bancos de dados para representação estrutural das entidades;

- Diagrama de redes de Petri, pelo formalismo - que pode ser útil em determinados contextos -, representação gráfica e ampla literatura;

- Diagrama BPMN (business process modeling notation), pela disseminação nos últimos anos justamente no contexto de sistemas de informação. 
Com base nessa pré-seleção, o resultado dessa etapa envolve os modelos de computação apresentados a seguir.

Para modelagem estática: diagrama de classes, diagrama de entidaderelacionamento, diagrama de objetos, diagrama de implantação (para modelagem de arquitetura).

Para moelagem dinâmica: diagrama de interação, rede de Petri, diagrama de transição de estados, diagrama de fluxo e de controle, diagrama de interação, diagrama de casos de uso, diagrama BPMN, diagrama de atividades.

\subsubsection{B - Selecionar um conjunto relevante de sistemas do domínio para análise}

Para a construção do catálogo de modelos de computação, selecionou-se o conjunto de sistemas de informação, pois o desenvolvimento deste tipo de sistemas é realizado por organizações que tem o software como meta de negócio e também por aquelas que tem o desenvolvimento de software como meio da estretécia do seu negócio. Desta forma, existe um público alvo significativo interessado em agilizar o desenvolvimento de sistemas com uso da abordagem MDD, em princípio.

Sendo o conjunto dos sistemas de informação muito amplo, e necessitando o processo de construção do catálogo de modelos de computação analisar sistemas específicos, foi necessário reduzir o escopo. Para selecionar um conjunto mais específico dentre os sistemas de informação, foi utilizada a classificação de (LAUDON; LAUDON, 2011) referente a sistemas de informação. As classes de sistemas destes autores são apresentadas a seguir:

- Sistemas Corporativos, denominados de Enterprise Resource Planning (ERPs), fornecem suporte à operação das Organizações;

- Sistemas de Cadeia de Suprimento (supply chain) gerenciam a interação das Organizações com fornecedores e clientes;

- Sistemas de comércio eletrônico (e-commerce) fornecem canais eletrônicos para venda a consumidores finais ou outras Organizações;

- Sistemas de Gestão de Conhecimento envolvem várias áreas relacionadas a conhecimento, como gestão de aprendizagem e colaboração, entre outras; 
- Sistema de Apoio à Tomada de Decisões Gerenciais consolidam informações operacionais e as estruturam de modo a prover suporte à gestão das Organizações.

Optou-se, inicialmente, analisar o contexto de Sistemas Corporativos (ERP) da classificação de (LAUDON; LAUDON, 2011), pois tem alta probabilidade de conter a representação dos principais elementos de negócio das empresas, por fornecerem suporte aos processo de negócio fundamentais de uma Organização. Como a construção do catálogo de modelos de computação tem natureza incremental, considerou-se que o resultado dessa análise seria representativa e os demais sistemas podem ser analisados posteriormente para a expansão do catálogo.

Foi utilizada, então, a descrição do sistema ERP da empresa SAP (Systemanalyse und Programmentwicklung, ou System Analysis and Program Development) apresentada em (MAGAL; WORD, 2011), por ser um dos sistemas de referência do mercado e possui maior fatia de mercado, sendo $25,5 \%$ em 2011 , de acordo com (SOURCE DIGIT, 2012). Além disso, sua descrição apresenta a organização de dados principais manipulados e a funcionalidade do sistema, em um grau de detalhe suficiente para se identificar os modelos de computação.

O sistema ERP da SAP apresenta os seguintes módulos (MAGAL; WORD, 2011):

- Contabilidade

- Aquisição

- Atendimento

- Produção

- Gerenciamento de inventário e armazéns

- Planejamento de materiais

Para a construção do catálogo de modelos de computação, todos os módulos foram analisados. Observou-se, ao longo da análise, que vários módulos apresentaram os mesmos modelos de computação. Como ilustração da execução do processo, foram selecionados três módulos: contabilidade, aquisição e atendimento, pois considerouse que seriam suficientes para demonstrar que os mesmos modelos de computação são usados como base em cada um dos módulos do ERP. 


\subsubsection{C - Analisar a descrição do sistema selecionado}

O resultado desta etapa é a identificação da parte da descrição do sistema considerado, que contém a lógica de execução do sistema selecionado e as entidades por ele manipuladas.

Para a execução do sistema, todos os módulos de SAP, citados na etapa B, foram analisados; no entanto, como ilustração no texto deste trabalho, foram selecionados os módulos de contabilidade, aquisição e atendimento (MAGAL; WORD, 2011).

Neste contexto, cada módulo de ERP é composto por processos, e cada processo é composto por uma ou mais tarefas que manipulam os dados.

Nesta seção são apresentados o objetivo dos módulos e seus processos constituintes, para fornecer uma visão inicial. O texto resultante que contém a lógica e as entidades dos módulos selecionados encontra-se no apêndice $A$, por ser detalhado e longo pela própria natureza, para permitir a identificação de modelos de computação.

\subsubsection{Contabilidade}

O objetivo do módulo de Contabilidade é registrar as consequências financeiras da execução de processos de negócios, tais como aquisições, atendimento, vendas, entre outros. As informações contábeis são utilizadas para que as Organizações planejem e gerenciem esses processos de negócio.

Os processos do módulo de Contabilidade são os seguintes:

- Contabilidade geral

- Contabilidade de Contas a Pagar

- Contabilidade de Contas a Receber

- Contabilidade de Ativos

As transações contábeis associadas aos ativos, ao longo do ciclo de vida, são relativas a:

- Aquisição

- Depreciação

- Descarte (retirement) 


\subsubsection{Aquisição}

O módulo de Aquisição fornece suporte à interação com fornecedores externos para aquisição dos produtos e dos serviços necessários para que a Organização cumpra seus objetivos.

Os processos do módulo de Aquisição são os seguintes:

- Processo de Determinação de Requisitos

- Processo de Determinação da Fonte de Suprimentos

- Processo de Processamento do Pedido

- Processo de Recebimento de Mercadorias

- Processo de Verificação da Fatura

- Processo de Processamento de Compra

\subsubsection{Atendimento}

O módulo de Atendimento trata os pedidos de compras de clientes e gera, como resultado, cotações, confirmações, faturas.

Os processos do módulo de Atendimento são os seguintes:

- Processo de Atividade de pré-venda

- Processo de Processamento do Pedido de Venda

- Processo de Expedição

- Processo de Cobrança

- Processo de Pagamento

- Processo de Gerenciamento de Crédito

\subsubsection{D - Identificar um conjunto de modelos de computação candidatos nos sistemas analisados}

Nesta seção é considerada a descrição dos módulos de Contabilidade, Aquisição e Atendimento do sistema ERP da SAP apresentados na seção 3.3.3 e descritos no Apêndice $A$ e são identificados os modelos de computação adequados para a descrição das funcionalidades e das entidades por elas manipuladas. 


\subsubsection{Contabilidade}

Da descrição do módulo de contabilidade na seção A.1.2, tem-se as seguintes considerações:

(a) Para cada tipo de transação que tem um efeito financeiro, executada por um determinado processo de negócio, deve haver uma operação contábil realizada. Como cada operação contábil implica em um crédito em uma conta e débito em outra, é necessário identificar, para cada tipo de transação, duas contas contábeis que são impactadas pela transação e, para cada uma das contas, como ela é impactada:

$$
\begin{aligned}
& \text { - + ou - Ativo } \\
& \text { - + ou - despesa } \\
& \text { - + ou - receita } \\
& \text { - ou - dívida }
\end{aligned}
$$

Usando a regra do $T$, em função dessa classificação, a conta contábil relacionada será debitada ou creditada.

(b) As contas referentes à contabilidade geral são estruturadas da seguinte forma:

- Contas subsidiárias são consolidadas em contas de reconciliação que, por sua vez, são refletidas nas contas contábeis propriamente ditas; por exemplo, há uma conta para cada fornecedor ou para cada cliente cadastrado;

- Nem toda transação implica no acesso a contas subsidiárias. Há transações que podem impactar diretamente as contas contábeis;

- Quando há contas subsidiárias envolvidas em uma transação, elas são alimentadas diretamente pela transação efetuada e a consolidação ocorre automaticamente nas contas de reconciliação e contábeis;

- Quando não há contas subsidiárias envolvidas em uma transação, a transação impacta diretamente as contas contábeis.

Com base no exposto em (a) e (b), entende-se que:

- Os algoritmos de contabilidade geral são simples e previamente definidos na Organização. Não sendo um aspecto variável da solução a ser concebida, não há motivo para desenvolver um DSML relativa a essa parte. Consequentemente, o modelo de computação para os algoritmos não é relevante. 
- O relacionamento entre cada tipo de transação previamente conhecida e as contas contábeis correspondentes pode, a priori, ser previamente definido. Sendo assim, não existe nenhum aspecto variável a ser definido, do ponto de vista de contabilidade. Entretanto, pode haver aspectos variáveis na solução pelas seguintes razões:

- novos tipos de transações podem ser definidos;

- a empresa tipicamente define uma contabilidade gerencial, específica para atender seus objetivos, além da contabilidade financeira, que é legal e prédefinida para cada país.

Desta forma, estes aspectos variáveis podem ser definidos, através da seguinte abordagem:

- Associar a cada novo tipo de transação, além das pré-definidas no ERP, um parâmetro de adição ou subtração de ativo, receita, despesa ou dívida, associado a cada uma de duas contas contábeis associadas;

- Definir relacionamentos entre tipo de conta subsidiária, conta de reconciliação correspondente e conta contábil correspondente a essa conta de reconciliação, para consolidação das operações que envolvem contas subsidiárias.

Em essência, o aspecto variável da solução consiste em estabelecer relacionamentos entre tipos de operações financeiras e tipos de contas (no caso das contas subsidiárias) ou contas específicas (no caso das contas contábeis).

O modelo de computação que permite estabelecer relacionamentos entre entidades, conforme a descrição anterior, é o de diagramas de classes ou diagramas de entidades e relacionamentos.

\subsubsection{Aquisição}

Da descrição do módulo de aquisição na seção A.2.2, foram destacados os assuntos que contribuem para a identificação de modelos de computação e estão descritos a seguir.

Fluxo do Processo de Negócio 
Assim como no caso dos demais módulos do ERP, as funcionalidades do módulo de aquisição estão estruturadas e sequenciadas de acordo com os passos do processo de aquisição que é automatizado por esse módulo.

Os atributos das entidades manipuladas definem os processos do módulo a serem executados: As Categorias de Itens classificam os materiais em aquisição e impactam o fluxo do processo de aquisição e, consequentemente, os fluxos do módulo do ERP que automatiza as etapas desse processo.

No ERP, a entidade Material está associada à entidade Categoria de Item, ou Categoria de Item é um atributo de Material. Conforme a descrição do processo de aquisição, o valor desse atributo é usado para definir os passos da sua execução, (Apêndice A). Portanto, uma representação relevante para a descrição do processo é um diagrama que descreve o fluxo do processo com caminhos alternativos a serem seguidos, em função do valor da Categoria do Item.

Regras de negócio ${ }^{1}$

$\mathrm{Na}$ descrição do processo de recebimento de mercadorias (seção A.2.2.4), há a informação de que o estoque é classificado em função da utilização. Um Material, classificado como reservado para inspeção de qualidade ou como estoque bloqueado, não pode ser utilizado para as atividades produtivas da organização. Deve haver, portanto, regras de negócio que, expressas em alto nível, definem o seguinte:

SE classificação do Material = "uso irrestrito" ENTÃO Material pode ser usado pelo processo de produção ou venda.

Pode-se, então, dizer que as regras de negócio expressam lógica de execução.

Ainda, na seção A.2.2.4, observa-se que a tarefa essencial, do ponto de vista do sistema, é registrar os materiais pertinentes à entrega no Documento de Recebimento de Bens, com base no Pedido de Compra. Os dados do Pedido de Compra são automaticamente transferidos para o Documento de Recebimento de Bens pelo sistema. Se os dados do Pedido de Compra não corresponderem à entrega efetuada, o usuário altera os valores no Documento de Recebimento de Bens. Isso implica que não é suficiente associar um Documento de Recebimento de

\footnotetext{
${ }^{1}$ Veja o apêndice $C$ para mais informações referentes a regras de negócio
} 
Bens a um Pedido de Compra. É necessário duplicar os dados de um pedido de compra no Documento de Recebimento de Bens para representar o recebimento efetivo e isso deve ser expresso no modelo do sistema. Entende-se que essa informação pode ser descrita através de regras de negócio pois as ações a serem efetuadas dependem de determinadas condições - exatamente como as regras de negócio são estruturadas.

No processo de processamento de compra (seção A.2.2.6) aborda-se a seleção de faturas para pagamento e o pagamento propriamente dito dessas faturas. Embora 0 texto não entre em detalhes, entende-se que a definição adequada de regras de negócio é suficiente tanto para selecionar as faturas para pagamento (em função de um conjunto de condições) quanto para efetuar o pagamento das faturas.

Configuração do sistema

No processo de processamento de pedido (seção A.2.2.3) tem-se que dados de precificação e termos de pagamento são incluídos a partir da cotação, registro de informações de compra, registros de outras condições ou contratos e acordos específicos com fornecedores, dependendo da configuração do processo em cada Organização. Essa configuração pode ser realizada de diversas formas: através de listas de itens que podem assumir valores pré-definidos ou de uma linguagem específica de domínio estrutural, que descreve os parâmetros dessa configuração.

Variabilidade versus algoritmos

No processo de processamento de pedido (seção A.2.2.3), tem-se que a maior parte dos dados de uma requisição de compra é incluída no Pedido de Compra. Outros dados são incluídos, dependendo de como o Pedido de Compra tiver sido criado e os documentos de referência que tenham sido usados. Observa-se que a lógica de programação referente ao preenchimento do Pedido de Compra, embora envolva condições, não envolve variabilidade. Isto porque as condições que definem a forma de preenchimento do Pedido de Compra são conhecidas a priori e, portanto, não precisam ser expressas por uma DSML.

Sistema centrado em dados

No processo de processamento de pedido (seção A.2.2.3), observa-se que a cardinalidade entre os documentos fonte e o Pedido de Compra é N:M, ou seja,. 
uma ou mais requisições podem ser usadas para gerar um ou mais Pedidos de Compra. Entende-se, então, que o modelo de computação demanda dois aspectos: a definição da cardinalidade da relação entre as entidades Requisição de Compra e Pedido de Compra, e um conjunto de regras de negócio que define como um Pedido de Compra é gerado a partir de uma ou mais Requisições de Compra.

Regras de negócio versus algoritmos

Na descrição do processo de recebimento de mercadorias (seção A.2.2.4) observase que a maior parte dos dados desse processo está contida no Documento de Entrega ou no Pedido de Compra. No entanto, dados adicionais sobre onde os materiais devem ser armazenados (planta ou local de armazenamento) e tipos de movimentação específicos são necessários. Para isso, o sistema pode sugerir valores para esses dados e o usuário pode alterar, se necessário. O ponto principal nessa operação é a definição do algoritmo que fornece a sugestão sobre planta ou local de armazenamento e sobre tipos de movimentação específicos. Magal e Word (2011) não detalham a lógica de execução dessas ações. Entende-se que regras de negócio podem ser suficientes para que essas definições sejam efetuadas, caso seja possível expressar o algoritmo de sugestão da planta através delas. Mesmo que seja necessária a utilização de um algoritmo mais complexo, a lógica de execução desse algoritmo não é um fator de variabilidade, pois seria previamente conhecida e não variaria frequentemente. Desta forma, não precisaria ser expressa em um modelo do sistema que tenha como objetivo a geração automática de código. $\mathrm{O}$ algoritmo seria, em vez disso, expresso em linguagem de programação e faria parte do código previamente definido do sistema. >> a partir daqui.

\subsubsection{Atendimento}

Da descrição do módulo de atendimento na seção A.3.2, foram destacados os assuntos que contribuem para a identificação de modelos de computação e estão descritos a seguir.

Regras de Negócio

Da seção A.3.1 tem-se que cada canal de distribuição tem suas próprias restrições, estratégias e abordagens para prover serviços e produtos aos clientes. Por exemplo, 
Atacado não inclui imposto sobre a venda, requer um volume mínimo de compras, oferece desconto por volume e pode ser designado a plantas específicas.

Entende-se que as regras de negócio norteiam a seleção e o funcionamento de cada canal de distribuição. As condições de precificação apresentadas no Apêndice A.3.2 também são, em essência, regras de negócio.

$\mathrm{Na}$ descrição do processo de processamento de pedido de venda (seção A.3.3.2), tem-se que um Pedido de Venda pode ser realizada com base em uma requisição de cliente, cotação, acordo, ou pedido de venda prévio. Um único documento de referência, por outro lado, pode ser base para criar vários pedidos de venda. Embora não haja detalhes no texto, é razoável inferir que regras de negócio vão definir a geração do Pedido de Venda, caso seja efetuado automaticamente.

$\mathrm{Na}$ descrição do processo de expedição (seção A.3.3.3), tem-se que, no caso de mercadorias a serem comercializadas, o valor é baseado no preço médio móvel; no caso de bens acabados, o valor é baseado no preço padrão, que leva em conta custos de produção. Essas definições são regras de negócio.

$\mathrm{Na}$ descrição do processo de cobrança (seção A.3.3.4) tem-se que a tarefa chave é a geração do documento de cobrança, que é tipicamente uma fatura para produtos ou serviços. Além disso, prevê a criação de um reembolso, se o cliente devolver as mercadorias; ou de uma cobrança complementar, se o cliente tiver pago a menos. Neste caso também as regras de negócio vão nortear a criação desses documentos. $\mathrm{Na}$ descrição do processo de pagamento (seção A.3.3.5) diz para identificar os itens em aberto e aplicar o pagamento a esses itens. Um cliente pode pagar múltiplas faturas de uma vez ou dividir uma única fatura em múltiplos pagamentos. Neste caso também não há muitos detalhes, mas pode-se inferir que as regras de negócio são utilizadas para definir como e quando pagar quais faturas.

Ainda na descrição do processo de pagamento (seção A.3.3.5), tem-se que, se o valor pago for menor que o valor da fatura e não há descontos aplicáveis, há duas situações possíveis: se a diferença for muito pequena, dentro do valor de tolerância definido no sistema, a conta é considerada paga; caso a diferença não seja desprezível, usa-se uma técnica de pagamento parcial: o pagamento é postado na conta do cliente e a fatura original permanece aberta. Pode-se também usar uma técnica de item residual em que o item original é fechado, e um novo item referente à 
diferença é postado. Observa-se que o texto expressa, de forma razoavelmente detalhada, as regras de negócio.

Processamento de informações e documentos

Na descrição do processo de atividade de pré-venda (seção A.3.3.1), tem-se que, além de enviar cotações (acordos formais para vender produtos específicos), a prévenda pode gerenciar contatos dos clientes e criar acordos gerais com os clientes. Pode-se registrar e obter dados referentes a clientes específicos, tais como as preferências e histórico de compras desses clientes.

Entende-se que uma função fundamental do ERP é processar informações. As regras de negócio, conforme já citado, vão nortear os aspectos mais relevantes desse processamento de informações. Entretanto, há um processamento de informações mais básico, essencialmente registro de informação, como citado anteriormente. Por exemplo, a seção A.3.3.1 afirma que a requisição funciona como uma referência para a criação da cotação. O fato de uma entidade funcionar como referência para criação de uma outra é frequente em diversos módulos do ERP. Neste caso, aborda-se especificamente a movimentação de informações entre entidades.

O modelo de computação identificado é o de BPMN que pode descrever a análise e a criação de entidades; mas pode haver modelos específicos para especificar aspectos mais detalhados da solução, por exemplo, cadastros, consultas, etc. A DSML seria derivada a partir de BPMN e, eventualmente, acrescida de outros modelos de computação para registrar os aspectos exemplificados.

$\mathrm{Na}$ descrição do processo de cobrança (seção A.3.3.4), já citado na seção de Regras de Negócio, tem-se que a tarefa chave é geração do documento de cobrança, tipicamente uma fatura para produtos ou serviços. Além disso, prevê a criação de um reembolso, se o cliente devolver as mercadorias; ou de uma cobrança complementar, se o cliente tiver pago a menos. Este caso é justamente a abordagem de geração de documentos a partir de outros documentos. Dependendo de como se conceba as DSMLs e as transformações, esta operação pode ser realizada através de uma combinação de regras de negócio e de sub-linguagens para descrever a estrutura dos documentos. 
Avaliação de crédito

Na descrição do processo de gerenciamento de crédito (seção A.3.3.6) tem-se que o processo pode ser configurado para considerar diversos critérios de avaliação de crédito, tal como o valor ainda a receber do cliente e a quantidade de valor dos pedidos em aberto. Fontes externas de dados de crédito também podem ser consideradas. Entende-se que uma lógica algorítmica ou regras de negócio podem ser utilizadas para representar o funcionamento da avaliação de crédito, conforme já citado na seção 3.4.4.2. Devido à complexidade da lógica de avaliação de crédito, provavelmente é mais adequado representá-la através de um algoritmo expresso não através de DSML, mas usando uma linguagem de programação, já que a lógica algorítmica deve ser usada para representar aspectos do sistema mais estáveis, com menos variabilidade.

\subsubsection{Conclusões sobre a execução da etapa D}

A análise efetuada sobre as entidades e as funcionalidades do ERP permite sintetizar as seguintes conclusões:

- As funcionalidades do ERP são, em essência, automações de processos de negócio.

- Para cada processo de negócio há um módulo no ERP que o automatiza parcialmente.

- Tipicamente, as atividades do processo de negócio correspondem às funções específicas do módulo correspondente do ERP, encadeadas segundo o fluxo do processo.

- Há muitas condicionais e muitas regras de negócio que se aplicam a esse fluxo de execução.

Com base nessa síntese, apresentam-se e justificam-se sucintamente os modelos de computação candidatos selecionados.

(1) Um ERP é um sistema fortemente centrado em dados e documentos. Em linhas gerais, as funções do sistema ERP consistem em obtenção, processamento e geração de documentos em ambiente digital, a partir das entidades significativas para o ERP. Por outro lado, os aspectos de lógica de negócio, na maior parte dos casos, são relativamente simples. 
Um dos modelos de computação representativos é correspondente à modelagem de dados. As entidades são elementos fundamentais em sistemas ERP e, para representá-las, o modelo de computação mais adequado é o diagrama de entidades e relacionamentos ou o diagrama de classes da UML.

Pode-se observar também que as regras de negócio podem ser utilizadas para descrever a geração de documentos a partir de outros documentos. Outra possibilidade é criar uma notação específica para representar essas ações; por exemplo, pode-se criar uma notação que relacione atributos de documentos ou entidades origem com atributos de documentos ou entidades destino, acrescido de regras de cálculo, quando pertinente.

Os documentos, bem como os seus atributos, podem ser representados por diagramas estruturais, tais como diagramas de entidades-relacionamentos ou diagramas de classes.

(2) Um outro modelo de computação representativo é um diagrama que contemple o fluxo do processo de negócio e identifique as funcionalidades correspondentes aos passos a serem automatizados.

Há dois tipos de diagramas que se adequam a essa abordagem:

- Diagramas de atividades

- Diagramas Business Process Modeling Notation (BPMN)

(3) Quanto a pontos de decisão e variabilidade, pode-se observar que:

- O fluxo do processo de negócio envolve condicionais, que definem quando cada passo deve ser efetuado;

- Outras condicionais mais específicas são determinadas a partir de regras de negócio que podem ser expressas através de um modelo de computação específico.

- Outra opção é representar os aspectos que representam a variabilidade apenas através de regras de negócio, expressas segundo um modelo de computação específico, possivelmente, através de uma DSL textual (OCL ou Drools $^{2}$ ), em vez de condicionais no fluxo do processo de negócio para representar essas variações.

\footnotetext{
${ }^{2}$ Citada no apêndice C
} 
(4) Os aspectos relacionados com a interface visual a ser representada por DSML, demandam um modelo de computação que permita estruturar o conteúdo dos seus elementos. Um modelo de computação estrutural, que represente esses elementos, seus relacionamentos e hierarquia entre eles é diagrama de classes ou diagrama de entidade-relacionamento.

\subsubsection{E - Caso haja candidatos alternativos a modelo de computação, selecionar um deles de cada grupo de alternativos}

Após a identificação dos modelos de computação, observa-se que são citados dois grupos com modelos de computação alternativos:

- Modelo de Entidades e Relacionamentos e Diagrama de Classes da UML para modelagem de dados;

- Diagrama BPMN e diagrama de atividades da UML para modelagem fluxo do processo de negócio.

$\mathrm{Na}$ modelagem de dados, ambos os diagramas podem representar, no plano conceitual, entidades do domínio do negócio, seus atributos e relacionamentos entre elas. O Diagrama de Classes pode também representar comportamento, através de definições de operações das classes. Como o catálogo está sendo definido para fins genéricos, um modelo de computação com mais recursos é interessante. Além disso, diagramas de classes possuem recursos para representar relacionamentos de agregação e composição, os quais enriquecem o modelo de computação. Por este motivo, selecionou-se o Diagrama de Classes para constar no catálogo.

$\mathrm{Na}$ modelagem fluxo do processo de negócio, existem, na literatura, fontes que explicitamente comparam as representações de diagramas BPMN e diagramas de atividades:

- Eloranta, Kallio e Terho (2006) utilizam, como base para a análise, dois frameworks usados para analisar notações de modelagem e seu poder de representação: o modelo Bunge-Weber-Wand (BWW) e o Workflow Patterns Framework. O primeiro é um modelo de referência que pode ser usado para identificar a capacidade de uma notação representar fenômenos do mundo real. O segundo contempla um conjunto de patterns de processos de negócio que podem ser avaliados com referência a uma determinada notação, para identificar 
a capacidade da notação para representar esses patterns. A conclusão é que, pelo primeiro modelo, as notações são muito similares e, pelo segundo critério, há vantagens na notação BPMN para representar fluxos de controle e de dados;

- Birkmeier, Klöckner e Overhage (2010) realizam uma comparação empírica entre as duas abordagens, através da utilização das notações por usuários de negócio, durante a execução de tarefas de modelagem. Não detetaram diferenças significativas em relação à usabilidade das duas notações.

As análises apresentadas identificam que não há grandes diferenças de poder de representação entre as duas abordagens, mas por conta do resultado apresentado por (ELORANTA; KALLIO; TERHO, 2006), seleciona-se a notação BPMN para representar a modelagem de processos de negócio do ERP.

\subsubsection{Etapa F - Descrever cada modelo de computação do catálogo}

Apresenta-se, a seguir, a descrição dos modelos de computação identificados, considerando os atributos do catálogo definidos na seção 3.1 :

1. Contexto do modelo de computação;

2. Nome do modelo de computação;

3. Conceituação básica do modelo de computação;

4. Elementos constituintes do modelo de computação;

5. Exemplos práticos do uso de modelo de computação;

6. Utilização do modelo de computação no contexto do MDD.

Nota-se que o contexto de todos os modelos de computação é referente ao sistema corporativo (ERP), devido à construção.

\subsubsection{Descrição de Diagrama BPMN}

\section{Contexto do modelo de computação:}

Sistemas corporativos, pertinentes ao contexto mais amplo de sistemas de informação.

\section{Nome do modelo de computação:}

Business Process Modeling Notation (BPMN) - Notação de Modelagem de Processos de Negócio

Conceituação básica do modelo de computação: 
Descreve o fluxo de atividades de processo, incluindo o fluxo de controle do processo.

\section{Elementos constituintes do modelo de computação:}

Objetos de fluxo (evento, atividade); objetos de conexão (fluxo de sequência, fluxo de mensagem, associação); raias (swimlanes); artefatos (objetos de dados, grupo, anotação) (LIEW; KONTOGIANNIS; TONG, 2004).

\section{Exemplos práticos do uso:}

Fluxos de processo de negócio, como os dos processos apresentados, automatizados pelo sistema ERP.

\section{Utilização do modelo de computação no contexto do MDD.}

- Em sistema ERP, a análise identificou que esse tipo de modelo de computação é o mais fundamental, por descrever a lógica de execução dos seus módulos.

- É possível derivar diretamente a sequência de passos da execução do sistema através desse modelo de computação e a execução condicional de passos é feita em função do valor de atributos dos objetos de dados que são produzidos ou consumidos pelas atividades que compõem o sistema.

- O foco não é representar os processos de negócio em alto nível, mas a sequência de atividades do sistema que fornece suporte à execução de processos de negócio.

- É importante destacar que o diagrama BPMN é o modelo de computação que fornece suporte à construção de DSML, não sendo a DSML propriamente dita. Isso implica que a notação de BPMN tipicamente deve ser especializada para representar aspectos relevantes do sistema, com o intuito de geração subsequente de código através de transformações automáticas, eventualmente combinados com outros modelos de computação. Por exemplo:

- Atividades do diagrama podem ser especializadas para representar manutenção de cadastros (criação, alteração, exclusão, pesquisa de dados);

- Atividades podem ser especializadas para representar pontos de execução de algoritmos já previamente implementados; 
- No caso de geração de documentos a partir de documentos origem, pode ser criada uma notação específica para representar essas ações.

\subsubsection{Descrição de Diagrama de Classes}

\section{Contexto do modelo de computação:}

Sistemas corporativos, no contexto mais amplo de sistemas de informação.

\section{Nome do modelo de computação:}

Diagrama de classes, conforme proposto pela Unifed Modeling Language (UML)

Diagramas de implantação e de componentes da UML são especializações do diagrama de classes.

\section{Conceituação básica do modelo de computação:}

Descreve a estrutura de um sistema, ou de um aspecto de um sistema, como estruturas de dados relevanes, por exemplo.

\section{Elementos constituintes do modelo de computação:}

Elementos que compõem a estrutura do sistema, e a estrutura interna de cada um desses elementos.

- Atributos.

- Diagramas de classe podem conter assinaturas de operações e, desta forma, representar aspectos do comportamento dinâmico do sistema que diagramas de entidade-relacionamento não podem representar.

- Relacionamentos entre elementos estruturais de um sistema: associações, agregações, composições, generalização-especialização.

\section{Exemplos práticos do uso:}

Representação de sistemas, layout da interface visual e estruturas de dados através dos seus componentes constituintes.

\section{Utilização do modelo de computação no contexto do MDD:}

A maior parte das DSMLs são estáticas, representando a estrutura dos elementos do domínio, tendo diagramas de classe como modelo de computação (KELLY; TOLVANEN, 2008). 
A análise do ERP identifica o uso desse modelo de computação em: descrição das estruturas de dados manipuladas pelo sistema, descrição da interface visual do sistema, descrição de documentos gerados a partir de documentos fontes ou processamento especifico de dados (em uso conjunto com diagramas BPMN) e descrição das operações contábeis.

\subsubsection{Regras de Negócio ${ }^{3}$}

\section{Contexto do modelo de computação:}

Sistemas corporativos, no contexto mais amplo de sistemas de informação.

\section{Nome do modelo de computação:}

Regra de negócio

\section{Conceituação básica do modelo de computação:}

Uma regra de negócio é uma declaração lógica que propicia que uma conclusão seja obtida a partir de um conjunto de condições.

A convenção é que regras sejam expressas segundo a forma SE <condição> ENTÃO <conclusão>

As regras de negócio devem ser escritas usando termos de um vocabulário estruturado denominado modelo de objetos, modelo de fatos, ou ontologia do domínio.

Devem ser manipuladas por máquinas de inferência de regras, que permitem inferências a partir de fatos previamente conhecidos. Isso permite que aspectos relevantes da lógica de execução um sistema sejam descritos de forma declarativa, em vez de ser através de algoritmos escritos no código do sistemas.

\section{Exemplos práticos do uso:}

Descrição das condições em que um desconto pode ser realizado no valor da venda, em um sistema vendas de varejo. Por exemplo: SE valor total da venda $>R \$ 1000,00$ ENTÃO aplicar desconto de 5\% ao valor total da venda.

\section{Utilização do modelo de computação no contexto do MDD:}

\footnotetext{
${ }^{3}$ Veja o Apêndice $C$ para mais informações sobre regras de negócio.
} 
Regras de negócio podem possibilitar uma forma fácil de expressar variabilidade, tanto para definir variantes do fluxo de execução dos sistemas gerados a partir das DSMLs quanto para definir lógica de execução que não seja excessivamente complexa.

\subsection{Considerações Finais do Capítulo}

O catálogo de modelos de computação se propõe a contribuir, de forma efetiva, para tornar o design de uma DSML mais sistemático e menos complexo, ao fornecer uma referência inicial que o projetista da DSML pode utilizar para gerar a sintaxe abstrata da DSML. Esta alternativa foi proposta com base nas pesquisas recentes dessa área, que propõem o uso de patterns de alto nível para fornecer suporte ao design de DSMLs (referências). Esses patterns correspondem aos modelos de computação do catálogo.

A construção deste catálogo é incremental. A análise do ERP da SAP, realizada neste capítulo, identificou os primeiros componentes do catálogo de modelos de computação. $O$ estudo de outros sistemas de informação, apresentados na seção 3.4.2, é uma evolução natural do trabalho realizado e pode identificar outros modelos de computação a serem incluídos neste catálogo.

A definição de um processo para a geração do catálogo, descrito na seção 3.2.2, vai permitir a evolução do catálogo, pois é um processo iterativo, a ser reaplicado quando houver outras categorias de sistemas consideradas relevantres.

É importante registrar que os modelos de computação não se constituem diretamente nas DSMLs, mas correspondem às referências usadas para o design das DSMLs. O design de cada DSML que considera esses modelos de computação será uma especialização ou extensão do modelo de computação para determinado domínio e para os objetivos de construção da DSML. 


\section{Uso do Catálogo de Modelos de Computação para Desenvolvimento de uma DSML}

Este capítulo tem a finalidade de apresentar a utilização do catálogo de modelos de computação, através do design de uma DSML. Para isso foi selecionado um domínio e definido um processo de desenvolvimento de DSML inserindo o uso do catálogo de modelos de computação gerado. São também apresentados os produtos resultantes e os comentários sobre a utilização do catálogo.

\subsection{Domínio do problema}

Foi selecionado o domínio de gestão de portfólio de projetos para a construção da DSML. A gestão de portfólio de projetos é um processo para priorizar e aprovar ou reprovar solicitações de execução de projetos, e para gerenciar o conjunto de projetos em execução, em alto nível, ao longo do tempo.

Esse domínio foi selecionado por seguintes motivos:

- É um domínio com vocabulário semelhante ao de sistemas corporativos.

- Conceituá-lo e compreendê-lo é relativamente simples, pois não demanda conhecimento aprofundado específico.

- O autor do trabalho tem acesso à ferramenta de software Rational Focal Point (comercializado pela IBM Rational), cuja finalidade é a definição de processos de gestão de portfólios específicos para organizações, através de configurações. A análise dos recursos de configuração da ferramenta permitiu obter maior informação sobre a variabilidade dos aspectos do domínio considerado.

Esta seção descreve os conceitos de gestão de portfólio de projetos, os recursos de Rational Focal Point utilizados para analisar o domínio de gestão de portfólio de projetos e um processo exemplo de priorização e seleção de projetos de TI.

\subsubsection{Conceituação do domínio}

Os conceitos fundamentais sobre o domínio de gestão de portfólio de projetos são apresentados, com base em (PROJECT MANAGEMENT INSTITUTE, 2008).

Um projeto é um empreendimento temporário executado para criar um produto, um serviço ou um resultado único. É temporário pois tem início e fim definidos. $\mathrm{O}$ 
produto, o serviço ou o resultado gerado pela execução do projeto é único, ainda que método para obter a solução possa se repitir para outros projetos.

Gestão de projetos é a aplicação de conhecimento, competências, ferramentas e técnicas a atividades do projeto para atender aos requisitos do projeto.

Um programa é um grupo relacionado de projetos gerenciados de forma coordenada, para obter benefícios e controle não disponíveis, caso se gerenciasse cada projeto individualmente. Um projeto pode ser ou não parte de um programa, mas um programa sempre é composto de projetos.

Um portfólio é uma coleção de programas, projetos e outros trabalhos relacionados, que são agrupados para facilitar gerenciamento efetivo do trabalho e atingir objetivos de negócio estratégicos. Os programas ou projetos do portfólio não necessariamente são interdependentes ou diretamente relacionados.

A Gestão de Portfólio refere-se à gestão centralizada de um ou mais portfólios. Consiste em identificar, priorizar, autorizar, gerenciar e controlar projetos, programas e outros trabalhos relacionados, para atingir objetivos de negócio estratégicos específicos.

\subsubsection{Ferramenta Rational Focal Point}

O Rational Focal Point, conforme já citado, propicia a construção ou adaptação de processos de gestão de portfólio de projetos sem a necessidade de programação.

O conhecimento sobre a estrutura manipulada pela ferramenta é útil aos objetivos deste capítulo, porque propicia a identificação dos elementos do domínio e da DSML, em uma abordagem bottom-up, para análise do domínio em questão. Isso complementa e enriquece a abordagem top-down, que parte dos conceitos do domínio para definir e projetar a DSML.

A figura 3 é uma representação informal, oriunda de material de treinamento da ferramenta, e apresenta os principais elementos do Rational Focal Point. 


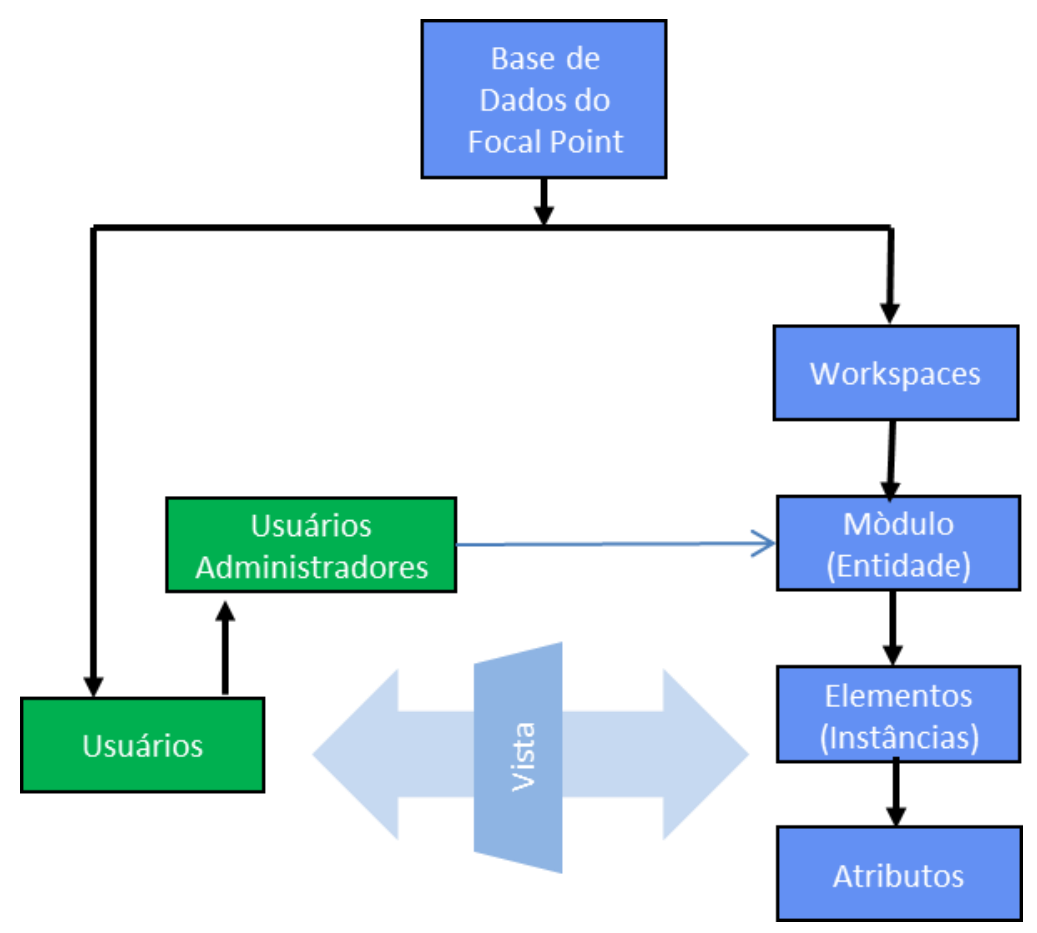

Flgura 3 - estrutura informal dos elementos do Rational Focal Point

Um workspace é uma área de trabalho a que os usuários da ferramenta têm acesso para obter informações ou efetuar ações pertinentes ao processo de gestão de portfólio de projetos. Cada workspace corresponde a um tema de interesse e pode existir tantos workspaces quanto se considere adequado. Os usuários podem ser cadastrados em um ou mais workspaces.

Um módulo é o termo que a ferramenta utiliza para denominar uma entidade. Exemplos de módulos: Produtos, Projetos, Necessidades de Negócio, Aplicações, Requisitos. Há módulos pré-definidos, correspondentes a entidades mais comuns do domínio, mas podem-se criar quaisquer módulos que se queira e definir livremente os atributos desses módulos. Os exemplo de módulos são: Propostas de projetos (a serem detalhadas, analisadas, aprovadas e reprovadas), com atributos como descrição, data de início e fim previstas para o projeto, entre outros.

Os módulos podem ser interrelacionados. Um elemento é uma instância de módulo.

Um atributo no Rational Focal Point corresponde ao conceito convencional de atributo de uma entidade e cada atributo deve necessariamente ser associado a um determinado tipo. A ferramenta fornece um conjunto pré-definido de tipos de atributos. 
Uma vista apresenta um subconjunto dos elementos de um módulo e um subconjunto dos atributos desse módulo, e é definida a partir de regras para seleção dos elementos do módulo. Como exemplo de vistas pode-se citar: meus requisitos, todos os requisitos, requisitos ativos, requisitos arquivados, novos requisitos. A cada usuário é atribuído o direito de acesso a determinadas vistas.

Um atributo de um módulo pode ter associado um critério de priorização e os seus valores devem ser considerados para a priorização dos elementos do módulo. Por exemplo, pode-se definir que um critério de priorização das propostas é o valor presente líquido gerado pela execução do projeto, ou seja, o valor presente do retorno do investimento menos os custos do projeto.

A ferramenta possui um critério de priorização específico previamente implementado denominado Avaliação em Pares. Consiste em apresentar, para cada avaliador, em um determinado estágio do processo, pares de propostas em análise, para que ele as compare, considerando uma determinada questão específica. Esse algoritmo seleciona, sucessivamente, pares de propostas a serem comparadas por avaliador, até que seja possível obter uma avaliação consistente, com base na questão formulada. Diversos avaliadores podem ser solicitados a fornecer informação referente a essa avaliação.

Um fluxo de trabalho (workflow) pode ser associado a determinada entidade. Esse workflow contempla atividades, estados e transições de estados, válidas para a entidade, e definição das condições que os atributos da entidade satisfazer, para que se possa efetuar uma determinada mudança de estado. Esses objetos são criados e manipulados a partir de funções disponíveis aos usuários que desempenham o papel de administrador.

\subsubsection{Um exemplo de processo do domínio}

Um dos processos relevantes na gestão de portfólios de projetos é a de seleção dos projetos que a serem executados, a partir do conjunto de propostas de projetos elaboradas. Para ilustrar o desenvolvimento da DSML, foi selecionado este processo que é apresentado na Figura 4. 


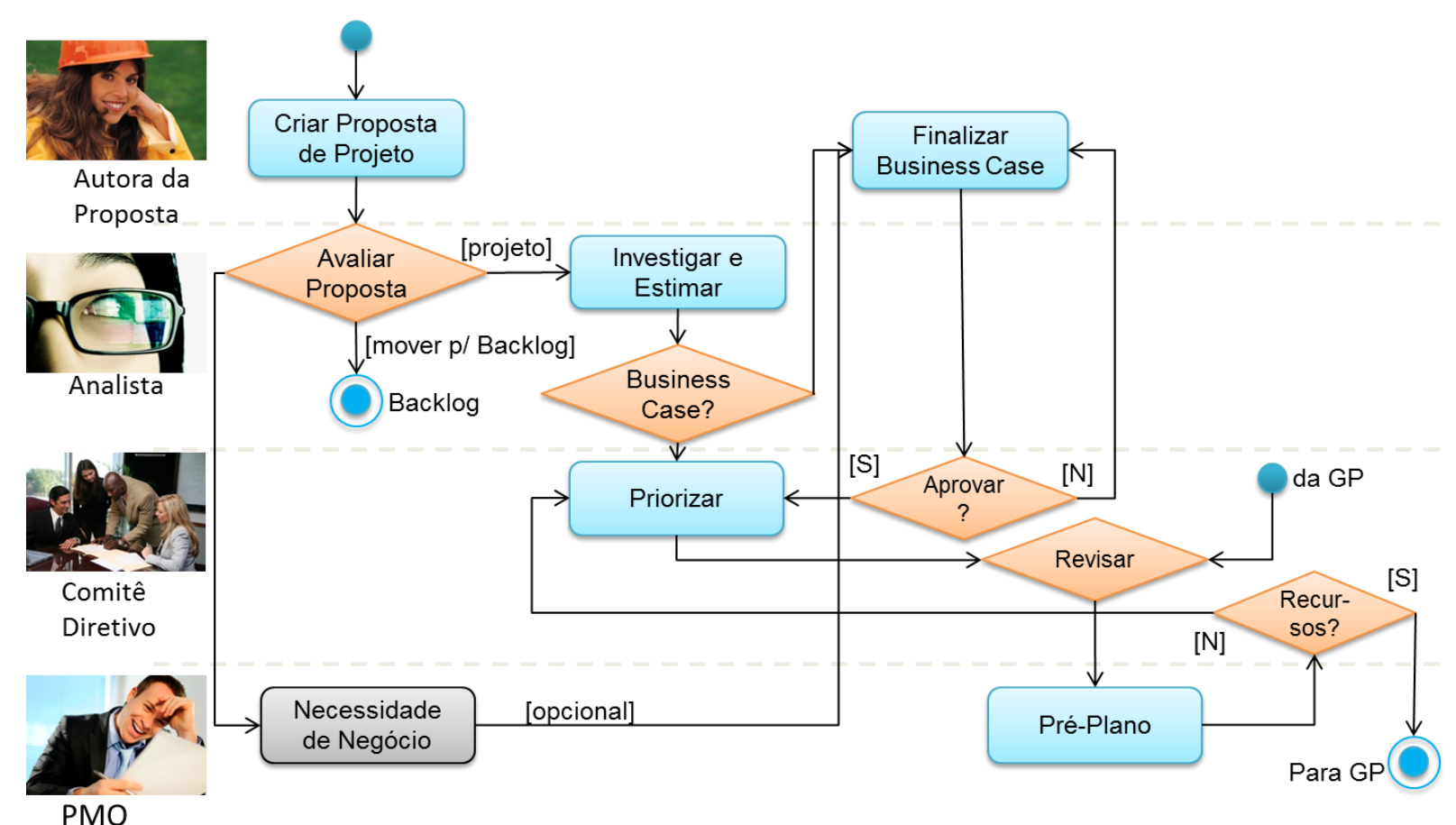

Flgura 4 - Processo exemplo de seleção de projetos

Nesse processo, qualquer membro da Organização pode gerar uma Proposta de projeto, através do preenchimento das informações básicas tais como objetivo e justificativa. A proposta é, então, submetida à aprovação e seu estado é alterado para "em análise".

Um analista acessa as propostas e, após analisar as informações iniciais nela contidas, pode optar por arquivar a proposta (mudança de estado para "arquivado") ou, caso avalie que é necessária uma investigação aprofundada, pode dar continuidade ao processo, alterando o estado para "em estimativa".

Além disso, o analista preenche os atributos referentes ao projeto neste estado, tais como custo do projeto e retorno financeiro esperado. Em função desses valores, o analista pode alterar o estado para "business case" (caso de negócio), estado em que é necessário realizar uma avaliação econômico-financeira mais aprofundada. $\mathrm{O}$ autor da proposta acessa as propostas neste estado e preenche os atributos tais como de custo e faturamento previsto ao longo do tempo. Essas propostas são novamente analisadas pelo analista.

As propostas que passaram pelos analistas, tendo sido ou não submetidas às avaliações econômico-financeiras mais aprofundadas, devem passar para o estado 
"em priorização". As propostas neste estado são priorizadas manualmente ou com auxílio de ferramentas, com base em critérios de avaliação previamente definidos, baseados em valores de atributos específicos das propostas. Entre os critérios de priorização definidos podem-se citar valor presente líquido do projeto (baseado em atributos da proposta) e adesão a objetivos estratégicos, previamente associados à proposta pelo analista.

Com base nos critérios de avaliação pré-definidos, a ferramenta classifica as propostas em ordem decrescente, e o comitê diretivo seleciona quais projetos devem efetivamente ser executados, alterando o estado das propostas. Os projetos aprovados passarão por um planejamento preliminar.

\subsection{Processo para Desenvolvimento da DSML}

Para ilustrar o desenvolvimento da DSML com uso de catálogo de modelos de computação, foi definido um processo que tomou como base os trabalhos de (citar os trabalhos explicitamente), apresentados na seção 2.3 e inclui-se explicitamente um passo que utiliza o catálogo de modelos de computação (passo 3). Suas etapas são:

1. Decisão pelo uso da DSML

2. Análise do domínio

3. Seleção dos modelos de computação

4. Design da DSML

5. Implementação da DSML

\subsubsection{Decisão pelo uso da DSML}

Esta etapa consiste em analisar os patterns de decisão propostos por (MERNIK; HEERING; SLOANE, 2005) e verificar se algum deles se encaixa no domínio selecionado e nos objetivos da DSML. O termo pattern, neste contexto, corresponde a situações típicas em que uma DSML deve ser desenvolvida.

(MERNIK; HEERING; SLOANE, 2005) recomenda o desenvolvimento de DSML, quando ocorre uma das situações apresentados a seguir:

- Existência de notações específicas: em certas situações, é o fator decisivo para uso de DSML. Duas situações típicas citadas são a transformação de notação visual em textual (desenvolvimento de uma DSML quye contemple uma notação 
gráfica, expressiva, que seja posteriormente numa notação textual, processável computacionalmente) e a criação de uma notação amigável para uma API existente ou a transformação da API em uma DSML.

- AVOPT (domain-specific analysis, verification, optimization, parallelization, and transformation): Consiste de um conjunto de manipulações computacionais efetuadas sobre modelos específicos de determinado domínio. Nas situações em que o padrão AVOPT se aplica, a utilização de linguagens de propósitos gerais frequentemente não é viável, porque os padrões de código fonte envolvidos são muito complexos ou não são bem definidos.

- Automação de Tarefas: programadores geralmente consomem tempo, no desenvolvimento de sistemas, em tarefas tediosas e que seguem os mesmos padrões. Nesses casos, o código requerido pode ser gerado automaticamente por um gerador de aplicações (compilador) para uma DSML apropriada.

- Linhas de Produto: Membros de uma linha de produto de software compartilham uma arquitetura comum e são desenvolvidos a partir dos mesmos elementos básicos. O uso de DSMLs pode frequentemente facilitar a especificação de cada um desses membros.

- Representação de Estruturas de Dados: código centrado em dados baseia-se em estruturas de dados cuja complexidade pode tornar difícil escrever e manter. Essas estruturas podem ser mais facilmente expressas utilizando DSMLs.

- Percurso de Estruturas de Dados: pode ser mais fácil e confiável percorrer estruturas de dados complexas utilizando uma DSML adequada.

- Front-end de sistemas. Um front-end baseado em DSML pode ser utilizado para tratamento de configuração e adaptação de sistemas.

- Interação: interação baseada em texto ou menu com software aplicativo frequentemente tem que ser suplementada com uma DSML apropriada para a especificação de entradas complexas ou repetitivas. Por exemplo, o modo interativo do Microsoft Excel é suplementado por uma linguagem de macros Excel para tornar a ferramenta programável.

- Construção de GUI: frequentemente é efetuada utilizando uma DSML.

\subsubsection{Análise do domínio}

A abordagem adotada para esta etapa tem base na seção 2.3 .3 e é a seguinte: 
- Gerar explicitamente um Modelo de Domínio, como um produto da Análise, o qual apresenta os conceitos do domínio e relacionamentos entre esses conceitos. Isso porque se considerou útil dispor de uma representação explícita do domínio como fonte de informação para a etapa de design da DSML.

- Selecionar um formalismo de modelagem dentre as alternativas propostas pelos textos da seção 2.3.3, para expressar o modelo de domínio. Foi selecionado o diagrama de classes da UML, em que cada classe representa um conceito do domínio. Considerou-se que a notação de um diagrama de classes é amplamente conhecida e há semântica claramente definida para os tipos de relacionamentos representados (associação, composição, agregação, generalização / especialização)

- Utilizar tanto uma abordagem top-down quanto bottom-up para identificar os conceitos do domínio. Para a abordagem top-down é usado o conhecimento sobre um processo negócio e, para a abordagem bottom-up, são analisados os recursos de configuração da ferramenta Rational Focal Point.

\subsubsection{Seleção dos Modelos de Computação}

Para as diretrizes desta etapa, foram utilizadas as propostas por (KELLY; TOLVANEN, 2008) como base, apresentadas a seguir:

- A seleção do modelo de computação depende do alvo da modelagem e não apenas do domínio. O código a ser gerado também influencia a escolha do modelo de computação e a DSML como um todo.

- A seleção do modelo de computação depende se a DSML vai representar comportamento dinâmico ou apenas estruturas estáticas.

- Caso se deseje comportamento dinâmico, deve-se avaliar se os sistemas, gerados a partir de modelos construídos através da DSML, envolvem comportamento concorrente, distribuído, comunicação assíncrona, conexões bidirecionais, ou comportamento não determinística.

- Os aspectos comportamentais são capturados estendendo algum modelo de computação conhecido.

A seleção dos modelos de computação para a DSML é feita através da consulta do catálogo de modelos de computação, tendo como referência o domínio em questão 
e os objetivos da DSML. As diretrizes citadas anteriormente contribuem para selecionar o modelo de computação oriundo do catálogo.

Os atributos de cada modelo de computação pertinente ao catálogo fornecem uma orientação mais específica para as necessidades de modelagem da DSML.

\subsubsection{Design da DSML}

Esta etapa é baseada em (KELLY; TOLVANEN, 2008) que apresenta diretrizes detalhadas para o design de uma DSML; para isso, usa, como referência, o modelo de domínio, os objetivos da DSML e os modelos de computação selecionados.

Usa como entrada o modelo de domínio gerado na etapa de análise e o(s) modelo(s) de computação selecionado(s) e gera a sintaxe abstrata (ou meta-modelo) e a sintaxe concreta da DSML.

Inicialmente são definidos os conceitos de modelagem, que se constituem nas classes do meta-modelo. A seguir, o meta-modelo propriamente (ou seja, a sintaxe abstrata da linguagem) é formalizado, usando uma ferramenta especializada no desenvolvimento de DSMLs. Finalmente, é produzida a sintaxe concreta da linguagem.

\subsubsection{Definição dos conceitos de modelagem}

Este passo consiste em mapear os conceitos do domínio em conceitos de modelagem, ou seja, a partir de conceitos do domínio, são identificados os conceitos correspondentes que constarão no meta-modelo (design) da DSML.

O texto de (KELLY; TOLVANEN, 2008) apresenta as diretrizes para definição dos conceitos de modelagem, apresentadas no Apêndice D, seção D.1.

\subsubsection{Formalização da DSML através de um meta-modelo}

A DSML deve ser formalizada através de um meta-modelo, para que a as transformações dos modelos por ela representados possam ser realizados automaticamente.

O uso de uma ferramenta de meta-modelagem é recomendável, para que o metamodelo possa ser executado. 
A linguagem para representar o meta-modelo depende da ferramenta a ser utilizada, mas deve, no mínimo, permitir definir os conceitos da modelagem, propriedades desses conceitos, conexões legais entre eles, estruturas hierárquicas do modelo, e regras. Além disso, o suporte para reuso e diferentes abordagens para integração de modelos é também essencial.

\subsubsection{Notação para a DSML}

A representação visual dos modelos é importante para a aceitação da linguagem, apesar de não ser relevante para as transformações. Uma boa prática é consultar os usuários sobre símbolos e outros elementos da representação da linguagem a que eles estejam acostumados.

As diretrizes para a escolha de símbolos e representações podem ser encontradas no Apêndice D, seção D.2.

\subsubsection{Implementação da DSML}

As abordagens identificadas para o desenvolvimento de DSMLs utilizam, geralmente, ferramentas para implementar as DSMLs (como o GME - Generic Modeling Environment, da Universidade Vanderbilt; e a ferramenta MetaEdit+, da empresa MetaCase). Alguns exemplos estão descritos no apêndice B.

Este tipo de ferramenta possui recursos para representar o design da DSML e gerar, de forma automática, a implementação correspondente. Parte-se de uma linguagem em mais alto nível (a linguagem de meta-modelagem que descreve a sintaxe abstrata da DSML, mais a descrição da sintaxe concreta) e gera-se uma linguagem em baixo nível, que propicia definir os modelos gerados utilizando a DSML.

O acesso à implementação da DSML se dá através de uma outra função da própria ferramenta de meta-modelagem. Ou seja, a ferramenta de meta-modelagem (definição do design da DSML) é também a ferramenta de modelagem (criação de modelos utilizando a DSML implementada).

\subsection{Desenvolvimento da DSML}

Esta seção descreve o desenvolvimento da DSML exemplo, através do processo definido na seção 4.3. É apresentado o escopo da DSML e a descrição da execução das etapas do processo em questão. 
Cada subseção, descrita a seguir, corresponde à execução de uma etapa do processo de desenvolvimento.

\subsubsection{Escopo da DSML}

Deseja-se construir uma DSML para definir processos de seleção de candidatos a projetos. Os projetos selecionados farão parte do portfólio de projetos da Organização. O escopo definido para a DSML corresponde a uma parte do processo de gestão de portfólio.

A DSML produzida deve especificar os seguintes aspectos de um processo de seleção de projetos de portfólio:

- Variabilidade do fluxo de atividades do processo: deseja-se que, através da DSML, seja possível especificar o fluxo de atividades específico do processo de seleção de projetos sob medida para uma Organização específica. O fluxo apresentado na figura 4 é apenas um exemplo. Deseja-se que se possa definir fluxos variados, em termos de atividades, papéis envolvidos e atividades de decisão.

- Variabilidade das entidades abordadas: deseja-se especificar, através da DSML, as entidades pertinentes ao domínio da solução, seus atributos, e relacionamento entre elas. O exemplo citado na seção 4.2.3 contém as entidades Proposta, Objetivos Estratégicos e Necessidade de Negócio. Um outro processo poderia não incluir as entidades Objetivo Estratégico nem Necessidade de Negócio, mas incluir as entidades Requisito Funcional, Requisito Não Funcional, Área de Negócio Cliente, por exemplo, que estariam associadas à entidade Proposta. Deve ser possível criar, com modelos construídos usando a DSML, essas entidades, seus atributos, e os relacionamentos entre elas, conforme a necessidade.

- Variabilidade dos critérios de priorização: deseja-se especificar, através da DSML, os critérios desejados para priorizar os candidatos a projetos, relacionar cada critério ao atributo correspondente da entidade que está sendo priorizada, definir o peso desse critério, e registrar se sua contribuição é positiva ou negativa. Quando desejado, um critério de priorização específico - cujo algoritmo está previamente implementado na ferramenta - pode ser utilizado. Exemplo: Avaliação em Pares. 


\subsubsection{Decisão pelo desenvolvimento da DSML}

Esta etapa consiste na análise dos patterns de decisão propostos para verificar se é possível, encaixar o desenvolvimento da DSML em um ou mais deles. Em caso positivo, vale à pena desenvolver a DSML.

Identificou-se que o desenvolvimento da DSML de Seleção de Projetos se encaixa nos seguintes patterns:

- Notações, porque espera-se que a DSML, permita expressar o fluxo de atividades do processo, utilizando uma notação gráfica semelhante à apresentada no processo exemplo da seção 4.2.3.

- Automação de Tarefas, porque a DSML propicia a definição gráfica de entidades, seus atributos e relacionamentos entre elas, bem como a definição do fluxo de atividades em si, contemplando atividades, papéis e entidades manipuladas. Os produtos gerados pela DSML serão automaticamente traduzidos em definições em mais baixo nível.

- Linha de Produto, pois vai automatizar os processos de seleção de projetos específicos a cada Organização, os quais vão possuir arquitetura e componentes comuns.

- Representação de Estruturas de Dados, porque a DSML será usada para especificar entidades, atributos e relacionamentos entre elas.

Observa-se que a DSML de seleção de projetos encaixa-se em quatro dos patterns de decisão propostos por (MERNIK; HEERING; SLOANE, 2005).

O nível de automação do desenvolvimento de processos específicos de seleção de projetos é significativo. A automação integral do processo é possível com base nos modelos definidos utilizando a DSML. Pode-se prever que mesmo a interface visual, não abordada explicitamente, pode ser gerada automaticamente, com base nas definições de atividades, entidades e critérios de priorização. Essa conclusão foi confirmada através da ferramenta Rational Focal Point, que gera a interface visual de forma automática, com base na configuração do processo e entidades, de forma equivalente ao comportamento da DSML.

Considerando os patterns de decisão atendidos pela DSML e a análise do nível de automação a ser atingido nos processos de seleção de projetos, decide-se por desenvolver da a DSML. 


\subsubsection{Análise do Domínio}

O modelo de domínio, resultante da análise do domínio, é apresentado nas figuras 5 e 6. Esse modelo foi gerado pela abordagem top-down, identificando os conceitos relevantes do domínio através do processo exemplo de seleção de projetos da seção 4.2.3 e pela abordagem bottom-up, identificando conceitos relevantes através da análise da ferramenta Rational Focal Point. As abordagens se revelaram complementares e a disponibilidade de ambas enriqueceu o modelo de domínio.

A existência de dois diagramas deve-se à restrição de espaço físico para representação. Conceituamente, é apenas um diagrama. As entidades com mesmo nome, que aparecem nos dois diagramas, representam uma única entidade. Utilizouse a terminologia do Rational Focal Point: por exemplo, a classe Módulo representa uma entidade.

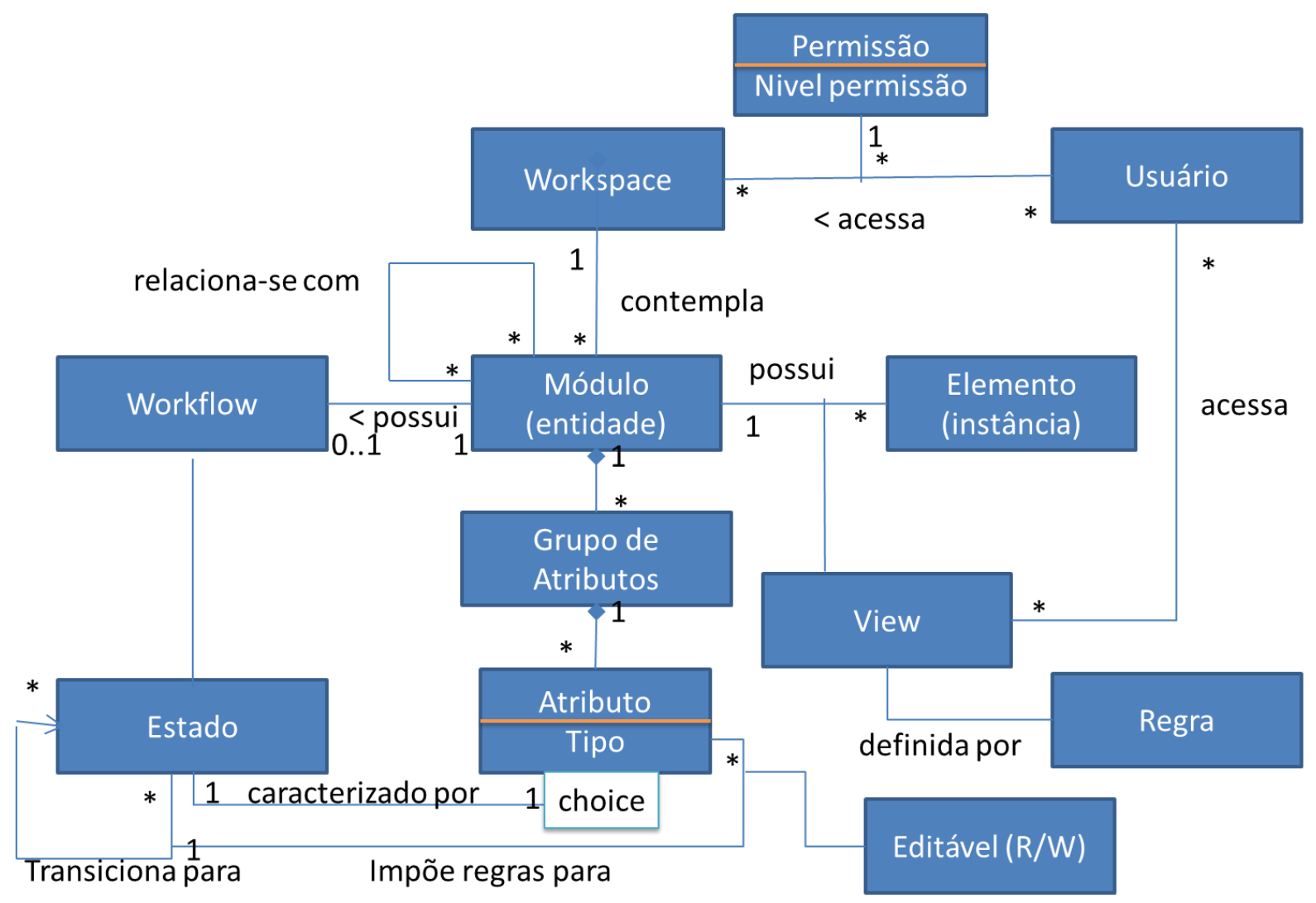

Flgura 5 - Modelo de domínio, parte 1 


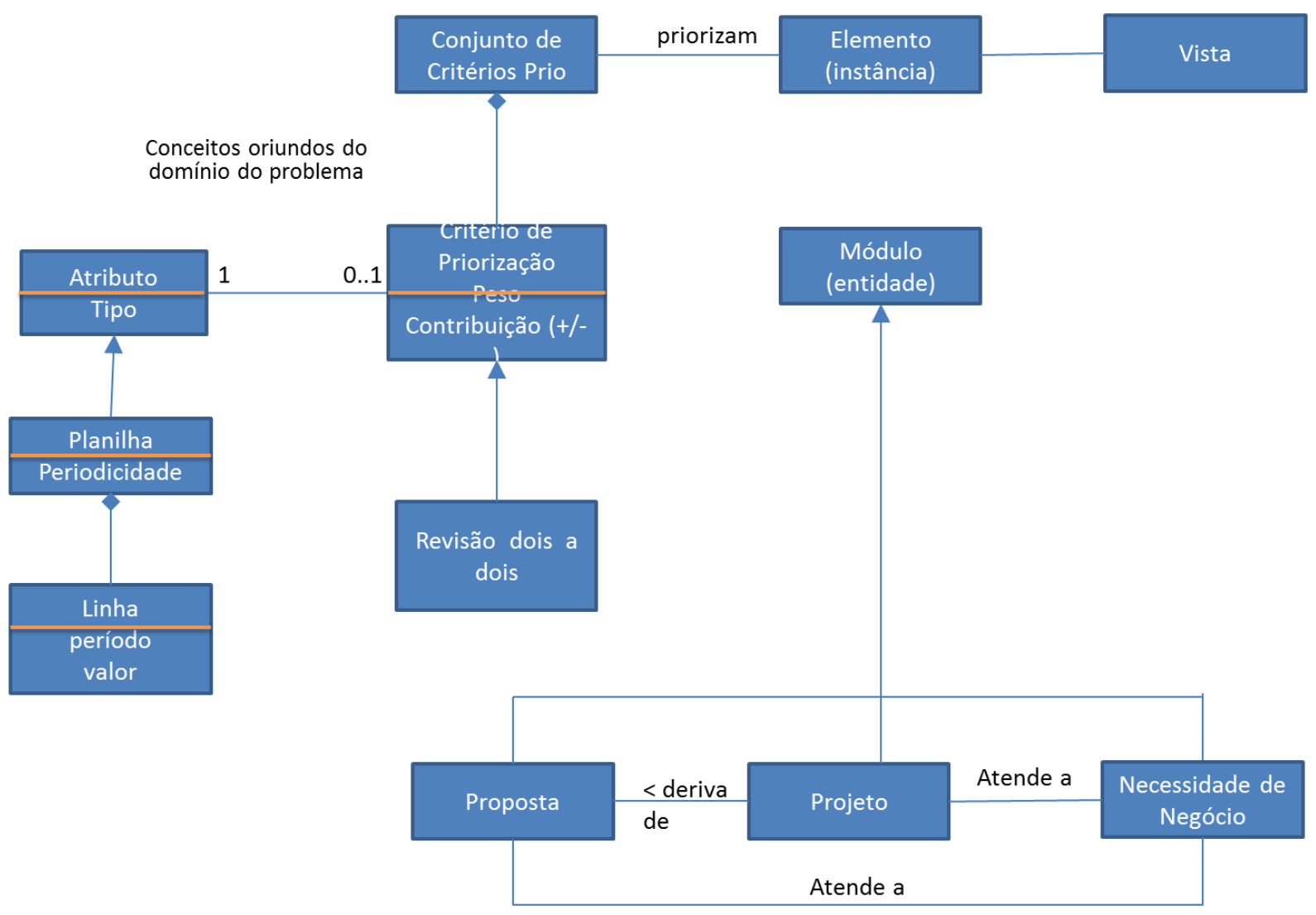

Flgura 6 - Modelo de domínio, parte 2

Boa parte das entidades e relacionamentos do modelo de domínio foi descrita na seção 4.2, quando se apresentou o domínio. A seguir são apresentadas explicações complementares, decorrentes das decisões efetuadas durante a construção do modelo de domínio.

O modelo de domínio agrupa os atributos de determinado módulo em Grupos de Atributos. A razão é que uma entidade pode ser descrita por agrupamentos de atributos que caracterizam aspectos distintos. Muitas vezes é útil explicitar cada aspecto e os atributos que o caracterizam. Por exemplo, o módulo Proposta, pode ser descrita por atributos financeiros (faturamento previsto ao longo de cada período, custos previstos a cada período), atributos de planejamento de tempo (data prevista para início do projeto e para o fim do projeto), atributos de caracterização do projeto (objetivo, justificativa).

Os módulos principais podem ter fluxos de trabalho (workflows) associados. Um fluxo de trabalho é composto por atividades. Cada atividade está associada a um estado. Mudanças de estado propiciam a execução de uma próxima atividade, e só 
podem ser efetuadas se determinados atributos do módulo tiverem sido adequadamente preenchidos. Um exemplo típico de módulo que pode possuir fluxo de trabalho é o módulo Proposta; o processo de seleção de projetos exemplo apresentado na seção 4.2.3 apresenta os diversos estados pelos quais uma Proposta passa.

Um usuário da ferramenta de gestão de portfólio de projetos acessa cada módulo através de vistas. Uma vista é definida por uma regra de consulta a elementos do módulo correspondente. Essa consulta retorna determinados elementos que atendem à regra de consulta e apresenta atributos específicos desses elementos, previamente definidos.

O Modelo de Domínio fornece tipos de atributos especiais para módulos, por exemplo,. o tipo de atributo Planilha. Este atributo tem, por sua vez, um atributo periodicidade (mensal, trimestral, semestral, etc.).

A priorização de um módulo (como exemplo, do módulo Proposta) se dá com base em critérios que utilizam os atributos desse módulo. Por exemplo, um critério pode utilizar o atributo Valor Presente Líquido de cada proposta; outro critério pode utilizar um atributo que representa uma pontuação da aderência da proposta a objetivos estratégicos da Organização. Cada critério pode ter um peso e uma contribuição positiva ou negativa. Por exemplo, o valor presente líquido de uma proposta é um atributo com contribuição positiva (quanto maior o valor presente líquido, mais importante a Proposta para a Organização), enquanto que custo total do projeto é um atributo com contribuição negativa. Esses atributos são então combinados, considerando o peso de cada um e a contribuição, para se obter a priorização do módulo.

\subsubsection{Seleção dos Modelos de Computação}

É nesta etapa em que entra a utilização de catálogo de modelos de computação, para identificar os modelos de computação para embasar a DSML. Foram consideradas as diretrizes propostas por (KELLY; TOLVANEN, 2008), os aspectos de variabilidade para a DSML (seção 4.4.1) e os atributos dos modelos de computação do ao catálogo (seção 3.2.1). 
Kelly e Tolvanen (2008) definem que os modelos de computação devem ser selecionados com base no domínio e na intenção da DSML: representação de estruturas estáticas e/ou comportamento dinâmico, e o tipo de comportamento dinâmico, se for o caso.

Analisando os aspectos de variabilidade que se deseja representar utilizando a DSML da seleção de projetos, identifica-se que:

- Deve ser gerada uma estrutura estática de Módulos, atributos e relacionamentos entre os módulos.

- Deve ser possível descrever comportamento dinâmico, correspondente ao fluxo de atividades do processo de seleção de projetos.

- Deve ser possível descrever os critérios de priorização e os estados pelos quais passam determinados módulos.

O único modelo de computação para representar comportamento dinâmico que consta no catálogo é o diagrama BPMN, que é adequado para representar o fluxo de atividades do processo de seleção de projetos. Caso o usuário do catálogo não conhecesse esse modelo de computação a priori, uma análise dos atributos do modelo de computação revelaria essa adequação. Esse então é um modelo de computação a ser utilizado.

Quanto à estrutura de módulos, atributos e relacionamentos, o modelo de computação Diagrama de Classes é voltado para representar esse tipo de informação. Da mesma forma que no caso anterior, se o usuário do catálogo não conhecesse esse modelo de computação a priori, uma análise dos atributos do modelo de computação revelaria essa adequação.

Fica ainda pendente a necessidade de incorporar à DSML formas de representar critérios de priorização e a representação dos estados pelos quais passam cada instância dos módulos que tenham fluxo de estados não trivial. A priori, decidiu-se representar esses aspectos estendendo os modelos de computação selecionados anteriormente. Essa é uma decisão preliminar, a ser confirmada ou não durante o design da DSML. Caso na etapa de design se conclua que essa decisão não é adequada, pode-se buscar outros modelos de computação, atualmente não pertinentes ao catálogo, para representar esses aspectos, e assim enriquecer o catálogo. 


\subsubsection{Design da DSML}

O design da DSML foi elaborado com base no modelo de domínio, nos modelos de computação selecionados do catálogo e nas diretrizes de design definidas na apêndice D. O meta-modelo gerado é apresentado na figura 7 . 


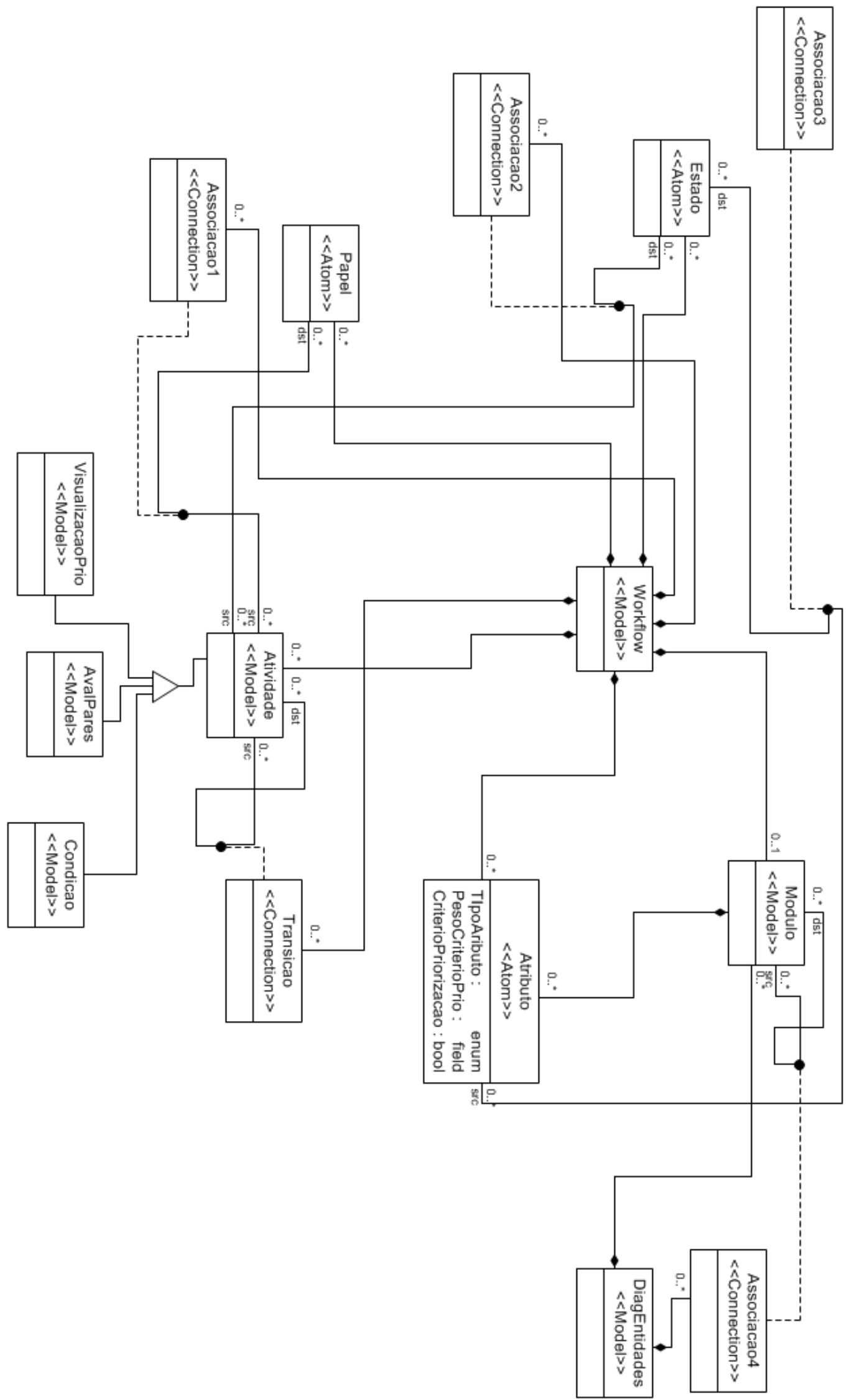

Flgura 7 - Metamodelo da DSML exemplo 
A metalinguagem utilizada para definir a sintaxe abstrata é oriunda da ferramenta open source Generic Modeling Environment (GME), citada no apêndice B (LEDECZI et al; 2001). Essa ferramenta foi selecionada por ser fruto de um projeto acadêmico do Instituto Isis da Universidade Vanderbilt, e pela sua natureza open source. Além disso, a análise da ferramenta em (KELLY; TOLVANEN, 2008), apresentada sucintamente no apêndice $B$, atribui a ela uma nota relativamente alta, inferior apenas à nota atribuída à ferramenta proprietária MetaEdit+.

A metalinguagem do GME é um diagrama de classes especializado pelo uso de estereótipos, e com conceitos específicos da solução de meta-modelagem utilizada pela ferramenta.

Essa metalinguagem contempla duas classes, uma com estereótipo Model, outra com estereótipo Atom, para representar Entidades do meta-modelo. A classe Model, além de ter atributos associados, pode ter estrutura interna, composta por outras classes, ao passo que um Atom não tem estrutura interna.

A metalinguagem do GME permite que os diagramas construídos pelo uso das DSMLs também sejam representados através de recursos específicos da sintaxe abstrata da linguagem. Na figura 7, duas classes com estereótipo Model representam tipos de diagramas que se pode construir: a classe Workflow e a classe DiagEntidades. O fato de que essas classes representam diagramas não é visível no diagrama apresentado na figura 7 , porque isso é configurado como valor de um atributo da meta-classe Model.

Na meta linguagem do GME, define-se quais meta-classes podem ser exibidas num diagrama através de uma relação de composição entre essas meta-classes e a meta-classe que representa o diagrama. No caso do meta-modelo gerado, as metaclasses que podem ser exibidas num diagrama do tipo Workflow são Estado, Atividade, Papel, Módulo, Atributo e as meta-classes que representam associações. As meta-classes que podem ser exibidas num diagrama do tipo DiagEntidades são Módulo, e a meta-classe que representa associação entre instâncias de módulos.

O tipo de diagrama representado pela meta-classe Workflow é baseado no modelo de computação BPMN e o tipo de diagrama representado pela meta-classe DiagEntidades é baseado no modelo de computação Diagrama de Classes. Ambos os modelos de computação foram utilizados como referência, estão modificados e 
especializados, para atender aos requisitos específicos da DSML da seleção de projetos.

A meta-classe fundamental do tipo de diagrama Workflow é a Atividade, que representa uma atividade efetuada por algum papel que utiliza o processo de seleção de projetos.

Há três especializações de Atividade: Condição, para representar uma atividade de decisão entre determinados caminhos possíveis no fluxo de atividade; AvalPares, para representar uma atividade de Avaliação em Pares dos candidatos a projetos; VisualizacaoPrio, que representa a visualização final dos candidatos a projetos já priorizados.

Há uma associação entre Atividade e Papel, que restringe qual papel pode executar determinada atividade; outra associação, entre Atividade e Estado, indica em que estado o Módulo correspondente deve estar para que aquela atividade possa ser executada.

Há uma associação 1:M entre Estado e Atributo, para indicar os atributos que necessariamente foram preenchidos para que a próxima transição de estado seja possível.

Os estados pelos quais passa o Módulo principal, desta forma, foram descritos usando o próprio diagrama derivado do modelo de computação BPMN. Essa solução de design faz com que não seja necessário outro tipo de diagrama, baseado no modelo de computação Diagrama de Transição de Estados (que até então não consta no catálogo de modelos de computação), para representar as transições de estado possível.

O modelo de domínio gerado na etapa de análise indica que cada critério de priorização está associado a determinado atributo do Módulo Principal. Há várias alternativas para projetar esse requisito. A solução escolhida, foi incorporar dois atributos à Classe da sintaxe abstrata denominada Atributo. Um atributo do tipo booleano denominado CriterioPriorizacao define se aquele Atributo corresponde a um critério de priorização. Um atributo do tipo Inteiro define o peso desse critério de priorização na priorização final. Essa solução tornou desnecessário que se construísse algum outro tipo de diagrama, baseado em algum modelo de 
computação, para representar os critérios de priorização e os atributos correspondentes nos quais são baseados.

A geração da sintaxe abstrata no GME é efetuada associando arquivos bitmap a cada classe de estereótipo Atom ou Model pertinente ao meta-modelo. A representação visual dos relacionamentos entre objetos dessas classes não demanda nenhuma ação específica do projetista da DSML - é efetuada automaticamente, usando uma notação previamente definida pelo GME.

\subsubsection{Implementação da DSML}

Utilizando ferramentas como o GME, a implementação da DSML é feita de forma automática, executando funções de tradução do meta-modelo gerado na própria ferramenta em uma implementação da DSML. No caso do GME, uma função denominada Intérprete gera a implementação da linguagem a partir da sintaxe abstrata e da sintaxe concreta previamente definidas.

Essa linguagem implementada é acessada também utilizando o GME. Ou seja, o GME é uma ferramenta de meta-modelagem, usando o editor que utiliza a metalinguagem apresentada na seção 4.4.5; e também uma ferramenta de modelagem, usando o editor do GME que trabalha com a DSML implementada.

\subsection{Considerações finais}

Um catálogo de modelos de computação, que apresente, descreva e exemplifique o uso de modelos de computação potencialmente úteis, fornece informação valiosa para projetistas de DSMLs, porque trazem orientação sobre quando utilizar cada modelo de computação específico. Para que essa contribuição se materialize na prática, os atributos de cada modelo de computação do catálogo devem ser descritos de forma cuidadosa, com descrições claras e bem desenvolvidas, focado no contexto de MDD com DSMLs.

Isso propicia, particularmente a projetistas inexperientes, uma referência inicial na qual podem se basear ao projetar uma DSML, bem como melhora a qualidade dos resultados, na medida em que o catálogo seja fruto de experiência prática, como no caso de design patterns que são úteis ao design de sistemas de software. 
O uso do catálogo de modelos de computação para a construção da DSML para seleção de projetos atingiu o objetivo de nortear o design da DSML, mitigando, mas não eliminando a complexidade do design da DSML.

A seguir são apresentadas conclusões mais gerais:

- Os modelos de computação constituem uma referência importante para o design da DSML. A sintaxe abstrata da DSML pode se basear em modelos de computação que devem ser então adaptados, especializados, para as especificidades do domínio em questão e dos requisitos da DSML,.ou seja, há um trabalho de criação a ser efetuado, tendo, os modelos de computação como referência.

- Os elementos constituintes do modelo de computação devem ser especializados para o domínio em questão. Determinados elementos podem ser excluídos, outros que não constam no modelo de computação acrescidos. Em suma, os modelos de computação não devem restringir a criatividade do projetista, que deve se beneficiar deles sem se restringir a eles.

- Para além dos atributos do catálogo, pode-se simplificar o design e aumentar a utilidade do catálogo um processo de desenvolvimento de DSMLs definindo diretrizes mais evoluídas e detalhadas que as presentes em (KELLY, TOLVANEN; 2008). Esse é um potencial trabalho futuro. 


\section{Considerações Finais}

Este capítulo tem como objetivo apresentar um conjunto de conclusões oriundas da execução do trabalho, explicitar contribuições e propor trabalhos futuros que deem continuidade à pesquisa efetuada e aos resultados obtidos.

\subsection{Conclusões}

A abordagem de desenvolvimento de software através de MDD não se difundiu amplamente na comunidade de engenharia de software, contrariamente ao almejado quando foi proposto no início dos anos 2000 (KLEPPE; WARMER; BAST, 2003). Em vez disso, passou a ser utilizada em nichos específicos, entre os quais se destaca o de desenvolvimento de software embarcado (KARSAI, 2003), e também, em Organizações específicas, para o desenvolvimento em larga escala de sistemas de informação (HUTCHINSON, 2011).

Isso ocorre pois, apesar de os ganhos de produtividade (pela automação parcial do processo de desenvolvimento) e qualidade (pelo reuso de arquiteturas, frameworks e componentes) serem significativos, os valores quantitativos desses ganhos diferem muito de acordo com a abordagem específica em que a DSML esteja sendo utilizada.

No que diz respeito à produtividade, Hutchinson (2011) cita estudos efetuados por The Middleware Company, em 2003 e 2004, focados exclusivamente no uso da ferramenta Compuware OptimalJ, os quais identificaram ganhos de produtividade de 35\%. Em um outro extremo, Kärnä, Tolvanen e Kelly (2009) afirmam que a abordagem baseada em DSMLs, que denominam Domain-Specific Modeling (DSM) produziu ganhos de produtividade de $750 \%$.

Ainda que haja variações tão extremas nas estimativas de ganhos de produtividade das diversas abordagens específicas pertinentes ao MDD, mesmo os ganhos obtidos no extremo inferior (35\%) são grandes o suficiente, por si só, para justificar o uso do $\operatorname{MDD}$ e, consequentemente, as pesquisas que poderão enriquecer e simplificar essa abordagem, de modo a propiciar sua utilização por comunidades mais amplas. 
O foco em pesquisas referentes às diversas variantes do MDD continua ativo, o que pode ser atestado pela quantidade de eventos acadêmicos relevantes dedicados ou que abordam esse tema, como a 17th IEEE International EDOC Conference (EDOC 2013), AIAA Infotech@Aerospace, INSTICC International Conference on Evaluation of Novel Approaches to Software Engineering, entre outros.

Dentre as diversas linhas de pesquisa de MDD, esta tese abordou 0 desenvolvimento de DSMLs e, mais especificamente, a linha de pesquisa que propõe construir meta-modelos de DSMLs com base em fragmentos de modelos previamente definidos e, em particular, com base em modelos de computação.

Os trabalhos que adotam essa abordagem, como (KELLY; TOLVANEN, 2008), (MANNADIAR; VANGHELUWE, 2010), explicitam a necessidade de identificar um conjunto básicos modelos de computação, mas nenhuma referência encontrada responde a esta questão de forma adequadamente estruturada. O catálogo de modelo de computação proposto nesta tese vem a atender a essa demanda.

Diversos trabalhos citados na seção 2.4 propõem que ferramentas especializadas para a geração de DSMLs contemplem funções que disponibilizem fragmentos de meta-modelos para inserção nos meta-modelos das DSMLs a serem construídas (EMERSON, SZTIPANOVITS; 2006), (LEVENDOVSKY, LENGYEL, MÉSZÁROS; 2009). Essa ideia também se aplica ao uso de modelos de computação na geração de DSMLs.

Entretanto, é importante destacar que o modelo de computação não resolve o problema de definição da DSML, sendo uma referência a ser usada, na medida do que seja conveniente. Isso porque o modelo de computação é, em si, independente de domínio, e não incorpora requisitos definidos para o desenvolvimento de uma DSML específica.

Por conta disso, conceitos e relacionamentos específicos do domínio, bem como os requisitos também específicos do desenvolvimento da DSML, devem ser mapeados sobre os elementos do modelo de computação e até mesmo estender ou modificar o modelo de computação. No exemplo de construção de DSML apresentado no capítulo 4, por exemplo, o modelo de computação BPMN foi alterado, e inclusive simplificado, para atender aos objetivos específicos da definição DSML para seleção de projetos. 
O catálogo de modelos de computação foi gerado com um conjunto de modelos de computação, para que se avalie a sua utilidade. Seu conteúdo irá aumentando à medida que surgirem outras necessidades para novos sistemas.

Durante a criação do catálogo de modelos de computação, identificou-se uma outra abordagem, distinta de MDD, para a construção de sistemas de informação, denominada gestão de decisão com regras de negócio, descrita sucintamente no apêndice C. Esta abordagem separa o código escrito das regras de negócio da Organização e gerencia essas regras usando sistemas denominados sistemas de gestão de regras de negócio (FISH; 2012).

Segundo a abordagem de gestão de decisão com regras de negócio, os elementos fundamentais, para especificar um sistema, são os modelos de processo de negócio e as regras de negócio. Estes elementos fazem parte do catálogo gerado. Ou seja, duas abordagens distintas para desenvolvimento de sistemas estabeleceram elementos fundamentais de construção de sistemas muito semelhantes. Essa percepção reforçou a validade dos elementos constituintes do catálogo de modelos de computação produzido.

\subsection{Contribuições do trabalho}

Esta tese traz duas contribuições fundamentais: o catálogo de modelos de computação gerado e o processo criado para geração desse catálogo.

O fato de o catálogo ter sido gerado a partir de um processo explicitamente definido implica que a identificação dos seus elementos pode ser reproduzida, não sendo, portanto, apenas fruto de intuição, como as soluções apresentadas em (PEDRO; BUCHS; AMARAL, 2008) ou (MANNADIAR; VANGHELUWE, 2010).

Em particular, considera-se, como uma contribuição relevante, a identificação de modelos de computação a partir de famílias de sistemas, tais como ERPs, e CRMs, considerados fundamentais para a maioria das Organizações, com base na premissa de que esses modelos serão potencialmente utilizados em outros sistemas do mesmo domínio.

A relevância do catálogo de modelos de computação para a construção de DSMLs é evidenciada por fontes como (PEDRO; BUCHS; AMARAL, 2008) e (MANNADIAR; VANGHELUWE, 2010) que não usam o termo modelo de computação, mas utilizam 
este conceito. No caso de (KELLY; TOLVANEN, 2008), o termo modelo de computação é citado explicitamente e é incluído no processo de desenvolvimento.

Por fim, a tese traz uma contribuição específica ao apresentar um exemplo prático de uso do catálogo para a criação de uma DSML exemplo. Verificou-se que as diretrizes para seleção de modelo de computação propostas de (KELLY; TOLVANEN, 2008) não constituem uma orientação suficiente, ao tentar aplicá-las. A análise dos atributos dos modelos de computação que pertencem ao catálogo é algo que orienta de forma mais precisa a seleção dos modelos de computação para determinada DSML. O exemplo do capítulo 4 traz uma contribuição específica à proposta de uso do catálogo para nortear a seleção de modelos de computação.

\subsection{Trabalhos Futuros}

Como forma de avaliar os modelos de computação do catálogo ou de expandir o catálogo, um trabalho futuro é aplicar o processo de identificação de modelos de computação para o desenvolvimento de DSMLs para outros conjuntos de sistemas e avaliar a utilidade do catálogo através da sua utilização na construção de outras DSMLs.

Além disso, o catálogo pode ser enriquecido ao incorporar uma descrição de sintaxe abstrata, baseada em alguma linguagem de meta-modelagem, para cada modelo de computação pertinente para o catálogo. Isso trará uma contribuição maior ao uso do catálogo, porque não demandará dos usuários do catálogo que eles próprios definam o meta-modelo referente ao modelo de computação, pois essa informação será previamente fornecida.

Outro possível trabalho futuro é a definição de um processo de desenvolvimento de DSMLs. Existem diversos processos definidos em textos acadêmicos, conforme citado na seção 2.3, mas nenhum tem o grau de maturidade e clareza de definição que processos definidos para outros contextos. Por exemplo, no contexto de desenvolvimento de software sem o uso de MDD, há processos maduros como o Rational Unified Process (RUP) (JACOBSON, BOOCH, RUMBAUGH; 1999) ou SCRUM (PICHLER; 2010). Seria muito útil trazer o formalismo e clareza da definição desses processos para o universo do desenvolvimento de desenvolvimento de DSMLs. 


\section{REFERÊNCIAS}

AGRAWAL, A.; KARSAI, G.; LEDCZI, A. And End-to-End Domain-Driven Software Development Framework. OOPSLA'03 26-30 Outubro 2003. ACM.

BELIX, J. Um Estudo sobre MDA: Suporte Fornecido pela UML e Reuso de Soluções Pré-definidas. Dissertação apresentada à Escola Politécnica da Universidade de São Paulo, 2006.

BALASUBRAMANIAN, K. et al. Developing Applications Using Model-Driven Design Environments. IEEE Computer Magazine. IEEE Computer Society, fevereiro 2006.

BLACKWELL, A. Metaphor in Diagrams. Ph.D. Thesis, Universidade de Cambridge, setembro, 1998.

BOOCH, G.; RUMBAUGH, J.; JACOBSON, I. The Unified Modeling Language User Guide - Second Edition. Addison Wesley, 2005.

BUSCHMANN, F. et al. Pattern-Oriented Software Architecture. A System of Patterns. Wiley and Sons, 1996.

CHEN, K.; SZTIPANOVITS, J.; NEEMA, S. Toward a Semantics Anchoring Infrastructure for Domain-Specific Modeling Languages. EMSOFT'05. ACM. 1922 setembro 2005.

CONSEL, C.; MARLET, R. Architecturing Software Using A Methodology for Language Development. IRISA /INRIA University of Rennes 1. PLILP, 1998.

COOK, S.; JONES, G.; KENT, S.; CAMERON WILLS, A. Domain-Specific Development with Visual Studio DSL Tools. Addison-Wesley, 2007.

CZARNECKI, K. et al. Feature Models are Views on Ontologies. 10h International Software Product Line Conference, IEEE, 2006.

CZARNECKI, K.; EISENECKER, U. Generative Programming - Methods, Tools, and Applications. Addison-Wesley, 2000.

DEURSEN, A.; KLINT, P.; VISSER, J. Domain-Specific Languages: An Annotated Bibliography. ACM SIGPLAN Notices, 2000.

ENGELS, G. et al. A Methodology for Specifying and Analyzing Consistency of Object-Oriented Behavioral Models. In: $8^{\text {th }}$ European Software Engineering Conference held jointly with $13^{\text {th }}$ ACM SIGSOFT International Symposium on Foundations of Software Engineering. Proceedings. Vienna, Austria, 2001, p. 176185.

FISH, A. Knowledge Automation. How to Implement Decision Management in Business Processes. John Wiley and Sons, 2012.

FRANCE, R.; GHOSH, S.; DIGH-TRONG, T.; SOLBERG, A. Model-Driven Development Using UML 2.0: promises and Pitfalls. IEEE Computer Magazine. IEEE Computer Society, fevereiro 2006.

FOWLER, M. Analysis Patterns: Reusable Object Models. Reading, MA.: Addison-Wesley, 1996. 
GAMMA, E.; HELM, R.; JOHNSON, R.; VLISSIDES, J. Design Patterns. Elements of Reusable Object-Oriented Software. Addison-Wesley, 1994.

GREENFIELD, J.; SHORT, K.; COOK, S.; KENT, S. Software Factories Assembling Applications with Patterns, Models, Frameworks, and Tools. Wiley Publishing, 2004.

HUTCHINSON, J. An Empirical Assessment of Model-Driven Development in Industry. PhD Thesis submitted to the School of Computing and Communications Lancaster University, 2011.

JACOBSON, I.; BOOCH, G.; RUMBAUGH, J. The Unified Software Development Process. Addsion-Wesley, 1999.

KÄRNÄ, J.; TOLVANEN, J.; KELLY, S. Evaluating the Use of Domain-Specific Modeling in Practice. Domain-Specific Modeling Forum, 2009.

KARSAI, G. et al Model-Integrated Development of Embedded Software. Proceedings of the IEEE, janeiro 2003.

KELLY, S.; TOLVANEN, J. Domain-Specific Modeling: Enabling Full Code Generation. John Wiley \& Sons, Inc, 2008.

KLEPPE, A.; WARMER, J.; BAST, W. MDA Explained. The Model Driven Architecture: Practice and Promise. Addison-Wesley, 2003.

LARMAN, C. Applying UML and Patterns - an Introduction to Object-Oriented Analysis and Design and the Unified Process. Prentice Hall PTR, 2002.

LAUDON, K.; LAUDON, C. Management Information Systems (12th Edition). Prentice Hall, 2011.

LEDECZI, A.; MAROTI, M.; BAKAY, A.; KARSAI. G.; GARRETT, J.; THOMASON, C.; NORDSTROM, G.; SPRINKLE, J; VOLGYESI, P. The Generic Modeling Environment. Proceedings of WISP'2001,IEEE. 2001.

MAGAL, S.; WORD, J. Integrated Business Processes with ERP Systems. Wiley, 2011.

MANNADIAR, RAPHAEL; VANGHELUWE, HANS. Domain-Specific Engineering of Domain-Specific Languages. Proceedings of the 10th Workshop on DomainSpecific Modeling (DSM'10). Part of Systems, Programming, Languages, and Applications: Software for Humanity (SPLASH). HSE-Press, B-120, October 2010.

MELLOR, S.; CLARK, A.; FUTAGAMI, T. Model-Driven Development. IEEE Software. IEEE Computer Society. Set-out 2003.

MERNIK, M.; HEERING, J.; SLOANE, A. When and How to Develop DomainSpecific Languages. ACM Computing Surveys, vol 37, No. 4, dezembro 2005, pgs. 316-344.

MONTEIRO, J. Ruby on Rails Brasil. http://rubyonrails.com.br, 2013.

MOSTERMAN, PIETER; VANGHELUWE, HANS. Computer Automated MultiParadigm Modeling in Control System Design. IEEE International Symposium on Computer-Aided Control System Design, pages 65-70. IEEE Computer Society Press, September 2000. 
NORDSTROM, S.; SHETTY, S.; CHHOKRA, K.; SPRINKLE, J.; EAMES, B.; LEDECZI, A. ANEMIC: Automatic Interface Enabler for Model Integrated Computing. Generative Programming and Component Engineering (GPCE), 2003.

OBJECT MANAGEMENT GROUP. UML 2.1 Metamodel. Modelo Gráfico que expressa o metamodelo UML no formato MDL, utilizado pela ferramenta Rational Rose, 2005.

OBJECT MANAGEMENT GROUP. Object Constraint Language Available Specification, version 2.0. 2006.

PICHLER, R. Agile Product Management with Scrum: Creating Products that Customers Love. Addison-Wesley Signature Series, 2010.

SCHMIDT, D. Model-Driven Engineering. IEEE Computer Magazine. IEEE Computer Society, fevereiro 2006.

SIMONS, M. et al Organization Domain Modeling (ODM) Guidebook, Version 2.0. Informal Technical Report for STARS, STARS-VC-A025/001/00, 14 de junho de 1996.

SPINELLIS, D. Notable Design Patterns for Domain-Specific Languages. J. Syst. Softw. 56, 91-99, 2001.

THE ECLIPSE FOUNDATION. Eclipse Modeling Project. http://www.eclipse.org/modeling/, 2013.

VISSER, E. WebDSL: A Case Study in Domain-Specific Language Engineering. TUD-SERG-2008-023, 2008.

WEISZFLOG, W. Michaelis Moderno Dicionário Da Língua Portuguesa. Editora Melhoramentos, 2003. 


\section{A Apêndice A}

A seção 3.3.3 apresenta sucintamente os módulos de contabilidade, aquisição e atendimento.

Neste apêndice, são apresentadas as informações referentes a esses módulos, obtidas de (MAGAL; WORD, 2011), em um nível de detalhe suficiente para posterior identificação de um conjunto de modelos de computação candidatos.

O módulo de contabilidade é descrito a seguir numa estrutura de subseções distinta dos módulos de aquisição e atendimento, porque a contabilidade é gerada de forma subsidiária à execução tarefas de outros módulos, enquanto que os módulos de aquisição e atendimento, entre outros, são executados de forma autônoma, através das tarefas que os constituem.

Os processos de aquisição e atendimento são descritos pelos dados fundamentais (entidades) manipuladas pelo sistema, tarefas executadas e produtos da execução do de cada processo.

No caso dos módulos de aquisição e atendimento, cada processo é constituído por uma ou mais tarefas.

A descrição dos módulos seguiu a estrutura e a terminologia do ERP SAP.

Uma Organização é tipicamente composta por Companhias. Cada companhia possui seu próprio CNPJ, mas é filiada à Organização.

\section{A.1 Contabilidade}

\section{A.1.1 Conceitos}

A seguir, são apresentados os conceitos básicos referentes aos processos de Contabilidade:

- Em linhas gerais, há dois tipos de contabilidade:

- Contabilidade Financeira, relacionada ao público externo, é usada para cumprir exigências legais ou regulamentares, gera demonstrações contábeis conforme exigências legais e produz relatórios conforme prescritos por entidades reguladoras; 
- Contabilidade Gerencial, relacionada ao público interno, é usada para auxiliar a gerência dos processos de negócio da Organização, trata custos e receitas e produz relatórios definidos pela Organização.

- Balanço é uma fotografia da empresa em determinado momento. Identifica ativos, passivos e ações.

- Declaração de Renda identifica a mudança de posição financeira de uma empresa ao longo do tempo. Identifica receitas, custos, e lucros ou prejuízos

- Demonstrações de Fluxo de Caixa apresentam os recebimentos e pagamentos num determinado período de tempo.

- Grupos de Contas organizam Contas com características similares. Por exemplo, todas as Contas Bancárias e Contas em Espécie são consolidadas em um grupo chamado Ativos Líquidos.

- Plano de Contas é uma lista ordenada de contas que compõem a contabilidade geral de uma empresa. Há três tipos de plano de contas:

- Plano de Contas Operacional registra o impacto financeiro das transações do dia a dia da organização.

- Plano de Contas Específico de um país é um mapeamento do plano de contas operacional para atender necessidades específicas de contabilidade de um determinado país.

- Plano de Contas de Agrupamento agrupa as contas das diversas empresas que compõem a Organização para consolidar a contabilidade no nível mais geral.

- Contas de Reconciliação são contas intermediárias que consolidam operações individuais. Nem todos os dados financeiros são mantidos diretamente nas Contas de Contabilidade Geral. É necessário, em diversas situações, que contas individuais registrem operações específicas e que os valores dessas operações sejam consolidados nas Contas de Contabilidade Geral. Essas contas individuais são denominadas contas subsidiárias.

- Contas de Contabilidade Geral são contas definidas com base em contas específicas da Contabilidade Operacional. Constituem-se numa instanciação da contabilidade operacional para uma determinada empresa que compõe a Organização. Cada Conta Operacional é classificada como Conta de Balanço ou Conta de Lucros e Perdas: balanços de Contas de Balanços são registrados na 
própria conta; balanços de Contas de Lucros e Perdas são transportados para contas distintas, específicas.

\section{A.1.2 Processos}

A seguir são descritos os processos contábeis, conforme a automação realizada no sistema ERP SAP (MAGAL; WORD, 2011). Os processos foram descritos no nível de detalhe considerado suficiente para a identificação dos modelos de computação envolvidos.

\section{A.1.2.1 Contabilidade Geral}

Nesse processo, cada transação implica em um Registro de Débito e um registro de crédito em determinadas contas. As contas são agrupadas em Contas de Balanço (ativos, dívidas e ações) e Contas de Lucratividade (receitas e despesas).

Usa-se uma técnica chamada Conta T para definir como debitar e creditar contas afetadas por uma determinada transação. Usa-se a letra $\mathrm{T}$ para referenciar essa técnica porque, a cada transação financeira corresponde um débito e um crédito em contas contábeis específicas. A letra T, visualmente, separa, de um lado, as contas a crédito das contas a débito para cada transação. Os débitos são registrados do lado esquerdo do $\mathrm{T}$, e os créditos, do lado direito. A tabela 4, apresentada a seguir, define que tipo de conta deve ser creditada ou debitada em determinado tipo de transação.

Débito

Crédito

\begin{tabular}{|l|l|}
\hline Ativos e Despesas + & Ativos e Despesas - \\
\hline Receitas e dívidas - & Receitas e dívidas + \\
\hline
\end{tabular}

Tabela 4 - contas a serem creditadas e debitadas numa transação financeira - (MAGAL; WORD, 2011)

\section{A.1.2.2 Contabilidade de Contas a Pagar}

Este processo efetua a contabilidade de contas a pagar, conforme os princípios contábeis vigentes.

As Organizações usam contas subsidiárias para registrar o dinheiro devido aos fornecedores. Essas contas não são parte da contabilidade geral, mas estão 
associadas a contas especiais denominadas contas de reconciliação. O processo de Contabilidade de Contas a Pagar, entretanto, é o mesmo da Contabilidade Geral.

\section{A.1.2.3 Contabilidade de Contas a Receber}

Este processo tem a lógica equivalente à de contas a pagar, para abordar valores a receber de fornecedores.

\section{A.1.2.4 Contabilidade de Ativos}

Esse processo visa registrar as consequências financeiras associadas ao ciclo de vida completo de um ativo, da sua aquisição ao seu descarte. Os ativos podem ser tangíveis (computadores, imóveis, automóveis), intangíveis (propriedade intelectual, patentes, marcas) e financeiros (ações, empréstimos).

Os ativos podem ser associados às companhias que pertencem à Organização, às áreas de negócio e aos centros de custo, e são usados para acumular os custos incorridos nos vários processos. Na contabilidade de ativos, o custo principal é a depreciação, que ocorre ao longo do ciclo de vida do ativo.

Os dados contábeis sobre cada ativo são mantidos em contas subsidiárias para cada ativo. Contas subsidiárias de ativos são associadas a contas de reconciliação correspondentes. Essa associação é efetuada em função da classe (ou categoria) de ativo à qual o ativo pertence.

Uma classe de ativo é um grupo de ativos que possuem características similares. Por exemplo, ativos de computação, como computadores, impressoras, monitores, podem ser incluídos numa mesma classe de ativos.

Cada classe de ativos é associada a uma mesma conta de reconciliação na contabilidade geral.

Cada classe de ativos possui parâmetros que informam como os ativos daquela classe devem ser tratados, principalmente no que diz respeito à determinação da conta e da depreciação.

A determinação da conta é a associação entre cada conta subsidiária de ativos com a conta de reconciliação correspondente. Isso é feito através da classe à qual o ativo pertence. 


\section{A.1.2.5 Transações contábeis associadas aos ativos ao longo do ciclo de vida}

São consideradas as transações de aquisição, depreciação e descarte.

Os ativos podem ser construídos pela Organização ou adquiridos de um fornecedor externo.

No primeiro caso, uma classe especial de ativos, em construção, é usada durante a produção e os custos correspondentes são registrados nas contas de reconciliação da contabilidade geral.

No segundo caso, os ativos podem ser adquiridos de fornecedor cadastrado ou de fornecedor eventual:

- Quando a aquisição de um fornecedor cadastrado não usa o processo de aquisição, não há pedido de compra e o registro da aquisição é realizado manualmente nas contas de contabilidade e subsidiárias.

- Quando a aquisição de um fornecedor cadastrado, o processo de aquisição é utilizado, ocorrendo: pedido de compra, registro de entrada de mercadoria, recebimento da fatura e pagamento. O processo é semelhante ao anterior, mas efetuado automaticamente como parte do processo de aquisição.

- No caso de a compra ser de um fornecedor eventual, sem cadastro na Organização, não há conta subsidiária do fornecedor. A transação é registrada manualmente usando a conta subsidiária do ativo, a conta de reconciliação correspondente, e uma conta de compensação especificamente designada. Uma conta de compensação armazena os dados temporariamente até que os dados sejam movidos para outra conta.

Ao longo do tempo, o valor dos ativos diminui devido ao desgaste. O valor do ativo é, então, o valor adquirido menos a depreciação acumulada.

A depreciação pode ser comum (periódica, planejada e recorrente) ou não planejada (devido a algum evento extraordinário).

Há diversos métodos de depreciação e, para cada tipo de ativo, deve estar associado um método de depreciação.

Quando um ativo completa seu ciclo de vida, é descartado. O descarte pode implicar em venda e, se isso ocorrer, o processo de venda da Organização pode ser utilizado. 


\section{A.2 Aquisição}

\section{A.2.1 Conceitos}

Os materiais e os serviços de uma Organização podem ser agrupados em categorias de itens, de acordo com a forma em que são adquiridos. Essas categorias determinam, portanto, os passos do processo de aquisição e os dados necessários para a execução do process.

No ERP SAP, estão previstas as seguintes categorias de itens, e os respectivos passos do processo de aquisição:

- Processo de aquisição padrão

- Criar a requisição;

- Converter a requisição em um pedido de compra e enviar a um fornecedor;

- Receber o material quando for enviado pelo fornecedor, usando o passo do processo recebimento de compras;

- Comprador recebe uma fatura e paga ao vendedor.

- Consignação

- Fornecedor é pago apenas quando o comprador vende os materiais. Neste caso não há fatura.

- Pedido de terceiro

- Fornecedor envia diretamente para o cliente final;

- Usado para itens que são vendidos exatamente como são comprados;

- Não há fatura para a Companhia, também neste caso.

- Subcontratação

- Materiais são fornecidos pela Companhia para um fornecedor, que os utiliza para criar produtos semi-acabados, e os envia de volta para a Companhia.

- Há o passo adicional de enviar materiais para o fornecedor.

- Transferência de estoque

- A Organização usa o processo de aquisição para obter materiais de outra planta da própria Organização.

- Não há geração de fatura nem pagamento.

- Serviços 
- Não envolve o recebimento de materiais.

- Nesse caso, é necessário um mecanismo para registrar os serviços efetuados, como por exemplo uma folha de serviços.

O estoque é classificado em função das permissões dos materiais. O sistema ERP SAP considera a seguinte classificação: uso irrestrito, inspeção de qualidade ou estoque bloqueado (usado apenas para a obtenção de amostras) e estoque em trânsito.

A movimentação de bens ou materiais ocorre quando são recebidos, armazenados ou enviados aos clientes. Esse passo do processo resulta em mudança no estoque e pode ser de quatro tipos:

- Recepção de bens: recebimento de material de um fornecedor ou do processo produtivo para armazenamento; estoque aumenta;

- Atribuição de bens: oposto da recepção de bens, ou seja, retirada de bens do local armazenado para que seja utilizado no processo produtivo ou entregue a um cliente final; estoque reduz;

- Transferência de estoque: envolve a movimentação física de materiais de um local a outro;

- Transferência de postagem: mudança da classificação de material.

\section{A.2.2 Processos}

A seguir são descritos os seguintes processos relacionados à Aquisição: Determinação de Requisitos, Determinação da Fonte de Suprimentos, Processamento de Pedido, Recebimento de Mercadorias, Verificação da Fatura e Processamento de Compra.

\section{A.2.2.1 Processo de Determinação de Requisitos}

O processo é disparado pelo processo de planejamento de materiais ou de manutenção de plantas, produção de plantas, ou ainda manualmente por um indivíduo.

O produto é uma requisição de compra, que é um documento interno, usado para requisitar materiais necessários. Não é uma formalização da solicitação de compra.

Os dados relevantes para esse processo são: 
- Categoria do item

- Quantidade

- Data de entrega desejada

- Local de entrega desejado

- Número do material (para itens de estoque)

- Objeto de atribuição de conta (em alguns casos)

O número do material é usado para obtenção de informações adicionais, como descrição, grupo do material, grupo de compra, unidade de medida, preço avaliado. Nesse processo é realizada a criação da requisição de compra, usando os dados especificados e o documento resultante é uma Requisição de Compra.

\section{A.2.2.2 Processo de Determinação da Fonte de Suprimento}

A fonte de suprimento pode ser conhecida ou não.

Se for conhecida, a requisição de compra é diretamente transformada em um Pedido de Compra e, neste caso, o fornecedor é selecionado a partir de uma Lista de Fontes.

Ainda com a fonte conhecida, pode-se usar um esquema chamado Acordo de Compra Delineado, que consiste de acordos de longo prazo entre o fornecedor e a empresa compradora. Neste caso, os Pedidos de Compra podem ser emitidos quando o comprador necessitar ou as entregas podem ser planejadas para intervalos regulares, com quantidades pré-definidas.

Se a fonte do suprimento não for conhecida, deve ser enviado uma Requisição de Cotação para diversos fornecedores. As propostas são avaliadas, uma é selecionada e, então, é emitido o Pedido de Compra, com base na cotação selecionada.

Neste caso, pode-se também gerar o Pedido de Compra sem ter uma cotação como base, como no caso em que uma cotação foi fornecida verbalmente e não foi inserida no sistema.

\section{A.2.2.3 Processo de Processamento do Pedido}

Nesse processo o pedido de compra é formalizado e enviado ao fornecedor.

A entidade fundamental neste processo é o pedido de compra, composto por: 
- Cabeçalho: válido para todo o documento e contém o número do pedido de compra, fornecedor, moeda, datas, termos de pagamento.

- Itens: cada item contém número do material, descrição, quantidade, data de entrega, preço.

Os dados do Pedido de Comprasão obtidos de fontes diversos. Como exemplo, pode-se citar:

- Para o material, podem ser necessárias certas características, como por exemplo o peso;

- Para o fornecedor podem-se incluir métodos de comunicação, pessoa de contato, endereço, condições;

- Dados de precificação e condições de pagamento são incluídos no pedido de compra a partir da cotação, registro de informações de compra, ou contratos e acordos específicos com fornecedores, dependendo de como o processo é configurado em cada Organização.

A maior parte dos dados de uma requisição de compra é incluída no Pedido de Compra. Se os dados necessários não estiverem disponíveis para serem incluídos automaticamente, devem ser fornecidos manualmente durante a elaboração do Pedido de Compra.

Em geral, uma ou mais requisições de compra podem ser usadas para gerar um ou mais Pedidos de Compra. Por exemplo, um gerente de compra pode receber várias requisições de compra do mesmo material e consolidá-las em um único pedido de compra de um único fornecedor, para obter vantagem de preço.

Por outro lado, uma requisição pode contemplar materiais diferentes que devem ser adquiridos de fornecedores distintos. Neste caso, as requisições podem gerar mais de um Pedido de Compra.

Os dados das Requisições de Compra devem ser atualizadas quando os Pedidos de Compras forem gerados para permitir a rastreabilidade da aquisição.

Nesse processo é feita a criação do Pedido de Compra e o seu envio ao fornecedor. Como resultado é gerado o Pedido de Compra que é enviado ao fornecedor através dos recursos de comunicação do ERP, como impressão, e-mail, EDI, web services e 
fax. Os fornecedores também podem usar o mesmo tipo de recursos para aceitar ou recusar pedidos.

\section{A.2.2.4 Processo de Recebimento de Mercadorias}

Este processo é responsável pelo registro dos materiais recebidos do fornecedor.

Esses materiais são acompanhados de um Documento de Entrega que contém os materiais entregues e é usado, juntamente com o Pedido de Compra para conferir a correção da entrega durante o processo de recebimento. Os dados do Pedido de Compra são, então, copiados para o Documento de Recebimento de Bens, gerado nesse momento.

Um único Pedido de Compra pode resultar em diversas entregas e diversos Pedidos de Compra pode resultar em uma única entrega.

A maior parte dos dados deste processo está contida no Documento de Entrega e no Pedido de Compra. São também necessários dados adicionais sobre o local de armazenamento dos materiais e tipos de movimentação específicos. O sistema pode sugerir valores para esses dados e o usuário pode alterar, se necessário.

Nesse processo, é feito o registro dos materiais recebidos no Documento de Recebimento de Bens, a partir dos dados do Pedido de Compra que são automaticamente transferidos pelo sistema. Se os dados do Pedido de Compra não corresponderem à entrega efetuada, o usuário altera os valores no Documento de Recebimento de Bens.

Outros passos adicionais podem ser subsequentes a este: criação de lotes de inspeção, gerado pela funcionalidade de Gestão da Qualidade do ERP; definição de requisitos de transferência, gerados pela funcionalidade de gestão de armazéns e que dispara o processo de Gestão de Armazéns; geração de notificações, que avisa os interessados da chegada do material.

Como resultado, obtém-se o documento de Recebimento de Bens, registros financeiros de contabilidade geral, entre outros.

\section{A.2.2.5 Processo de Verificação da Fatura}

Este processo realiza a verificação da correção da fatura recebida, antes de autorizar o pagamento. 
O método mais comum é uma verificação tripartite entre o Pedido de Compra, o Documento de Recebimento ou Entrega, e a Fatura. O objetivo é garantir que a quantidade e preço dos três documentos estão consistentes.

Esse processo manipula os seguintes dados:

- Fatura, com número do vendedor, data, quantidade e valor dos materiais;

- Documento material, com número do pedido de compra, materiais entregues, e respectivas quantidades entregues;

- Pedido de compra, com número do pedido de compra, número do vendedor, materiais demandados e respectivas quantidades demandadas e preços.

Esse processo consiste da realização das seguintes passos:

- O usuário informa dados da fatura (fornecedor, data, valor) e número do Pedido de Compra. O sistema obtém os dados do Pedido de Compra (fornecedor, quantidade, material, preço) e dados de recebimento de bens referente ao Pedido de Compra.

- O usuário verifica se os dados estão corretos e, se estiverem, aprova a fatura. Podem haver discrepâncias entre os documentos citados acima. Se for o caso, os valores de tolerância para mais ou menos referentes às políticas e de compra e contabilidade dirão se essas discrepâncias podem ser toleradas. Esses valores de tolerância máxima aceitos constam nos dados sobre o Material.

Como resultado, obtém-se o seguinte:

- A verificação de Fatura impacta a Contabilidade Geral, pois é uma transação contábil que deve ser registrada pela Contabilidade Geral;

- Um documento Fatura também é criado no sistema, com as informações da fatura recebida;

- O histórico do Pedido de Compra é atualizado e um relacionamento para o Documento Fatura é acrescido.

\section{A.2.2.6 Processo de Processamento de Compra}

Este processo é disparado pelo recebimento e verificação da fatura. 
Os pagamentos são efetuados manualmente ou automaticamente por um Programa de Pagamento. Tipicamente, uma Organização tem uma quantidade de faturas a pagar e o método mais comum é efetuar pagamentos periodicamente, diariamente ou semanalmente.

O programa seleciona todas as faturas autorizadas em um determinado período de tempo e cria os pagamentos.

Os dados relevantes ao processo são os seguintes:

- Fatura com número do fornecedor, data, quantidade de itens,

- Fornecedor com condições de pagamento;

- Método de pagamento, endereço de pagamento.

Este processo consiste da realização dos seguintes passos:

- Para pagamentos manuais, o usuário seleciona o método de pagamento e o banco, e fornece o número do fornecedor e o valor do pagamento.

- O sistema exibe uma lista de faturas pendentes daquele fornecedor e o usuário seleciona as que devem ser pagas. O sistema aplica então descontos com base nas condições de pagamento selecionadas.

- Após o pagamento ser registrado na contabilidade geral, o pagamento real pode ser efetuado. Se o pagamento for feito eletronicamente, o sistema envia o pagamento automaticamente. Se for manualmente, o usuário imprime um cheque e o envia ao fornecedor.

- Caso haja um programa eletrônico de pagamento, o programa recupera e processa todas as faturas pendentes de pagamento, usando os parâmetros especificados no programa de pagamento. Usuários são envolvidos apenas se houver exceções que o sistema não consiga tratar.

Como resultado, obtém-se:

- Pagamento do fornecedor realizado;

- Atualização da contabilidade geral. >>

\section{A.3 Atendimento}

Neste módulo, os dados manipulados foram definidos no nível geral, e não individualmente para cada processo abordado, para evitar informações repetidas. 


\section{A.3.1 Conceitos}

A seguir, são apresentados os conceitos básicos referentes aos processos de Atendimento:

- Organização de Vendas: Uma Organização possui uma ou mais estruturas de vendas, cada uma delas responsável pela distribuição de bens e serviços para uma área geográfica específica. A Organização de Vendas corresponde ao nível mais alto de agregação dos relatórios de vendas. É responsável por: negociar termos e condições de vendas para aquele mercado e por gerenciar disputas com clientes.

- Canal de Distribuição: É o meio usado para entregar bens e serviços aos clientes. Os canais típicos são atacado, varejo e online, e, cada canal tem suas próprias restrições, estratégias e abordagens para fornecer serviços e produtos aos clientes. Por exemplo, atacado não inclui imposto sobre a venda, requer um volume mínimo de compras e oferece desconto por volume; pode ser designado a plantas específicas.

- Divisão: Agrupa materiais e serviços similares. Tipicamente, é associada a uma linha de produtos da Organização. A cardinalidade da relação entre Divisão e Organização de Vendas é M:N, ou seja, uma Divisão contempla diversas Organizações de Vendas.

- Área de Vendas: combinação única entre Organização de Vendas, Canal de Distribuição e Divisão. Define qual Canal de Distribuição uma Organização de Vendas usa para vender produtos pertinentes a uma Divisão. Uma área de vendas está associada a apenas um Código de Companhia. Todos os documentos associados ao processo de atendimento pertencem a apenas uma área de vendas.

- Planta: uma Planta de Entrega é uma instalação a partir da qual a companhia efetua entrega de produtos e serviços a seus clientes. Uma planta pode ser associada a uma ou mais cadeias de distribuição. Uma cadeia de distribuição é uma combinação única de organização de vendas e canal de distribuição, e pode estar associada a uma ou mais plantas.

- Ponto de Expedição: É o local em uma planta, a partir do qual os produtos são enviados. 
- Área de Controle de Crédito: É o nível organizacional responsável pelo crédito ao consumidor. Determina o crédito dos clientes, limites de crédito e gerencia a atribuição de crédito a clientes específicos. Pode ser centralizada ou descentralizada.

\section{A.3.2 Dados}

Os dados relevantes desse processo são os seguinte:

- Material, com os seguintes atributos: cliente; organização de vendas: planta de entrega, unidades de vendas, quantidades mínimas, ponteiro para condições de preço; canal de distribuição; planta.

- Cliente:

- Dados Gerais: nome, endereço, número da conta do cliente; são definidos no nível da organização como um todo e válidos para todas as áreas de venda e para Companhias que compõem a organização;

- Dados de contabilidade: termos de pagamento, contas de reconciliação; são definidos no nível de cada companhia da organização;

- Dados de área de vendas: dados relacionados a vendas, despacho, cobrança e funções dos parceiros (são específicos de uma determinada área de vendas).

- Se um cliente é atendido por diversas áreas de vendas, haverá dados relacionados a esse cliente para cada uma das áreas de vendas, de modo que a Organização possa trabalhar com condições de vendas distintas para esse cliente.

- Um cliente pode ter quatro papéis relacionados a uma venda:

- Pessoa (física ou jurídica) para quem o produto é vendido e que submete o pedido;

- Pessoa que recebe o produto;

- Pessoa que é cobrada;

- Pessoa que paga, pois o pagamento pode se terceirizado para outra companhia.

- Registro de informação cliente-material: São dados referentes a um cliente e um material. Refere-se a compras de um material específico por um cliente 
específico. Por exemplo, um determinado cliente solicita que determinado tipo de produto seja transportado por um meio específico.

- Condições de 76: São condições para os vários componentes do preço final de venda: preço bruto, descontos, frete, sobretaxas, impostos. Podem ser valores fixos, percentagens ou baseadas em uma escala decrescente. Podem ser independentes ou relativas a outras condições. Por exemplo, o preço de um produto pode ser dependente do material e independente do cliente; ou pode depender do cliente, significando que os preços variam para clientes distintos. Como diversas condições são definidas para um produto, uma companhia deve ter um procedimento para determinar quais condições se aplicam a um cliente específico. Esse procedimento é denominado técnica de condições e consiste em identificar tipos de condições disponíveis (preço bruto, preço específico do cliente, descontos, fretes, sobretaxas, entre outros) e determinar os que se aplicam às condições específicas de um pedido.

\section{A.3.3 Processos}

\section{A.3.3.1 Processo de Atividade de pré-venda}

Este processo é disparado por uma Solicitação ou uma Requisição de Proposta.

Além de enviar cotações (acordos formais para vender produtos específicos), a prévenda pode gerenciar contatos dos clientes e criar acordos gerais com os clientes.

Pode registrar e obter dados referentes a clientes específicos, tais como as preferências e histórico de compras desses clientes. Isso propicia análise de dados para a criação de estratégias de marketing e de vendas, concebidas para encorajar clientes a efetuar novas compras. O módulo também pode rastrear automaticamente potenciais clientes.

As tarefas deste processo são:

- Recebimento de requisições e criação de cotações.

- Registro de clientes e seus padrões de compras e criação de acordos de longo prazo com eles.

O resultado é o registro ERP da requisição feita pelo cliente no sistema. A requisição funciona como uma referência para a criação da cotação e para identificar vendas 
perdidas; a partir disso, podem-se criar estratégias para evitar que perdas de vendas se repitam no futuro.

Esse processo pode gerar, cotações, contratos e acordos de venda de longo prazo, bem como comunicar a cotação ao cliente.

\section{A.3.3.2 Processo de Processamento do Pedido de Venda}

Neste processo o pedido de venda é formalizado, após as devidas verificações para garantir sua exatidão.

A Criação do Pedido de Venda pode ser realizada com base em uma requisição de cliente, cotação, acordo, ou pedido de venda prévio. Um único documento de referência, por outro lado, pode ser base para criar vários pedidos de venda.

O Pedido de Venda é o único documento gerado neste passo.

No entanto, deve-se ainda realizar:

- Verificação de disponibilidade: verifica a disponibilidade atual do material ou o tempo de atender a data de entrega prevista, ou a data em que estará disponível. Isso é efetuado com base em parâmetros do Mestre Material. Deve levar em conta o tempo necessário para preparação dos materiais para entrega, planejamento do transporte (com base em peso, volume, meio de transporte), carga (movimentação dos materiais para os caminhões), atribuição dos bens (contabilidade).

- Reserva de material: para que os materiais não possam ser usados para outros pedidos.

- Transferência de requisitos: para o processo de planejamento de materiais, para que haja aquisição de insumos e produção.

\section{A.3.3.3 Processo de Expedição}

Este processo é disparado quando a data de entrega dos pedidos é atingida e consiste em diversas etapas para preparar e enviar encomendas.

O documento central é o Documento de Entrega, que identifica os materiais a serem embarcados, o destinatário, a planta de origem e o local de armazenamento.

A criação de um Documento de Entrega gera uma autorização para entrega. Podese realizar um único carregamento ou a entrega de itens em diversos pedidos. $O$ 
Documento de Entrega serve como requisição para a coleta dos materiais. Esse documento é transformado em uma Ordem de Transferência do armazém, que é usada para completar o movimento físico dos materiais.

O passo de coleta é opcional e é disparado quando o documento de entrega é criado.

O Documento de Entrega é convertido em uma Ordem de Transferência no gerenciamento do armazém, a qual é usada para realizar a transferência física dos materiais necessários para a entrega.

Após a coleta, os materiais são mantidos em uma Área de Preparação, na qual são empacotados apropriadamente.

A Expedição tem impacto financeiro e, consequentemente, contábil. As contas de estoque do material enviado são creditadas e a conta Custo de Bens Vendidos é debitada. No caso de mercadorias a serem comercializadas, o valor é baseado no preço médio móvel; no caso de bens acabados, o valor é baseado no preço padrão, que leva em conta custos de produção.

A expedição é concluída com o envio de mercadorias e gera vários resultados, enquadrados nas seguintes categorias: impactos à contabilidade; documentos para registrar dados da transação; atualizações nos dados mestres e documentos previamente criados.

\section{A.3.3.4 Processo de Cobrança}

Esse processo visa a criação de faturas e memorandos de crédito e débito e pode ser baseado em entregas já despachadas ou em pedidos ainda não entregues.

A principal tarefa é a geração do documento de cobrança, tipicamente uma fatura para produtos ou serviços. Além disso, prevê a criação de um reembolso, se o cliente devolver as mercadorias; ou de uma cobrança complementar, se o cliente tiver pago a menos.

Após a cobrança ser efetuada, contas de reconciliação de contas a receber e de contas de faturamento da contabilidade geral são atualizadas. 


\section{A.3.3.5 Processo de Pagamento}

Esse processo corresponde ao recebimento do pagamento de um cliente. $O$ pagamento é aplicado aos itens adequados (aqueles ainda não pagos) na conta do cliente.

Os itens em aberto devem ser identificados e o pagamento deve ser aplicado a esses itens. Um cliente pode pagar múltiplas faturas de uma vez ou dividir uma única fatura em múltiplos pagamentos.

Quando o pagamento do cliente é registrado, as contas relevantes da contabilidade geral são atualizadas. O pagamento pode ser menor que 0 valor originalmente devido, se descontos se forem aplicados. As contas de contabilidade devem refletir isso.

Se o valor pago for menor que o valor da fatura e não há descontos aplicáveis, há duas situações possíveis. Se a diferença for muito pequena, dentro do valor de tolerância definido no sistema, a conta é considerada paga. Caso a diferença não seja desprezível, usa-se uma técnica de pagamento parcial, em que o pagamento é postado na conta do cliente e a fatura original permanece aberta. Pode-se também usar uma técnica de item residual, em que o item original é fechado, e um novo item referente à diferença é postado.

\section{A.3.3.6 Processo de Gerenciamento de Crédito}

Esse processo define se deve ser atribuído crédito a um cliente para compra de mercadorias e pode ser executado em três pontos distintos do módulo de atendimento:

- Quando um pedido é criado ou alterado;

- Quando a entrega é autorizada e, consequentemente, um documento de entrega é criado ou alterado;

- Durante a saída de mercadorias, na expedição.

O processo pode ser configurado para considerar diversos critérios de avaliação de crédito, tal como o valor ainda a receber do cliente e a quantidade de valor dos pedidos em aberto; fontes externas de dados de crédito também podem ser consideradas. 
A exposição total ao crédito é calculada como a soma dos pedidos em aberto, entregas agendadas, faturas em aberto e o valor do pedido atual.

Se o limite de crédito for inferior à exposição ao crédito, há três resultados possíveis:

- Avisar ao usuário e permitir a continuação do processo;

- Exibir uma mensagem de erro e não permitir que o processo continue;

- Bloquear a entrega do pedido.

Todos os três resultados citados são possíveis quando um pedido ou um documento de entrega estão sendo criados ou alterados. Durante a etapa de saída de mercadorias, entretanto, a única opção é bloquear o envio. 


\section{B Apêndice B - Ferramentas geradoras de DSML atualmente disponíveis}

\section{Características recomendadas para ferramentas}

Kelly e Tolvanen (2008) identificaram as seguintes categorias de características que uma ferramenta adequada deve possuir, com base em estudo de ferramentas, referências bibliográficas e interação com desenvolvedores de ferramentas e outros interessados em ferramentas geradoras de DSMLs, :

- Meta-meta-modelo

- Notação

- Geradores

- Suporte ao projetista da linguagem

- Funcionalidade geral da ferramenta de modelagem

- Integração de ferramentas

Estas características são brevemente descritas a seguir. Como os autores consideram que as duas primeiras categorias são as mais importantes, elas foram destacadas.

\section{Meta-meta-modelo}

O meta-meta-modelo é o conjunto de conceitos fornecidos para que o projetista da linguagem possa construir o meta-modelo. Os recursos básicos de um meta-metamodelo são oriundos dos elementos e seus relacionamentos da modelagem de dados ou da modelagem orientada a objetos.

Outros recursos que o meta-meta-modelo deve contemplar são:

- Conceito explícito de grafo

- Um grafo será composto de um conjunto de objetos e relacionamentos associados. Isso permite que o modelo seja dividido em submodelos, com benefícios para o gerenciamento do modelo e do projeto da linguagem por vários projetistas, concorrentemente.

- Podem-se acrescentar conceitos em mais larga escala ao conceito de grafo; por exemplo, um conjunto de grafos forma um modelo, um conjunto 
de modelos forma um projeto, um conjunto de projetos é armazenado em um repositório.

- Propriedades ou atributos do tipo objeto

- A maior parte dos atributos ou propriedades de meta modelos são do tipo string; no entanto, propriedades que sejam referências a outros objetos são úteis para integrar modelos.

- Restrições sobre os valores de propriedades ou atributos

- A linguagem de meta-modelagem deve permitir a especificação de verificações sobre o valor das propriedades, de modo a garantir que apenas valores válidos sejam atribuídos às propriedades.

- Conceito explícito de papel

- Explicitar o papel que cada objeto desempenha quando há uma conexão com outro objeto, particularmente em relacionamentos que envolvem mais de dois objetos; por exemplo, superclasse ou subclasse, todo ou parte de uma agregação.

- Reuso de objetos em modelos

- Permite ganhos de produtividade e de facilidade de representação dos modelos.

- Um objeto pode ser reutilizado conforme se segue: como o valor de uma propriedade de vários objetos; exibido várias vezes em uma única visualização do mesmo grafo (ou seja, em um único diagrama), por uma conveniência de representação; exibido uma vez em várias representações (ou pontos de vista) do mesmo grafo; como um elemento de vários grafos diferentes da mesma DSML; como um elemento de vários grafos de DSMLs distintas.

- Ligação para sub-grafos

- Como uma consequência direta do particionamento de um modelo em diversos grafos, surge a necessidade de construir um grafo de alto nível em que cada objeto possui um link para o grafo correspondente de nível mais baixo.

- Conceito explícito de porta (port)

- Linguagens de modelagem que descrevem hardware geralmente contemplam uma representação como a de diagramas de circuitos 
eletrônicos nos quais objetos têm um conjunto de portas a partir das quais se conectam com outros objetos. Tipicamente, portas de entrada se conectam a portas de saída.

- Definição de restrições (constraints) arbitrárias

- Uma linguagem de meta-modelagem deve permitir que o projetista defina um conjunto de regras comuns que possam ser verificadas automaticamente.

\section{Notação}

As características da sintaxe concreta da DSML estão apresentadas a seguir:

- Paradigmas de representação

- Com base em uma determinada sintaxe abstrata, há diversos paradigmas de representação distintos que podem ser utilizados: diagrama gráfico (nós e segmentos de retas, caixas e linhas, bolhas e arcos), matriz (objetos nos eixos e relacionamentos nas células, por exemplo), tabela, ou texto estruturado.

- Editor de símbolos gráficos

- O editor de símbolos é um elemento importante pois sem ele, o tempo gasto para definir os símbolos freqüentemente é excessivo. Algumas ferramentas oferecem uma quantidade limitada de símbolos préprogramados. Cada símbolo criado deve ser associado a um determinado elemento da sintaxe abstrata da linguagem.

- Símbolos dos papéis

- Constituem um caso especial, porque devem rotacionar juntamente com a linha sobre a qual são exibidos.

- Roteamento das linhas dos papéis

- Uma questão importante da sintaxe concreta é o suporte que a ferramenta fornece para o traçado das linhas entre os objetos, no sentido de minimizar o cruzamento de linhas ou a superposição entre linhas e objetos.

\section{Exemplos de Ferramentas geradoras de DSMLs}

Kelly e Tolvanen (2008) apresentam quatro ferramentas, sendo que duas delas possuem um nível de maturidade maior, e duas delas ainda em versões iniciais: 
- MetaEdit+ (MetaCase), desde 1995: A ferramenta foi fruto do trabalho de um grupo de pesquisa acadêmico, que posteriormente fundou a empresa MetaCase. $\mathrm{Na}$ escala de evolução definida por (KELLY; TOLVANEN; 2008), o MetaEdit+ está no nível 6. Metamodelagem e modelagem são efetuadas no mesmo ambiente integrado.

- GME (Generic Modeling Environment) (LEDECZI et al; 2001), desde 2000: O meta-meta modelo do GME difere significativamente dos de outras ferramentas de mesma natureza, pois contempla um conceito forte de porta (port) e um conceito fraco de relacionamento, provavelmente por conta de herança de engenharia elétrica. Não existe o conceito básico de grafo, mas objetos podem conter objetos e, portanto, formar hierarquias. Na escala de evolução definida, está no nível 5.

- DSL Tools (Microsoft), desde 2006: Originalmente, parte do Visual Studio 2005 SDK 3.0 é uma combinação de frameworks, linguagens, editores geradores e wizards que permitem ao usuário especifiar suas próprias linguagens e ferramentas de modelagem e se constitui em um elemento central do projeto denominado Software Factories (Fábricas de Software) da Microsoft. Pelo menos em suas versões iniciais, o DSL Tools não contempla múltiplos grafos, relacionamentos $\mathrm{n}$-ários, papéis e portas e apresenta dificuldades para reuso. A ferramenta é classificada no nível 3 da escala de evolução.

- Eclipse Modeling Project (THE ECLIPSE FOUNDATION; 2013), desde 2006 : Ferramenta ainda não atende aos objetivos definidos e uma nova versão está sendo elaborada. Classificada no nível 3 da escala de evolução atualmente.

Em geral, essas ferramentas seguem o mesmo padrão de utilização. Elas se constituem no ambiente para a geração das DSMLs e também no ambiente para a modelagem de domínio, com base nas DSMLs geradas. Trabalham em dois níveis de abstração.

Tipicamente, são ferramentas que permitem modelagem visual tanto da DSML quanto dos modelos de domínio produzidos através dela. O MetaEdit+ permite duas formas de modelar a DSML, visual ou baseada no preenchimento de formulários.

Todas se baseiam em metamodelagem para definir a DSML e não em gramáticas livres de contexto. A linguagem de metamodelagem é um substrato da UML com 
semântica bem definida, contemplando essencialmente diagramas de classes da UML e restrições escritas em OCL.

Com base nesse arcabouço que, em linhas gerais, é comum, cada ferramenta implementa recursos específicos para modelar as DSMLs. 


\section{Apêndice C-Regras de Negócio}

Uma regra de negócio é uma declaração lógica que propicia a obtenção de conclusões a partir de um conjunto de condições. Geralmente, regras são expressas conforme a sentença Se <condições> Então <conclusões > .

Fish (2012) afirma que as regras são declarações discretas e independentes, e cada uma delas expressa um único átomo de conhecimento de negócio executável.

O termo independente, neste contexto, implica que o significado de uma regra é inteiramente auto contido e não depende de outras regras. Isso faz com que regras de negócio difiram de linguagens de programação convencionais, nas quais a sequência das declarações é relevante para o resultado obtido.

Em 2002, uma organização denominada Business Rules Group, existente desde 1988 e focada na promoção de regras de negócio como ferramenta de automação da gestão de conhecimento, publicou o que denominou um Manifesto das Regras de Negócio (ROSS; 2003), cujos títulos dos artigos que os compõem são apresentados a seguir:

- Requisitos como elementos principais, nunca secundários

- Independentes dos processos, não contidas neles

- Conhecimento explícito, não um sub-produto

- Declarativas, não procedimentais

- Expressões bem formadas, não ad hoc

- Arquitetura baseada em regras, não uma implementação indireta

- Processos orientados às regras, não programação baseada em exceções

- A serviço do negócio, não da tecnologia

- "De, por e para" as pessoas do negócio, e não "de, por e para" as pessoas de TI

- Gerir lógica de negócio, não plataformas de Hardware/Software

Regras de negócio são escritas usando termos de vocabulário estruturado conhecido como modelo de objetos, modelo de fatos, ou ontologia de domínio (FISH, 2012). Esse modelo de objetos ou ontologia contempla em si toda a lógica de relacionamento entre os conceitos ou classes de objetos que o compõem, inclusive relacionamentos de generalização / especialização. As regras de negócio se referem 
sempre a atributos desse modelo de classes ou ontologia. Desta forma, tornam-se simultaneamente precisas e legíveis por especialistas do domínio.

Há ferramentas de mercado focadas no processamento automático de regras de negócio. Um exemplo é o JBoss Drools (BROWNE; 2009). Essas ferramentas são denominadas sistemas de gestão de regras de negócio. O elemento central dessas ferramentas é um motor de regras de negócio, que infere uma conclusão para cada regra com base nas condições correspondentes. Algumas dessas condições podem ser avaliadas automaticamente com base nos dados de entrada, outras demandam que a conclusão de outras regras. Há diferentes estratégias para avaliar conjuntos de regras. Um algoritmo denominado RETE (do latim, rede, ou pente), criado por Charles Forgy (FORGY; 1982) ainda nos anos 70, e evoluído desde então, é a referência fundamental para avaliação de regras por motores de regras de negócio.

Para além do uso de algoritmos que otimizem o processamento de regras de negócio, outra forma de otimização é dividi-las em conjuntos de regras de alguma forma interrelacionadas, e avaliar apenas um conjunto de cada vez. Um critério de agrupamento pode ser, por exemplo: cada conjunto de regras toma uma decisão e contém apenas regras que contribuem para essa decisão. Para além de eficiência, essa organização torna o conjunto total de regras mais gerenciável (FISH; 2012). 


\section{Apêndice D}

\section{D.1 Diretrizes para definição dos conceitos de modelagem}

São apresentadas as diretrizes para definição dos conceitos de modelagem a partir dos conceitos do domínio, recomendadas em (KELLY, TOLVANEN; 2008).

Em uma DSL, ao contrário de uma GPL, a definição da linguagem deve conter todos os conceitos relevantes do domínio, ou seja, definir possuir a representação desses conceitos na linguagem, e não deixar a seleção desses conceitos para o projetista. Desta forma, é possível verificar, reutilizar, integrar com outros modelos e gerar código mais facilmente.

Comumente, um conceito do domínio é mapeado em um conceito de modelagem. Pode haver casos, entretanto, em que o relacionamento seja 1 para $\mathrm{n}$.

Após definir os conceitos de modelagem, devem-se definir propriedades, relacionamentos, papéis ou portas.

Um conceito pode ser expresso, alternativamente através de:

- Um objeto de modelagem

- Uma propriedade de um objeto

- Um papel ou relacionamento

- Uma propriedade de um papel

A DSML deve també representar as variações. O caso mais simples é a representação da variação através de uma propriedade do conceito de modelagem, possivelmente com valores pré-definidos a serem escolhidos pelo usuário.

Esse parâmetro pode ser um valor, um objeto que possui propriedades adicionais, um grafo ou um conjunto de grafos.

A variação pode também ser expressa por meio de elementos do modelo que são adicionados à especificação.

A variação pode ainda ser expressa por meio de conexões entre os elementos de modelagem. 
A variação não implica necessariamente em acrescentar funcionalidade. Conceitos de modelagem podem ser usados para remover ou, mais precisamente, ignorar certos elementos de modelagem durante a geração de código.

Nem todo conceitos do domínio precisa estar na linguagem, pois alguns conceitos relevantes do domínio podem ser expressos pela combinação de conceitos mais básicos.

\section{D.2 Diretrizes de Design}

São apresentadas, a seguir, as diretrizes para o design de uma DSML, recomendadas por (KELLY; TOLVANEN, 2008):

- Pictogramas estilizados funcionam melhor que foto-realismo, segundo estudos de dimensão cognitiva (BLACKWELL, 1998), pois tornam os modelos mais fáceis de ler, entender, lembrar e utilizar.

- A pior abordagem é usar o mesmo símbolo abstrato para conceitos distintos (por exemplo, o uso dos perfis DA UML).

- A melhor abordagem é obter representações para a notação diretamente da representação dos conceitos do domínio.

- Se o domínio for relacionado com as interfaces do usuário, a notação pode ser definida de forma mais fácil, pois em geral pode existir uma série de notações com significados bem estabelecidos.

- Deve-se procurar usar símbolos utilizados em representações conhecidas; por exemplo, em UML, o estado inicial de um diagrama de estados é representado por um círculo cheio e o estado final, por um círculo cheio dentro de um aro. Se a linguagem a ser projetada precisar definir semântica adicional para os estados inicial e final, pode-se estender essas representações.

Os modelos não se limitam a símbolos. Podem-se escolher diferentes estilos de representação. Em certos casos, matrizes ou tabelas podem funcionar melhor que diagramas.

São apresentadas, a seguir, as diretrizes para a definição dos símbolos da DSML recomendadas por (KELLY; TOLVANEN, 2008):

- Usar tipos diferentes de notações para diferentes conceitos de modelagem. 
- Usar quadrados e retângulos quando precisar mostrar texto dentro do símbolo, pois o espaço é mais bem aproveitado do que em elipses, nuvens, círculos, triângulos, etc.

- Mostrar apenas dados relevantes na representação visual. As ferramentas de modelagem podem usar filtros e mostrar os detalhes em folhas de propriedades e browsers próximos aos modelos.

- Se a linguagem é nova para os usuários, pode-se oferecer mais direcionamento, como mostrar o nome do conceito como parte do símbolo.

- Usar cores, pois elas ajudam a representação e leitura dos modelos e melhoram a aparência. Cores de sinais de tráfego podem ser usadas para indicar preferências ou escolhas e cores distintas podem destacar prioridades.

- Se níveis de detalhe distintos precisarem ser exibidos visualmente, pode-se optar por diferentes versões do símbolo com base nos requisitos de usuário, por exemplo, um mostrando apenas algumas propriedades, outro mostrando todos os detalhes.

- Símbolos de elementos de modelagem que contém outros elementos podem ser exibidos transparentes para mostrar suas partes internas ou, alternativamente, pode-se criar dois símbolos para o mesmo conceito agregado: um quando o conceito não é utilizado como agregação e outro como agregação. 